Representação de tomadas como suporte à segmentação em cenas

Tamires Tessarolli de Souza Barbieri 

SERVIÇO DE PÓS-GRADUAÇÃO DO ICMC-USP

Data de Depósito:

Assinatura:

\section{Representação de tomadas como suporte à segmentação em cenas}

\section{Tamires Tessarolli de Souza Barbieri}

Orientador: Prof. Dr. Rudinei Goularte

Dissertação apresentada ao Instituto de Ciências Matemáticas e de Computação - ICMC-USP, como parte dos requisitos para obtenção do título de Mestre em Ciências - Ciências de Computação e Matemática Computacional. VERSÃO REVISADA 
Ficha catalográfica elaborada pela Biblioteca Prof. Achille Bassi e Seção Técnica de Informática, ICMC/USP, com os dados fornecidos pelo(a) autor(a)

B236r $\begin{aligned} & \text { Barbieri, Tamires Tessarolli de Souza } \\ & \text { Representação de tomadas como suporte à segmentação } \\ & \text { em cenas / Tamires Tessarolli de Souza Barbieri; } \\ & \text { orientador Rudinei Goularte. -- São Carlos, 2014. } \\ & 93 \text { p. } \\ & \text { Dissertação (Mestrado - Programa de Pós-Graduação } \\ & \text { em Ciências de Computaço e Matemática } \\ & \text { Computacional) -- Instituto de Ciências Matemáticas } \\ & \text { e de Computação, Universidade de São Paulo, 2014. } \\ & \text { 1. Multimídia. 2. Vídeo digital. 3. Representação } \\ & \text { Rudinei, orient. II. Título. cenas. I. Goularte, }\end{aligned}$


"Each day is a gift and not a given right Leave no stone unturned, leave your fears behind And try to take the path less travelled by That first step you take is the longest stride" Chad Kroeger 



\section{Dedicatória}

Ao meu esposo Paulo, pelo carinho e compreensão.

À minha família, pelo amor incondicional e apoio em todos os momentos. 


\section{Agradecimentos}

Agradeço ao meu esposo Paulo, por estar comigo em todos os momentos durante essa caminhada, pelo carinho, por entender as minhas dificuldades e estar sempre disposto a me apoiar. Você torna tudo mais fácil para mim!

Agradeço aos meus pais, Pedro e Sandra, por, mesmo à distância, estarem sempre presentes, por acreditarem em mim, apoiarem minhas decisões e tornarem possível que eu finalizasse mais essa etapa de minha vida. Agradeço também à minha irmã Samira pelos momentos de descontração, por torcer por mim e estar sempre ao meu lado.

Agradeço ao meu orientador, Prof. Dr. Rudinei Goularte, por me acompanhar durante todo esse processo. Agradeço pela paciência e compreensão nos momentos mais difíceis, pelos conselhos, sugestões e por me ajudar a crescer profissionalmente. Muito obrigada!

Agradeço aos meus amigos pelas conversas, incentivos e pelos momentos de diversão.

Agradeço ao pessoal do grupo de pesquisa pelas sugestões que ajudaram a aprimorar o trabalho. Agradeço ao ICMC por fornecer a estrutura necessária para a realização deste mestrado e aos funcionários da Seção de Pós-Graduação por estarem sempre dispostos a ajudar.

Agradeço à FAPESP (processo no 2012/19025-0) e ao CNPq pelo apoio financeiro.

Por fim, agradeço a todos que direta ou indiretamente contribuíram para a conclusão deste trabalho. 


\section{Resumo}

A área de Personalização de Conteúdo tem sido foco de pesquisas recentes em Ciências da Computação, sendo a segmentação automática de vídeos digitais em cenas uma linha importante no suporte à composição de serviços de personalização, tais como recomendação ou sumarização de conteúdo. Uma das principais abordagens de segmentação em cenas se baseia no agrupamento de tomadas relacionadas. Logo, para que esse processo seja bem sucedido, é necessário que as tomadas estejam bem representadas. Porém, percebe-se que esse tópico tem sido deixado em segundo plano pelas pesquisas relacionadas à segmentação. Assim, este trabalho tem o objetivo de desenvolver um método baseado nas características visuais dos quadros, que possibilite aprimorar a representação de tomadas de vídeos digitais e, consequentemente, contribuir para a melhoria do desempenho de técnicas de segmentação em cenas.

Palavras-chave: multimídia, vídeo digital, representação de tomadas, segmentação em cenas. 


\section{Abstract}

The Content Personalization area has been the focus of recent researches in Computer Science and the automatic scene segmentation of digital videos is an important field supporting the composition of personalization services, such as content recommendation or summarization. One of the main approaches for scene segmentation is based on the clustering of related shots. Thus, in order to this process to be successful, is necessary to properly represent shots. However, we can see that the works reported on the literature have left this topic in backgroud. Therefore, this work aims to develop a method based on frames visual features, which enables to improve video shots representation and, consequently, the performance of scene segmentation techniques.

Keywords: multimedia, digital video, shot representation, scene segmentation. 


\section{Sumário}

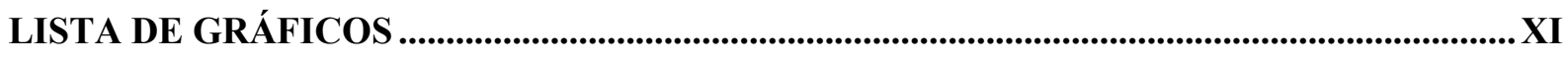

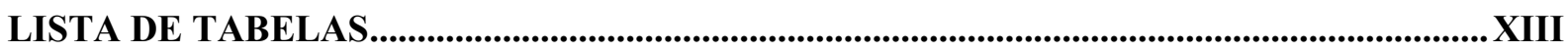

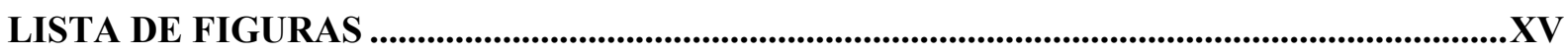

LISTA DE ALGORITMOS .................................................................................................................XVII

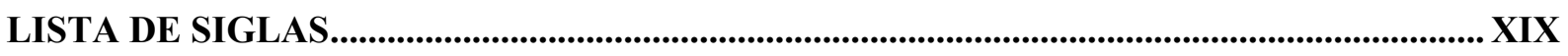

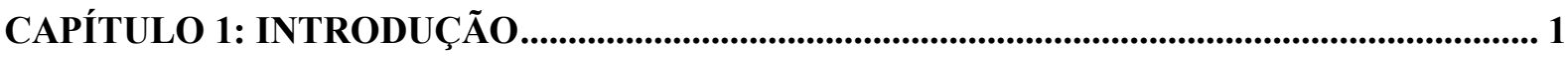

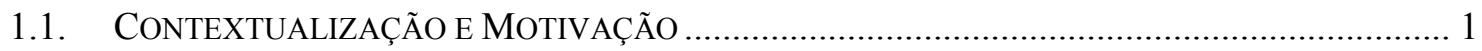

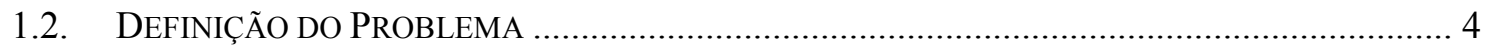

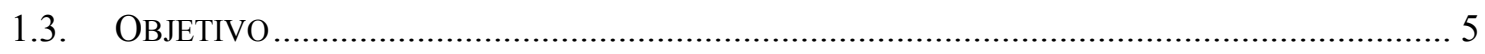

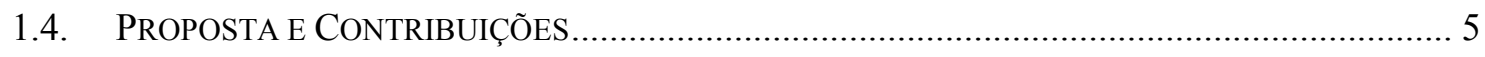

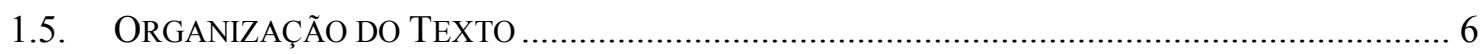

CAPÍTULO 2: REPRESENTAÇÃO DE IMAGENS ........................................................... 7

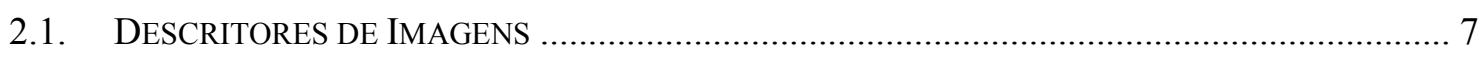

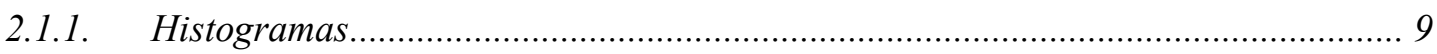

2.1.2. Extratores de Características Locais ……........................................................ 11

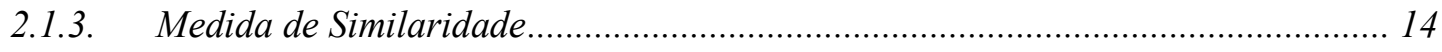

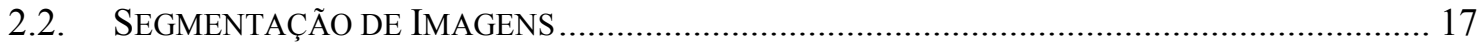

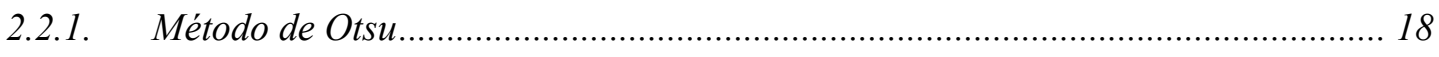

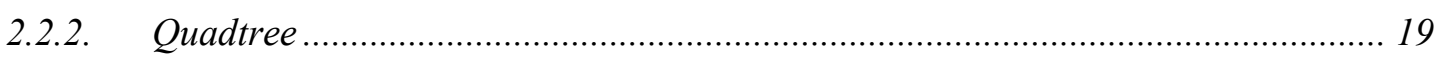

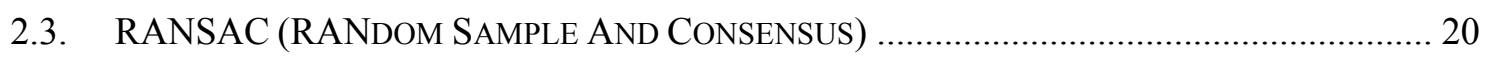

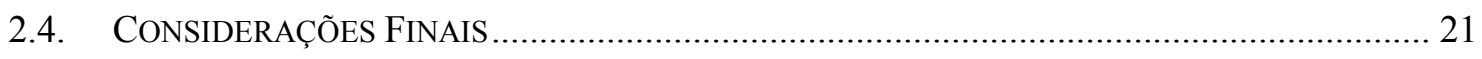

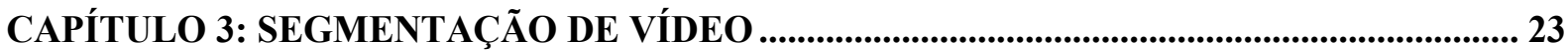

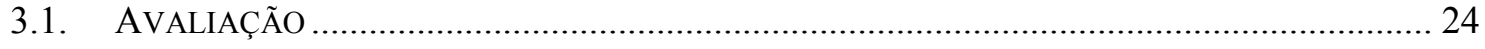

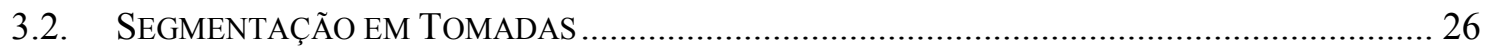

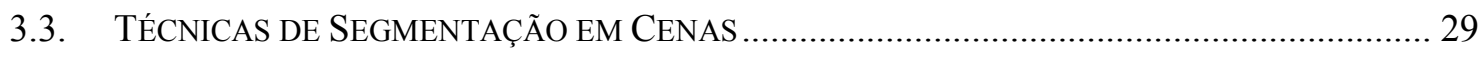

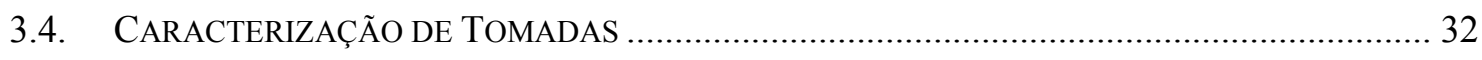

3.4.1. Trabalhos Relacionados a Técnicas de Segmentação em Cenas por Agrupamento

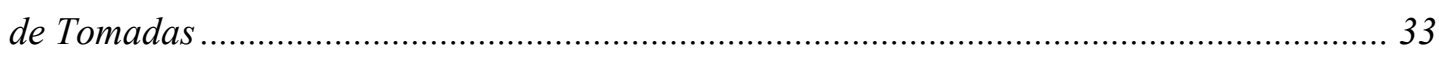

3.4.2. Trabalhos Relacionados a Métodos de Caracterização de Tomadas...................... 35 
3.5. MÉtodos de REPRESENTAÇÃo de TOMADAS BASEAdOS EM EXTRATORES DE

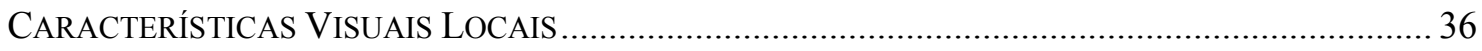

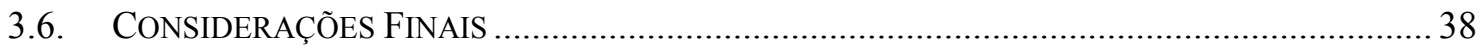

CAPÍTULO 4: REPRESENTAÇÃO DE TOMADAS ........................................................................... 39

4.1. MÉtodo de RePRESENTAÇÃo de TOMAdAS SHOt-HR (SHOt HigH

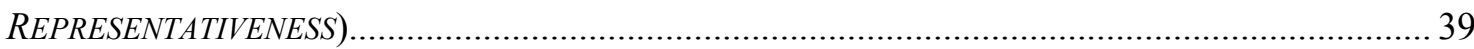

4.1.1. Extração e Redução de Características em Cada Quadro ...................................... 39

4.1.2. Redução de Características em Cada Tomada ....................................................... 45

4.1.3. Identificação de Correspondências entre Tomadas............................................... 47

4.2. MÉTOdo de SEleÇÃo de Quadros-Chave KS-SIFT (KEYFrame SET - SIFT) ............. 49

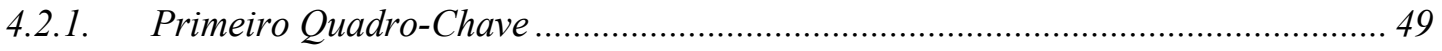

4.2.2. Análise do Número de Pontos de Interesse …............................................................50

4.2.3. Análise dos Vetores de Características................................................................... 51

4.2.4. Exemplo de Aplicação do Método KS-SIFT ............................................................... 52

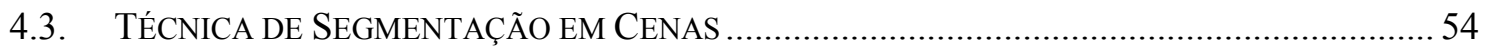

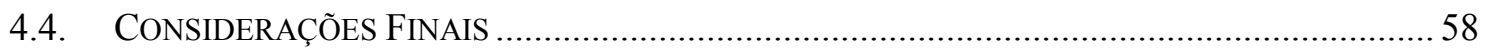

CAPÍTULO 5: EXPERIMENTOS E ANÁLISES............................................................................59

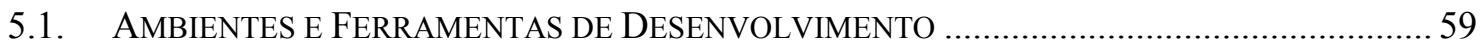

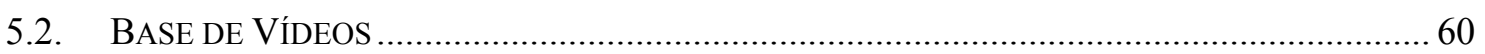

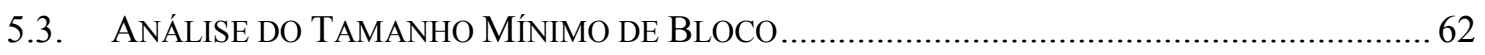

5.3.1. Análise da Taxa de Redução e Qualidade da Representação................................. 62

5.3.2. Avaliação de Blocos de $8 x 8$ e $16 x 16$ pixels.............................................................. 66

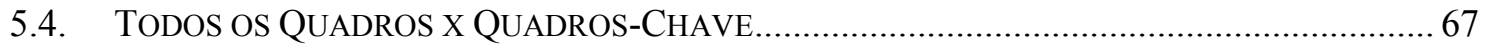

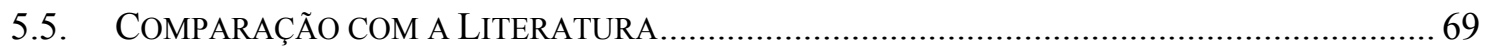

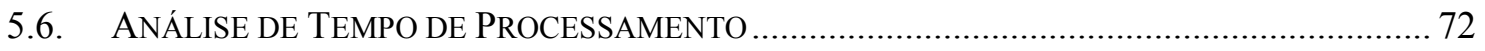

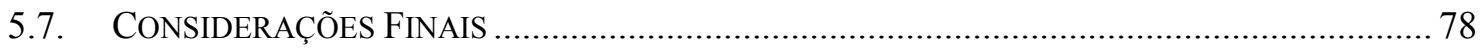

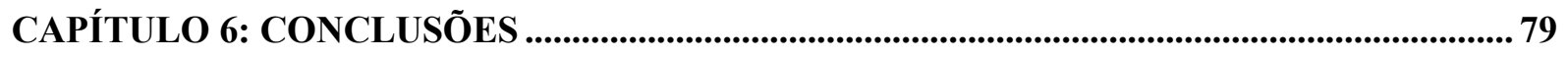

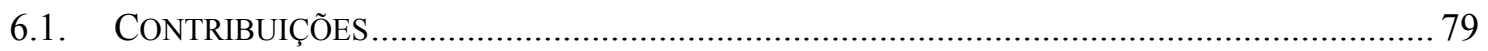

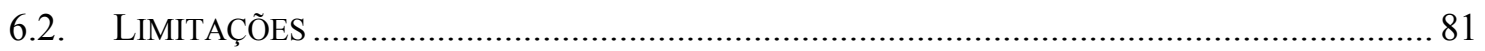

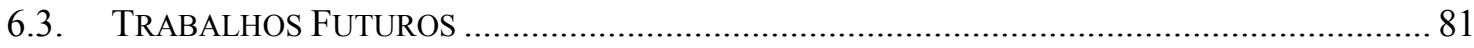

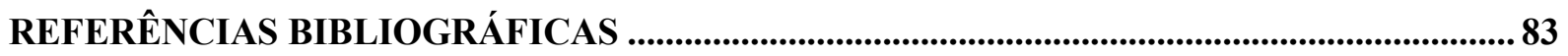




\section{Lista de Gráficos}

Gráfico 1. Exemplo de resultado da aplicação do método RANSAC.

Gráfico 2. Comparação entre os tempos de execução de cada processo na fase de extração e redução de características nos quadros.

Gráfico 3. Comparação entre os tempos de execução de cada processo na fase de redução de características nas tomadas. .73

Gráfico 4. Comparação do tempo de execução das três fases do método Shot-HR. .74

Gráfico 5. Tempos de execução para o método KS-SIFT (caso 2). 75

Gráfico 6. Tempos de execução para o método de Chergui et al. 75

Gráfico 7. Tempos de execução para o método de Baber et al. 75

Gráfico 8. Tempos de execução para o método de Tapu e Zaharia 75

Gráfico 9. Comparação entre os tempos de execução de diferentes métodos de representação de tomadas. .76 


\section{Lista de Tabelas}

Tabela 1. Definições de verdadeiros positivos e negativos, falsos positivos e negativos. ......25

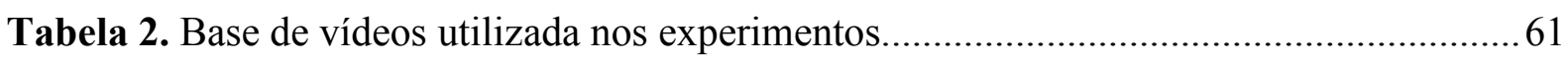

Tabela 3. Comparação entre os diferentes tamanhos mínimos de bloco utilizados na técnica Quadtree quanto à taxa de redução do número de pontos de interesse em relação aos pontos originalmente obtidos com o método SIFT e desvio padrão. 63

Tabela 4. Resultados da segmentação em cenas utilizando-se o método Shot-HR com duas configurações de blocos mínimos para a técnica Quadtree. 66

Tabela 5. Resultados da segmentação em cenas utilizando-se todos os quadros e quadroschave no método de representação de tomadas. 68

Tabela 6. Resultados da segmentação em cenas utilizando-se os métodos de representação de tomadas propostos e abordagens encontradas na literatura. . .70

Tabela 7. Tempos para a realização da segmentação em cenas. 78 


\section{Lista de Figuras}

Figura 1. Exemplo de estrutura do vídeo digital. ..............................................................

Figura 2. Uso de um descritor simples $D$ para computar a similaridade entre imagens. ......... 8

Figura 3. Histograma de intensidade que pode ser dividido por um limiar. .......................... 18

Figura 4. (a) Imagem particionada. (b) Quadtree correspondente. $R$ representa toda a região da imagem. Retirado de (Gonzalez \& Woods, 2010).

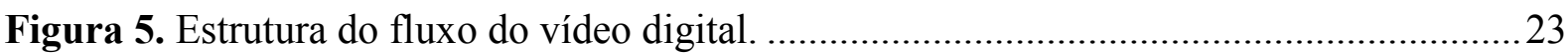

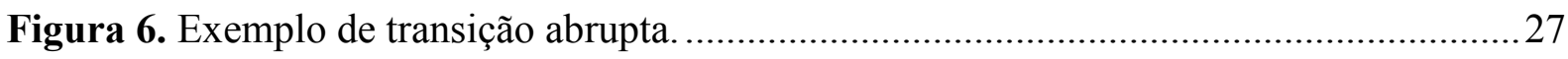

Figura 7. Exemplo de dissolução - transição gradual.........................................................27

Figura 8. Exemplo de wipe - transição gradual.................................................................28

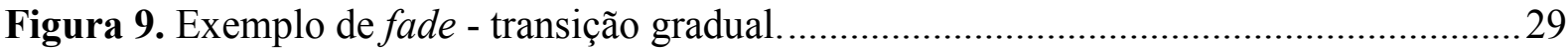

Figura 10. Resumo do processo de extração e redução de características em cada quadro....40

Figura 11. Exemplos de resultados do método de Otsu. Em (a) e (c), imagens em escala de cinza. Em (b) e (d), respectivas imagens binárias obtidas com o método de Otsu.

Figura 12. Exemplos de resultados da aplicação da técnica Quadtree. ...................................43

Figura 13. Resumo do processo de redução de características em cada tomada..................... 45

Figura 14. Exemplo de análise da diferença entre quadro atual e quadro-chave 50

Figura 15. Exemplos de conjuntos de quadros-chave selecionados com o método KS-SIFT.52

Figura 16. Simulação da execução da técnica de segmentação em cenas em um vídeo com 10 tomadas, no qual a medida de similaridade é o número de vetores de características correspondentes.

Figura 17. Exemplo de saída da segmentação automática em cenas. Trecho obtido para o filme Uma Mente Brilhante, utilizando-se o método de representação de tomadas Shot-HR. 62 Figura 18. Comparação entre os pontos de interesse resultantes do processo de redução para diferentes tamanhos mínimos de bloco na técnica Quadtree. Exemplo baseado na Figura 11a.

Figura 19. Comparação entre os pontos de interesse resultantes do processo de redução para diferentes tamanhos mínimos de bloco na técnica Quadtree. Exemplo baseado na Figura 11c. 
Figura 20. Exemplos de quadros-chave selecionados utilizando-se o método proposto por

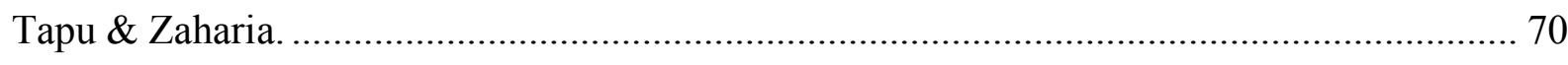




\section{Lista de Algoritmos}

Algoritmo 1. Cálculo do histograma em escala de cinza de uma imagem. Retirado de (Nixon

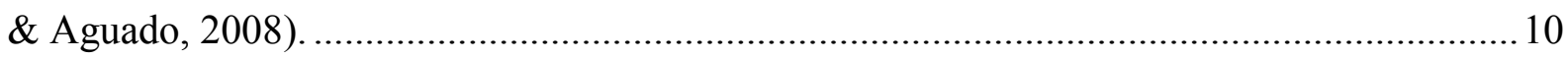

Algoritmo 2. Descrição da $1^{a}$ fase do método Shot-HR......................................................... 44

Algoritmo 3. Descrição da $2^{\mathrm{a}}$ fase do método Shot-HR.......................................................46

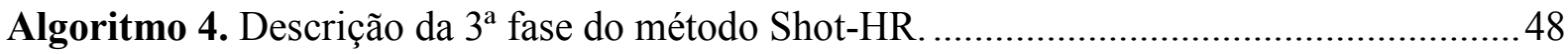

Algoritmo 5. Descrição do método KS-SIFT.............................................................................53

Algoritmo 6. Descrição da técnica de segmentação em cenas. ................................................57 
xviii 


\section{Lista de Siglas}

\begin{tabular}{|c|c|}
\hline $\mathrm{BoF}$ & Bag of Features \\
\hline BSC & Backward Shot Coherence \\
\hline CBIR & Content Based Image Retrieval \\
\hline $\mathrm{CCH}$ & Contrast Context Histogram \\
\hline CRG & Color Ratio Gradient \\
\hline HSV & Hue, Saturation, Value \\
\hline ICMC & Instituto de Ciências Matemáticas e de Computação \\
\hline ISM & International Symposium on Multimedia \\
\hline KS-SIFT & Keyframe Set - SIFT \\
\hline $\mathrm{M} 2 \mathrm{M}$ & Many to Many \\
\hline $\mathrm{M} 2 \mathrm{O}$ & Many to One \\
\hline MATLAB & MATrix LABoratory \\
\hline $\mathrm{O} 2 \mathrm{M}$ & One to Many \\
\hline $\mathrm{O} 2 \mathrm{O}$ & One to One \\
\hline OOS & One to One Symmetric matching \\
\hline PAE & Programa de Aperfeiçoamento de Ensino \\
\hline PCA & Principal Component Analysis \\
\hline PDF & Probability Density Function \\
\hline PGM & Portable Gray Map \\
\hline PNG & Portable Network Graphics \\
\hline PSB & Potential Scene Boundaries \\
\hline RANSAC & RANdom Sample And Consensus \\
\hline RGB & Red, Green, Blue \\
\hline $\mathrm{SAC}$ & Symposium on Applied Computing \\
\hline Shot-HR & Shot High Representativeness \\
\hline SIFT & Scale Invariant Feature Transform \\
\hline SURF & Speeded Up Robust Features \\
\hline SWMI & Sistemas Web e Multimídia Interativos \\
\hline USP & Universidade de São Paulo \\
\hline
\end{tabular}




\section{Capítulo 1: Introdução}

\subsection{Contextualização e Motivação}

Nos últimos anos houve um aumento na quantidade de dados multimídia disponíveis para acesso (Lu et al., 2011). Isso, em parte, pode ser explicado pela proliferação de dispositivos de baixo custo para capturá-los e codificá-los. Além disso, o avanço da tecnologia possibilitou o surgimento de uma grande variedade de meios que permitem ao usuário o uso de informações multimídia em qualquer lugar e a qualquer momento. Atualmente, as pessoas podem ter acesso a conteúdos usando diferentes tipos de dispositivos, tais como notebooks, tablets, smartphones, entre outros. Também as plataformas de acesso se modificaram, com novas redes, por exemplo, WiFi. Toda essa evolução criou ambientes heterogêneos, nos quais usuários com diferentes características desejam acessar conteúdos por meio de vários tipos de dispositivos e redes (Bouyakoub \& Belkhir, 2008). Com isso, surgiram desafios no tratamento dos dados, já que, geralmente, quando um dispositivo acessa um conteúdo multimídia para o qual não foi projetado, a experiência do usuário é insatisfatória (Magalhães \& Pereira, 2004). Por exemplo, dados em alta resolução poderão não ser visualizados corretamente em aparelhos eletrônicos com capacidades restritas, tais como telas com pequena área de visualização, restrições de processamento, memória e/ou banda para transmissão.

Além disso, a era digital trouxe outra importante característica: a interação do usuário com o conteúdo. Com os avanços da Web, as pessoas podem interativamente escolher diferentes caminhos de navegação, explorando variadas informações disponíveis, inclusive multimídia. Exemplos desse tipo de serviço são YouTube ${ }^{1}$, Netflix $^{2}$ e Last.fm ${ }^{3}$.

\footnotetext{
${ }^{1}$ YouTube é um site que permite que as pessoas assistam e compartilhem vídeos. Age como uma plataforma de distribuição para criadores e anunciantes de conteúdo original (www.youtube.com).

${ }^{2}$ Netflix é um serviço que permite a assinantes assistir a filmes e séries de TV transmitidos pela Internet (www.netflix.com).
} 
Também é importante ressaltar que atualmente os usuários não somente acessam conteúdos como também ativamente os produzem. Esse contexto, onde o volume de dados produzidos cresce contínua e rapidamente, leva ao problema da sobrecarga de informação: encontrar conteúdo de interesse em meio ao imenso volume de informações disponíveis (Hu et al., 2011; Magalhães \& Pereira, 2004; Toffler, 1984).

Visando contribuir para reduzir tal problema, o grupo de Sistemas Web e Multimídia Interativos (SWMI), do ICMC-USP (Instituto de Ciências Matemáticas e de Computação Universidade de São Paulo), tem como uma de suas linhas de pesquisa uma área atual: a Personalização e Adaptação de Conteúdo. Um sistema de adaptação procura decidir a versão de conteúdo ideal para apresentação e a melhor estratégia para gerar essa versão (Lum \& Lau, 2002; Mohan et al., 1999). Dessa maneira, é possível tornar os dados compatíveis com diversos ambientes, respeitando as limitações dos dispositivos e melhorando a experiência do usuário. Já a personalização é vista como um caso particular da adaptação, quando os dados são moldados para um único usuário (Barrios et al., 2005; Lu et al., 1998). Logo, são estudados meios de se customizar e/ou filtrar os dados segundo as preferências, interesses e necessidades de um usuário específico.

Trabalhos recentes (por exemplo: Chergui et al., 2012; Coimbra, 2011; Liu et al., 2009; Manzato, 2011; Tapu \& Zaharia, 2011b) estão direcionados à personalização multimídia, disponibilizando diferentes serviços cujo objetivo em comum é customizar o conteúdo com base nas preferências ou necessidades de cada indivíduo. Serviços que exploram essa funcionalidade podem ser categorizados em Seleção de Conteúdo, Sistemas de Recomendação e Sistemas de Sumarização (Adomavicius \& Tuzhilin, 2005). Além disso, vale destacar que a personalização pode ser aplicada a diversos conteúdos, incluindo vídeo digital, que é o foco deste trabalho.

Os sistemas de personalização de vídeo necessitam que metadados sejam extraídos para representar ${ }^{4}$ o conteúdo. Entretanto, o processo de extração de metadados é complexo e envolve alto custo computacional (Blanken et al., 2010). Por exemplo, é comum que os vídeos sejam descritos por meio de suas características visuais e que para obtê-las sejam utilizadas técnicas de extração de características de imagens com relativo alto custo de

\footnotetext{
${ }^{3}$ Last.fm é um serviço de recomendações musicais que, com base nas músicas que o usuário acessa, o ajuda a descobrir novos conteúdos (www.last.fm).

${ }^{4}$ Neste texto, os termos "representação", "descrição" e "caracterização" serão usados como sinônimos quando se referirem ao processo de representar um vídeo por meio de descritores, tornando a representação mais compacta.
} 
processamento. A aplicação de tais técnicas no domínio de vídeos mostra-se um problema frente a grande quantidade de imagens a ser analisada. Consequentemente, o passo inicial dos serviços de personalização é a segmentação dos vídeos, isto é, dividi-los em um conjunto de unidades com significado e mais facilmente gerenciáveis (Koprinska \& Carrato, 2001), de modo a reduzir o volume de dados e facilitar o processamento (Lu et al., 2011). Tais unidades podem ser quadros, tomadas ou cenas. Quadros são imagens obtidas por uma câmera a uma taxa constante, formando o vídeo (Richardson, 2002). Uma tomada pode ser definida como um conjunto de quadros capturados por uma única câmera e que representam uma ação contínua (Smeaton, 2007). Uma cena, por sua vez, é um grupo de tomadas semanticamente relacionadas (Rui et al., 1999; Zhai \& Shah, 2006). Essa estrutura do vídeo digital é ilustrada na Figura 1. Do ponto de vista do usuário, o mais interessante é que se obtenham cenas, já que elas contêm informações semanticamente mais relevantes. Além disso, diferente dos conceitos de quadro e tomada, o conceito de cena é familiar ao usuário comum. Por exemplo, é usual ouvir as pessoas comentando a respeito de cenas de filmes a que assistiram ou dizendo que determinada cena de uma série de televisão que gostam é engraçada ou ainda perguntando sobre uma cena da novela do dia anterior.

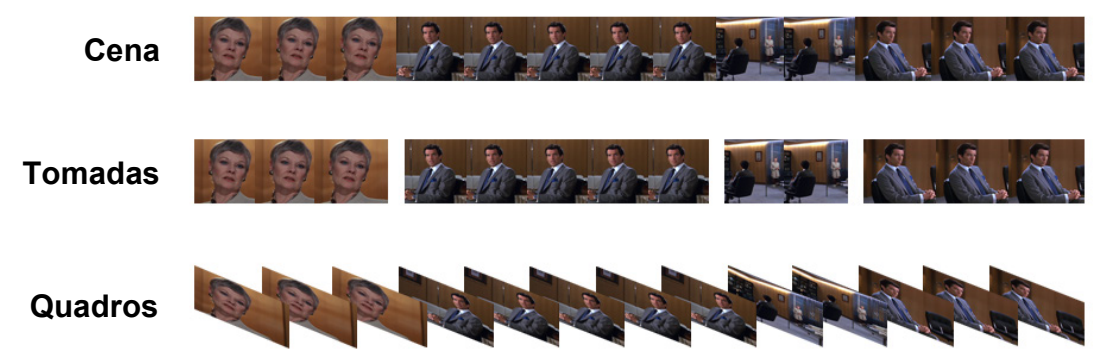

Figura 1. Exemplo de estrutura do vídeo digital.

Também é importante ressaltar que os sistemas de personalização, por exemplo, sistemas de sumarização (Almeida et al., 2012; Zhou et al., 2010), utilizam a segmentação do vídeo no nível de cenas. Esses serviços facilitam diversas atividades realizadas pelos usuários diariamente. No caso específico da sumarização, disponibiliza-se uma representação concisa do vídeo, a qual fornece uma ideia de seu teor, e o usuário tem a possibilidade de escolher se deseja assistir ao conteúdo completo ou não (Almeida et al., 2012). Tal serviço torna mais eficiente o acesso a informações em grandes bases de vídeo e permite que o usuário economize tempo ao realizar buscas. 
A segmentação de vídeos digitais em cenas, entretanto, ainda é um campo de pesquisa sendo investigado e que apresenta muitos desafios. Isso porque é um processo de maior complexidade do que a segmentação em quadros ou tomadas, devido principalmente à subjetividade do conceito e à semântica envolvida (Hu et al., 2011; Smeulders et al., 2000; Zhu \& Liu, 2008a).

Das abordagens utilizadas para realizar segmentação em cenas, as baseadas em agrupamento de tomadas se destacam devido a fatores como penetração na comunidade científica, disponibilidade, custo computacional e desempenho (Chasanis et al., 2007; Rasheed \& Shah, 2003; Sakarya \& Telatar, 2010; Tapu \& Zaharia, 2011b). De modo geral, para que um processo de segmentação em cenas tenha êxito é necessário, primeiro, caracterizar as tomadas, sendo este o problema tratado nesta dissertação (Seção 1.2).

\subsection{Definição do Problema}

No domínio de vídeos digitais, usualmente manipula-se um grande volume de informações, por isso, é necessário que a representação das tomadas seja compacta, a fim de tornar viável sua utilização e garantir eficiência em termos de tempo de processamento. Além disso, a qualidade dos resultados obtidos no processo de segmentação em cenas está fortemente relacionada à qualidade da caracterização de tomadas, sendo essencial garantir-se também a representatividade da mesma.

Contudo, para o problema de caracterização de tomadas, os trabalhos relacionados, de modo geral, utilizam soluções simples, que não demandem alto custo computacional, na busca por representações compactas dos dados. Diversos deles adotam quadros-chave como representação da tomada, isto é, selecionam um quadro ou um conjunto deles para sintetizar seu conteúdo mais relevante. Esse processo de seleção é realizado utilizando-se algoritmos que consideram informações do conteúdo, ou utilizando-se abordagens mais simples, como a extração de quadros-chave em posições fixas, por exemplo, o primeiro ou o quadro mediano de uma tomada (Baber et al., 2011; Coimbra, 2011; Gu et al., 2007; Li et al., 2001; Lin \& Zhang, 2000; Rasheed \& Shah, 2003). Essa abordagem apresenta a vantagem de possuir um baixo custo de processamento, já que, considerando o vídeo como um todo, analisa-se uma pequena quantidade de quadros do mesmo. Por outro lado, apenas uma imagem, na maioria dos casos, não é capaz de representar a variedade de informações presente em uma tomada, usualmente composta por centenas de imagens, que podem possuir conteúdos diferentes. 
Além disso, com algumas exceções, esses trabalhos descrevem o quadro-chave utilizando histogramas de cor. Entretanto, características de cor possuem semântica limitada e apesar dos histogramas apresentarem um baixo custo computacional, a tendência é que se obtenha baixa eficiência ao aplicá-los em tarefas de segmentação (Souza \& Goularte, 2013). Logo, obter uma caracterização de tomadas compacta e representativa mostra-se ainda um problema em aberto.

\subsection{Objetivo}

Este trabalho tem como objetivo o desenvolvimento de um método de representação de tomadas compacto e representativo que, consequentemente, possibilite contribuir para a melhoria de eficiência de técnicas de segmentação de vídeos digitais em cenas.

\subsection{Proposta e Contribuições}

O método de representação de tomadas proposto baseia-se em características visuais locais obtidas dos quadros do vídeo com o extrator SIFT (Scale Invariant Feature Transform) (Lowe, 1999) (Subseção 2.1.2), capturando informações importantes presentes nas imagens. Porém, embora a utilização desse extrator resulte em ganhos em termos de representatividade, ela introduz o problema do alto volume de dados uma vez que diversos vetores de características são obtidos de cada quadro do vídeo. Logo, a fím de se alcançar uma caracterização compacta, o volume de informações é reduzido em cada quadro individualmente e, em um passo posterior, considerando-se a tomada como um todo.

É fundamental que os processos de redução preservem a representatividade da caracterização, por isso as eliminações de informações são realizadas considerando-se a semântica do conteúdo analisado. No caso da redução de dados em cada quadro, utiliza-se uma técnica de segmentação de imagens, a Quadtree (Finkel \& Bentley, 1974) (Subseção 2.2.2), para se avaliar as regiões dos quadros das quais vetores de características podem ser excluídos, sem comprometer a qualidade da representação. No segundo passo, utiliza-se o algoritmo RANSAC (RANdom Sample And Consensus) (Fischler \& Bolles, 1981) (Seção 2.3) para ajustar um modelo aos dados da tomada, excluindo-se outliers. Visando sintetizar ainda mais a representação, propôs-se um método de seleção de quadros-chave, também baseado no 
extrator de características locais SIFT, que pode ser utilizado de maneira combinada aos processos de redução explicados anteriormente.

O método de representação de tomadas desenvolvido foi avaliado no contexto de segmentação em cenas e os resultados dos experimentos mostraram que ele é capaz de superar abordagens consideradas estado da arte reportadas na literatura, como Baber et al. (2011), Chergui et al. (2012) e Tapu \& Zaharia (2011a). Logo, o trabalho mostra que avanços na caracterização de tomadas têm potencial para aprimorar a qualidade de técnicas de segmentação em cenas e contribuir com serviços de Personalização de Conteúdo.

\subsection{Organização do Texto}

Esta dissertação está organizada em seis capítulos. O Capítulo 2 apresenta técnicas de processamento de imagens, que podem ser aplicadas ao contexto de vídeos digitais. Os tópicos principais incluem a discussão de descritores e métodos de segmentação de imagens utilizados neste trabalho. O Capítulo 3 discute a segmentação de vídeos em tomadas e em cenas e apresenta uma análise dos métodos de caracterização de tomadas encontrados na literatura e considerados estado da arte. O Capítulo 4 descreve o método de representação de tomadas proposto, baseado em todos os quadros e a abordagem para seleção de quadroschave. Também se discute a técnica de segmentação em cenas desenvolvida. O Capítulo 5 traz experimentos realizados para avaliar o método de representação de tomadas proposto no contexto de segmentação em cenas. Os resultados obtidos são analisados e comparados com abordagens de caracterização encontradas na literatura e pertencentes ao estado da arte. Também se discute o tempo de processamento necessário para a obtenção dos diferentes tipos de representação de tomadas. Por fim, o Capítulo 6 apresenta as contribuições e limitações do trabalho desenvolvido, bem como novas oportunidades de pesquisa. 


\section{Capítulo 2: Representação de Imagens}

Este capítulo apresenta conceitos e técnicas da área de Processamento de Imagens, que foram utilizados neste trabalho para manipulação de quadros de vídeo. Por se tratar de uma área de pesquisa ampla, com grande diversidade de conteúdo, optou-se por descrever apenas os tópicos diretamente relacionados ao trabalho desenvolvido. O capítulo está organizado em três seções. A Seção 2.1 traz conceitos e exemplos de descritores de imagens, os quais possibilitam o desenvolvimento de uma representação de tomadas baseada em características visuais. A Seção 2.2 discute técnicas de segmentação de imagens, que facilitam a extração de características e podem ser utilizadas como ferramentas para redução do volume de informações a serem processadas. Por fim, a Seção 2.3 apresenta o método RANSAC, utilizado para reduzir a quantidade de informações necessárias para representar uma imagem (ou um conjunto delas) e que pode contribuir para a obtenção de uma representação mais compacta de tomadas de vídeo.

\subsection{Descritores de Imagens}

Os serviços de personalização de vídeo necessitam, para operar, de uma representação computacional dos dados. Em muitos casos, essa representação é baseada em atributos visuais e obtida a partir da unidade mais básica do vídeo, isto é, o quadro, que é, na verdade, uma imagem. Assim, para extrair as características presentes em um quadro é necessário utilizar um descritor de imagem, capaz de gerar uma caracterização compacta dos dados, de modo a facilitar o processamento, mas ao mesmo tempo representativa do conteúdo.

Um descritor de imagem é composto por um algoritmo de extração para codificar características da imagem em vetores de características e por uma medida de similaridade para comparar duas imagens. Vale destacar que os vetores apresentam um volume de dados menor que a imagem em si, consistindo em uma representação mais compacta. A medida de similaridade é uma função de comparação, que fornece o grau de similaridade para um dado 
par de imagens representadas por seus vetores de características e é geralmente definida como uma função inversa à distância (por exemplo, Euclidiana), isto é, quanto maior o valor da distância, menos similares são as imagens (Torres \& Falcão, 2006).

A seguir são apresentadas definições de imagem, vetor de características e descritor de imagem, segundo Torres e Falcão (2006).

Uma imagem $\hat{I}$ é um par $\left(D_{l}, \vec{I}\right)$, onde:

- $\quad D_{I}$ é um conjunto finito de pixels (pontos em $\mathbb{N}^{2}$, isto é, $D_{I} \subset \mathbb{N}^{2}$ ) e

- $\quad \vec{I}: D_{I} \rightarrow \mathbb{R}^{n}$ é uma função que associa para cada pixel $p$ em $D_{I}$ um vetor $\vec{I}(p) \in \mathbb{R}^{n}$ (por exemplo, $\vec{I}(p) \in \mathbb{R}^{3}$ quando uma cor no sistema RGB (Red, Green, Blue) é associada a um pixel).

Um vetor de características $\vec{v}_{\hat{I}}$ de imagem $\hat{I}$ pode ser visto como um ponto no espaço $\mathbb{R}^{n}$ : $\vec{v}_{\hat{I}}=\left(\mathrm{v}_{1}, \mathrm{v}_{2}, \ldots, \mathrm{v}_{\mathrm{n}}\right)$, onde $n$ é a dimensão do vetor.

Exemplos de possíveis vetores de características são histogramas de cor, momentos de Zernike e filtros de Gabor. Eles codificam propriedades da imagem, tais como cor, forma e textura, respectivamente. Vale ressaltar que diferentes tipos de vetores de características podem requerer diferentes funções de similaridade.

Um descritor de imagem $D$ é definido como uma tupla $\left(\epsilon_{D}, \delta_{D}\right)$, onde:

- $\epsilon_{D}:\{\hat{I}\} \rightarrow \mathbb{R}^{n}$ é uma função que extrai um vetor de características $\vec{v}_{\hat{I}}$ de uma imagem $\hat{I}$.

- $\quad \delta_{D}: \mathbb{R}^{n} \mathrm{x} \mathbb{R}^{n} \rightarrow \mathbb{R}^{n}$ é uma função de similaridade (por exemplo, baseada na distância métrica) que computa a similaridade entre duas imagens como o inverso da distância entre seus correspondentes vetores de características.

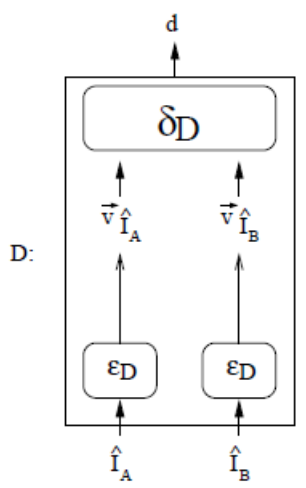

Figura 2. Uso de um descritor simples $D$ para computar a similaridade entre imagens.

Retirado de (Torres \& Falcão, 2006). 
A Figura 2 ilustra o uso de um descritor simples $D$ para computar a similaridade entre duas imagens $\hat{I}_{A}$ e $\hat{I}_{B}$. Primeiramente, o algoritmo de extração $\epsilon_{D}$ é usado para computar os vetores de características $\vec{v}_{\hat{I} A}$ e $\overrightarrow{\mathcal{V}}_{\hat{I} B}$ associados às imagens. Então, a função de similaridade $\delta_{D}$ é usada para determinar o valor da similaridade $d$ entre as imagens. Vale ressaltar que múltiplos descritores podem ser combinados em um descritor complexo, o qual é capaz de codificar várias propriedades da imagem ao mesmo tempo (Torres et al., 2005).

Como explicado anteriormente, várias propriedades podem ser extraídas de imagens, dando origem a diversas representações. Para cor, a Subseção 2.1.1 apresenta os histogramas, uma representação simples e amplamente utilizada no domínio de vídeos digitais. A Subseção 2.1.2 introduz os extratores de características locais SIFT (Lowe, 1999) e SURF (Speeded Up Robust Features) (Bay et al., 2006), que diferentemente dos histogramas não utilizam a cor como característica para representar as imagens e têm sido aplicados com sucesso em tarefas de recuperação baseada em conteúdo.

\subsubsection{Histogramas}

Histogramas podem ser calculados sobre quadros de vídeos em escala de cinza ou coloridos de algum espaço de cores, por meio da decomposição dos canais de cor (Marques Filho \& Vieira Neto, 1999).

O histograma em escala de cinza de uma imagem é uma função discreta formada pela contagem do número de pixels na imagem que possuem o mesmo valor de intensidade, representando um determinado nível de cinza. Quando essa função é normalizada para somar 1 para todos os níveis de cinza, ela pode ser tratada como uma função densidade de probabilidade que expressa a probabilidade de um certo tom de cinza ser encontrado na imagem (Petrou \& Petrou, 2010). Logo, o histograma de intensidade mostra quanto cada nível de cinza ocupa da imagem. Além disso, o contraste pode ser medido pelo intervalo entre os níveis.

O Algoritmo 1 apresenta como calcular o histograma em escala de cinza de uma imagem. Primeiramente, o histograma é inicializado com zero. Então é feita a contagem do número de pontos da imagem que possuem intensidade de certo valor. Essas contagens para os diferentes valores formam o histograma global, que é retornado como um vetor. Porém, ele também pode ser apresentado na forma de um gráfico, no qual plota-se o número de pixels em um nível de cinza contra o nível de cinza (Nixon \& Aguado, 2008). 


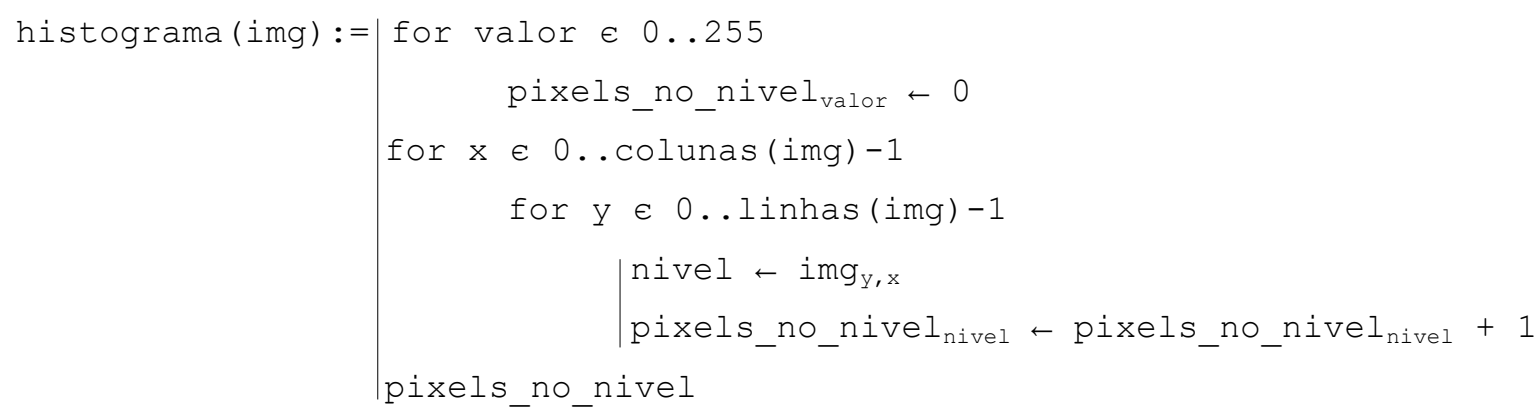

Porém, além do histograma em escala de cinza, histogramas de cor também podem ser extraídos. Um histograma de cor, segundo Marques (2011), pode ser definido como uma representação gráfica da frequência de cada nível de cor em uma imagem. Entretanto, enquanto histogramas em escala de cinza possuem apenas um canal de cor com 256 níveis, histogramas de cor, por exemplo, no espaço RGB, possuem três canais, isto é, o triplo de dados. Dependendo da imagem a ser processada, a combinação de cores para compor o histograma pode resultar em um volume alto de informação.

Assim, para reduzir tal volume de dados, as imagens coloridas sofrem o processo de quantização (Marques, 2011): cores próximas são agrupadas em um conjunto e, dentro desse conjunto, todas as cores são igualadas. Ao número de grupos da quantização costuma-se dar o nome de bins (caixas). Logo, uma imagem no espaço de cor RGB com 12 bins na proporção 4:4:4 (isto é, 4 para vermelho, 4 para verde e 4 para azul) seria representada em apenas 64 valores, ao invés de mais de 16 milhões caso a quantização não fosse utilizada. O tamanho do histograma é obtido por meio da combinação de todos os quatro valores de vermelho, quatro de verde e quatro de azul, formando então 64 combinações entre eles.

O processo de quantização apresenta vantagens tanto na redução do tamanho do histograma como em velocidade de processamento de operações sobre o histograma resultante. Como desvantagem, cita-se que a divisão de um histograma em bins resulta na perda irreversível de informações, como pequenos detalhes da imagem e degradês.

Duas das principais operações sobre histogramas são a intersecção e diferença absoluta de histogramas (Marques, 2011). Na intersecção de histogramas, dois histogramas de imagens diferentes sofrem a operação de intersecção para cada um de seus valores, sendo que os valores comuns são armazenados em um novo histograma. Caso se deseje um único valor, esse será a soma de todos os valores para cada uma das cores presentes no histograma da intersecção. 
Já no caso da diferença, dois histogramas sofrem a operação de diferença entre seus valores. Caso se deseje um valor único, o valor obtido de cada diferença é somado, em módulo, formando a diferença entre dois histogramas. Vale ressaltar que os valores são calculados em módulo para que não ocorram valores negativos.

Os histogramas consistem em uma abordagem de caracterização simples, mas são amplamente empregados, principalmente por serem fáceis de computar, exigirem um baixo custo de processamento e resultarem em uma representação compacta. Além disso, a cor é a característica de baixo nível mais comumente utilizada em sistemas de recuperação de imagens baseada em conteúdo (Stehling et al., 2002) e tem grande importância também no domínio de vídeos digitais. Entretanto, os histogramas não são capazes de capturar a semântica do conteúdo e, em alguns casos, imagens diferentes possuem histogramas semelhantes ou idênticos. Essas situações prejudicam a representatividade da caracterização.

\subsubsection{Extratores de Características Locais}

Um modo diferente dos anteriormente apresentados para se representar imagens é utilizar extratores de características visuais locais, que estão associados à identificação e descrição de pontos de interesse. Embora existam diversas técnicas de descrição local de imagens, todas se baseiam em três passos principais, explicados a seguir, segundo Bay et al. (2006).

- Pontos de interesse são selecionados em alguns locais da imagem, tais como cantos ou junções-T. A propriedade mais valiosa de um detector de pontos de interesse é a repetitividade, isto é, se é confiável para encontrar os mesmos pontos de interesse em diferentes condições de visualização.

- A vizinhança de cada ponto de interesse é representada por um vetor de características. Esse descritor deve ser diferenciado e, ao mesmo tempo, robusto a ruídos, detecção de erros e deformações geométricas e fotométricas.

- Os vetores de características de diferentes imagens são comparados. A comparação é frequentemente baseada no uso de distâncias, por exemplo, distância Euclidiana. A dimensão do vetor tem um impacto direto no tempo de execução deste passo.

Nesta subseção, descrevem-se os extratores de características locais considerados estado da arte e mais comumente utilizados em trabalhos da área de CBIR (Content Based Image Retrieval) e de vídeos digitais, sendo eles o SIFT e o SURF. 


\section{SIFT (Scale Invariant Feature Transform)}

O método SIFT transforma uma imagem em uma coleção de vetores de características locais, sendo cada um deles invariante a translação, escala e rotação e parcialmente invariante a mudanças na iluminação ou projeção 3D (Lowe, 1999). Tais vetores estão localizados tanto no domínio espacial quanto no domínio das frequências, reduzindo a probabilidade de perturbações por oclusão, desorganização ou ruídos (Lowe, 2004).

Para a extração das características é utilizada uma abordagem de filtragem em cascata, na qual as operações mais caras são aplicadas apenas em locais que passam por um teste inicial. A seguir são apresentados, segundo Lowe (2004), os quatro principais estágios de computação usados para gerar o conjunto de características de uma imagem.

1. Detecção de extremos escala-espaço. O primeiro estágio de computação realiza buscas em todas as escalas e locais da imagem. Tal estágio é implementado utilizando uma função de diferença de Gaussianas para identificar potenciais pontos de interesse invariantes a escala e orientação.

2. Localização dos pontos-chave. Em cada local candidato, um modelo detalhado é aplicado para determinar localização e escala. Pontos-chave são selecionados com base em medidas de sua estabilidade.

3. Atribuição de orientação. Uma ou mais orientações são atribuídas a cada ponto-chave baseadas nas direções de gradientes locais da imagem. Todas as futuras operações são realizadas nos dados da imagem que foram transformados com relação a orientação, escala e localização atribuídos para cada característica, provendo assim invariância a essas transformações.

4. Descritor de pontos-chave. Os gradientes locais da imagem são medidos, na escala selecionada, na região ao redor de cada ponto-chave. Eles são transformados em uma representação que permite níveis significativos de distorções locais de forma e mudanças na iluminação.

Um importante aspecto do SIFT é que ele gera um grande número de vetores de características, de 128 dimensões, que cobrem a imagem em termos de escalas e localizações. Por exemplo, uma imagem de 500x500 pixels dará origem a cerca de 2000 vetores (embora esse número dependa tanto do conteúdo da imagem quanto da escolha de diversos parâmetros). A quantidade de características é particularmente importante para o reconhecimento de objetos, pois, para uma identificação confiável de pequenos elementos em 
fundos desordenados, pelo menos três características de cada objeto devem apresentar correspondência (Lowe, 2004).

Porém, a alta dimensionalidade dos vetores obtidos com o SIFT mostra-se uma desvantagem no passo de comparação de representações de diversas imagens (Bay et al., 2006). Além disso, apesar do algoritmo do SIFT ser considerado o mais eficaz, sem a ajuda de hardwares para acelerar a execução, computadores comuns dificilmente conseguem realizar o processamento em tempo real (Huang et al., 2011).

\section{SURF (Speeded Up Robust Features)}

O método SURF possui detectores e descritores de pontos de interesse invariantes a escala e rotação. Isso porque essas propriedades apresentam um bom compromisso entre a complexidade das características e robustez para deformações comumente encontradas. Por sua vez, inclinação e perspectiva são considerados efeitos de segunda ordem, os quais são cobertos em algum grau pela robustez geral do método (Bay et al., 2006). O algoritmo possui dois componentes principais: o detector de pontos de interesse e o descritor, sendo cada um deles sucintamente explicados a seguir, de acordo com Bay et al. (2006).

- Detector de pontos de interesse. É baseado na matriz de Hessian (Lindeberg, 1998; Mikolajczyk \& Schmid, 2001), devido ao seu bom desempenho em termos de tempo de computação e precisão. O determinante de Hessian é utilizado para selecionar a localização e a escala.

- Descritor: possui dois passos principais, descritos a seguir.

1. Atribuição de orientação. A fim de ser invariante a rotação, identifica-se uma orientação reproduzível para cada ponto de interesse. Para isso, são calculadas as respostas Haar-wavelet nas direções $x$ e $y$, em uma vizinhança circular ao redor do ponto de interesse.

2. Componentes do descritor. Consiste em construir uma região quadrada em torno do ponto de interesse, alinhada à orientação selecionada no passo 1 e extrair dela os descritores.

É importante destacar que, em geral, esse algoritmo utiliza vetores com apenas 64 dimensões (apesar de ser possível utilizar os vetores estendidos com 128 dimensões), reduzindo, em relação ao SIFT, o tempo da computação das características e também da comparação entre representações de imagens, ao mesmo tempo em que aumenta a robustez (Bay et al., 2006). 
Além disso, a velocidade de processamento do SURF é três vezes maior que a do SIFT (Huang et al., 2011). Isso significa que o SURF possui um esquema de detecção e descrição de pontos de interesse superior em velocidade e, apesar disso, segundo Bay et al. (2006), autores da técnica, mantém a precisão.

\subsubsection{Medida de Similaridade}

Uma representação somente é útil no domínio de Recuperação Multimídia se permite comparações consistentes (Faloutsos, 1999), logo, torna-se clara a necessidade de uma medida de similaridade. Como discutido no início desta seção, representações podem ser comparadas por meio de distâncias.

Entretanto, quando extratores de características visuais locais são empregados, ao invés de pares de vetores de características, têm-se dois conjuntos a serem comparados. Existem métodos, como o Bag of Features (BoF) ${ }^{5}$ (Valle \& Cord, 2009), que processam os dados de uma representação e geram como saída um único histograma. Então, as tradicionais distâncias podem ser aplicadas. Porém, muitos desses métodos apresentam custo computacional elevado e dependem da definição de diversos parâmetros (como o tamanho do dicionário de palavras visuais, no caso do BoF) que possuem impacto direto na qualidade dos resultados. Sendo assim, uma alternativa para medir a similaridade entre dois conjuntos de dados, sem a necessidade de processamentos adicionais, é utilizar técnicas que avaliam a correspondência entre os vetores de características. Elas identificam quais vetores pertencentes a uma representação estão presentes em outra.

A seguir, discutem-se medidas de distância comumente utilizadas na área de Recuperação Multimídia e uma técnica de identificação de correspondências entre vetores de características de diferentes representações, que se destaca pelos resultados alcançados.

\section{Medidas de Distância}

Nesta subseção as distâncias são definidas em função das coordenadas de dois pixels, isto é, trata-se da distância entre vetores bidimensionais. Porém, pode-se estender a definição para vetores $n$ dimensionais.

\footnotetext{
${ }^{5}$ Em resumo, o método Bag of Features consiste em três fases: extração de características, construção de um dicionário de palavras visuais e representação da imagem por meio de um histograma indicando a frequência de ocorrência de diferentes palavras visuais.
} 
De acordo com Gonzalez \& Woods (2010), para os pixels $p, q$ e $z$, com coordenadas $(x, y)$, $(s, t)$ e $(v, w)$, respectivamente, $D$ é uma função distância ou medida de distância se:

(a) $D(p, q) \geq 0(D(p, q)=0$ se $p=q)$,

(b) $D(p, q)=D(q, p) e$

$(c) D(p, z) \leq D(p, q)+D(q, z)$.

A seguir, apresentam-se algumas medidas de distâncias comumente utilizadas na comparação de imagens, definidas segundo Gonzalez \& Woods (2010).

\section{Distância Euclidiana}

A distância euclidiana $\left(\mathrm{D}_{\mathrm{e}}\right)$ entre $p$ e $q$ é definida como:

$$
D_{e}(p, q)=\left((x-s)^{2}+(y-t)^{2}\right)^{1 / 2}
$$

Para essa medida de distância, os pixels que possuem distância de $p$ menor ou igual a um valor $r$ são os pontos contidos em um disco de raio $r$ centrado em $p$.

\section{Distância City Block}

A distância $\mathrm{D}_{4}$ (chamada de distância city block) entre $p$ e $q$ é definida como:

$$
D_{4}(p, q)=|x-s|+|y-t|
$$

Nesse caso, os pixels que têm uma distância $\mathrm{D}_{4}$ de $p$ menor ou igual a um valor $r$ formam um losango centrado em $p$. Por exemplo, os pixels com $\mathrm{D}_{4}=1$ são os vizinhos-4 de $p$.

\section{Distância Chessboard}

A distância $\mathrm{D}_{8}$ (chamada de distância chessboard) entre $p$ e $q$ é definida como:

$$
D_{8}(p, q)=\max (|x-s|,|y-t|)
$$

Nesse caso, os pixels que têm uma distância $\mathrm{D}_{8}$ de $p$ menor ou igual a um valor $r$ formam um quadrado centrado em $p$. Por exemplo, os pixels com $\mathrm{D}_{8}=1$ são os vizinhos-8 de $p$. 


\section{OOS (One to One Symmetric matching)}

Existem diversos algoritmos para encontrar correspondências entre vetores de características pertencentes a diferentes representações. Dependendo das restrições impostas, eles podem ser categorizados em muitos para muitos (M2M, de many to many), muitos para um ( $12 \mathrm{O}$, de many to one), um para muitos $(\mathrm{O} 2 \mathrm{M}$, de one to many) e um para um $(\mathrm{O} 2 \mathrm{O}$, de one to one). Os fatores que afetam a escolha da estratégia a ser utilizada incluem tolerância a ruídos, eficácia e eficiência da correspondência. No caso de vídeos, os quadros podem ter problemas de baixa resolução, perda de foco por movimentação e artefatos de compressão. Por isso, a tolerância a ruídos é um fator essencial na seleção do método de correspondência a ser utilizado (Zhao et al., 2007).

Nesse contexto, a técnica OOS (Zhao et al., 2007) destaca-se por ter como principal objetivo a otimização das correspondências e por apresentar desempenho superior a outros métodos encontrados na literatura. Isso porque a OOS é capaz de remover um grande número de correspondências causadas por ruídos e outras ambiguidades visuais presentes nas imagens (Zhou et al., 2009).

A técnica OOS é classificada como $\mathrm{O} 2 \mathrm{O}$, isto é, cada vetor de características em um conjunto pode ser mapeado a, no máximo, um vetor em outro conjunto. Além disso, assegurase que vetores em um par sejam vizinhos mais próximos. O método também possui a propriedade de simetria, responsável por gerar resultados estáveis e únicos, uma vez que garante que a correspondência de um conjunto $A$ para um conjunto $B$ seja a mesma de $B$ para $A$, a menos que os vetores de características possuam mais do que um vizinho mais próximo.

Outra característica da técnica OOS é permitir a correspondência parcial, ou seja, apenas um subconjunto de vetores de características é mapeado, a fim de se excluir pares com baixa similaridade. Para isso, adota-se um limiar, como indicado na Equação 4.

$$
\operatorname{Sim}(Q, P) \geq \propto
$$

O limiar $\alpha$ especifica a menor similaridade aceitável entre dois vetores de características para uma possível correspondência. A similaridade de dois vetores denotados por $Q=\left[q_{1}, q_{2}\right.$, $\left.\ldots, q_{n}\right]$ e $P=\left[p_{1}, p_{2}, \ldots, p_{n}\right]$ é definida na Equação 5. 


$$
\operatorname{Sim}(Q, P)=\sum_{i=1}^{n} q_{i} p_{i}
$$

onde $p_{i}$ e $q_{i}$ são normalizados, portanto estão no intervalo [-1, 1] e $|\mathrm{P}|=|\mathrm{Q}|=1$.

A Equação 5 especifica o ângulo cosseno de $Q$ e $P$ no espaço de características de alta dimensão. Supondo $K$ um conjunto de pares de vetores de características, que satisfazem a Equação 4 e foram identificados pela aplicação da técnica OOS em duas imagens, tem-se que a similaridade entre essas duas imagens pode ser determinada diretamente com base na cardinalidade de $K$ ou considerando-se cada par de vetores, de acordo com a Equação 6.

$$
K \operatorname{Sim}(K)=\frac{\sum_{(Q, P) \in K} \operatorname{Sim}(Q, P)}{|K|}
$$

onde $|\mathrm{K}|$ denota a cardinalidade de $K$ e $K$ Sim calcula a similaridade média dos pares de vetores de características (Zhao et al., 2007).

\subsection{Segmentação de Imagens}

O processo de extração de características é dependente do conteúdo dos quadros do vídeo, sendo que imagens com muitas informações impõem uma complexidade maior ao processo. Assim, como uma alternativa para facilitar a extração de características ou reduzir a quantidade de vetores obtidos (quando extratores de características locais são utilizados), podem ser empregadas técnicas de segmentação de imagens. Com elas, é possível mapear as regiões mais importantes para a caracterização. Tais técnicas podem ser categorizadas em Detecção de ponto, linha e borda, Limiarização, Segmentação baseada em região e Segmentação usando watersheds morfológicas (Gonzalez \& Woods, 2010). Entre elas, o método de Otsu (1979) e a Quadtree (Finkel \& Bentley, 1974), técnicas de limiarização e segmentação baseada em região, respectivamente, se destacam pela simplicidade e baixa dependência de ajuste de parâmetros. Neste trabalho, tais técnicas são utilizadas em conjunto, para reduzir o número de cores das imagens e identificar blocos homogêneos. Então, os vetores de características podem ser filtrados, reduzindo-se informações, mas, ao mesmo tempo, considerando-se a semântica do conteúdo. Essas técnicas são detalhadas nas Subseções 2.2.1 e 2.2.2. 


\subsubsection{Método de Otsu}

Em virtude de suas propriedades intuitivas, simplicidade de implementação e velocidade computacional, a limiarização tem uma posição central nas aplicações de segmentação de imagem. Ela pode ser vista como um problema teórico de decisão estatística cujo objetivo é minimizar o erro médio incorrido na atribuição de pixels para dois ou mais grupos (também chamados de classes). A solução é baseada em apenas dois parâmetros: a função densidade de probabilidade (PDF, de probability density function) dos níveis de intensidade de cada classe e a probabilidade de que cada classe ocorra em uma determinada aplicação. Infelizmente, estimar as PDFs não é uma questão simples, de modo que o problema geralmente é simplificado tornando viáveis as suposições sobre a forma das PDFs, como assumir que são funções gaussianas.

Mesmo com as simplificações, o processo de implementação de soluções utilizando essas suposições pode ser complexo e nem sempre adequado para aplicações práticas. Nesse sentido, o método de Otsu (1979), classificado como uma técnica de limiarização global ótima, mostra-se uma alternativa atraente. O termo global refere-se ao fato de um ou mais limiares serem aplicáveis à imagem inteira para separação dos pixels em classes. Por exemplo, supondo que o histograma de intensidade apresentado na Figura 3 corresponda a uma imagem, $f(x, y)$, composta por objetos claros sobre um fundo escuro de tal modo que os pixels do objeto e do fundo tenham valores de intensidade agrupados em dois grupos dominantes (modos), uma maneira óbvia de extrair os objetos do fundo é selecionar um limiar $T$, que separa estes modos. Então, qualquer ponto $(x, y)$ na imagem em que $f(x, y)>T$ é chamado de ponto do objeto; caso contrário, o ponto é chamado ponto de fundo.

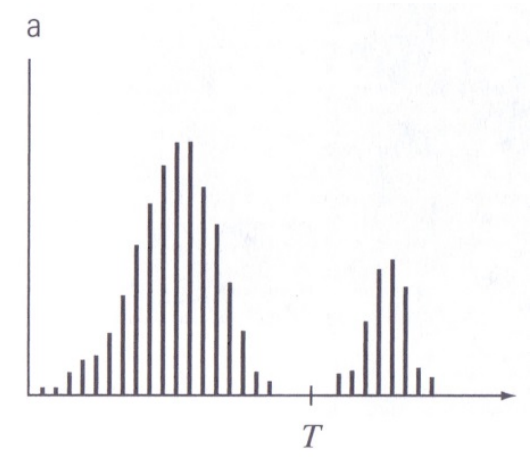

Figura 3. Histograma de intensidade que pode ser dividido por um limiar. Retirado de (Gonzalez \& Woods, 2010). 
Além disso, o método é ótimo no sentido de que maximiza a variância entre classes, uma medida bem conhecida utilizada na análise estatística discriminante. A ideia básica é que as classes com limiares bem estabelecidos devem ser distintas em relação aos valores de intensidade de seus pixels e, inversamente, que um limiar que oferece a melhor separação entre as classes em termos de valores de intensidade seria o melhor limiar (limiar ótimo). Além do componente ótimo, o método de Otsu tem a importante peculiaridade de se basear inteiramente em cálculos realizados no histograma de uma imagem, um arranjo 1D obtido facilmente (Gonzalez \& Woods, 2010).

\subsubsection{Quadtree}

As técnicas de segmentação baseadas em região consistem em encontrar as regiões de uma imagem de forma direta. Para isso, uma alternativa é subdividir uma imagem em um conjunto de regiões distintas na tentativa de satisfazer as condições de segmentação estipuladas. Assumindo que $R$ representa a região de uma imagem inteira e selecionando uma propriedade $Q$, uma abordagem para segmentar $R$ é dividi-la sucessivamente em regiões quadrantes cada vez menores de modo que, para qualquer região $R_{i}, Q\left(R_{i}\right)=V E R D A D E$. Começa-se com a região inteira. Se $Q(R)=F A L S O$, pode-se dividir a imagem em quadrantes. Se $Q$ é $F A L S A$ para qualquer quadrante, divide-se esse quadrante em subquadrantes e assim por diante.

(a)

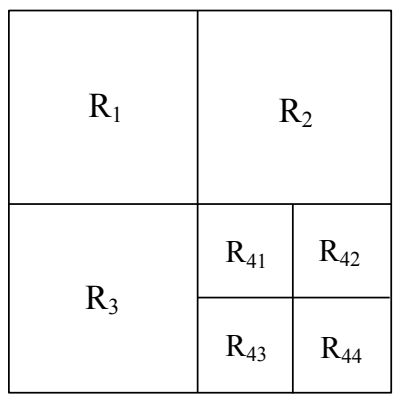

(b)

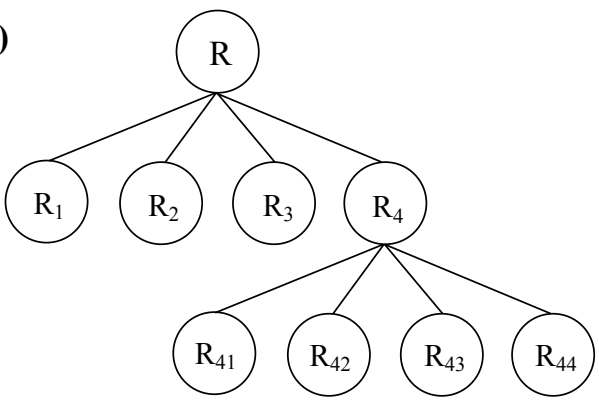

Figura 4. (a) Imagem particionada. (b) Quadtree correspondente. $R$ representa toda a região da imagem. Retirado de (Gonzalez \& Woods, 2010).

Essa técnica de divisão em particular tem uma representação conveniente na forma das chamadas quadtrees, isto é, as árvores em que cada nó possui exatamente quatro descendentes, como ilustrado na Figura 4 (as imagens correspondentes aos nós de uma quadtree podem ser chamadas de quadrirregiões ou quadri-imagens). Pode-se notar que a raiz 
da árvore corresponde à imagem inteira e que cada nó corresponde à subdivisão de um nó em quatro nós descendentes. Nesse exemplo, apenas $R_{4}$ continuou a ser subdividida (Gonzalez \& Woods, 2010).

$\mathrm{Na}$ quadtree cada nó folha representa uma região homogênea e o número de nós folhas indica o número de regiões resultantes após o processo de segmentação (Sonka et al., 1998). Vale ressaltar que é usual especificar um tamanho mínimo de quadrirregião além do qual nenhuma divisão é realizada (Gonzalez \& Woods, 2010).

\subsection{RANSAC (RANdom Sample And Consensus)}

Ao utilizar extratores de características locais (Subseção 2.1.2) um alto volume de informações pode ser obtido, sendo a segmentação de imagens, discutida na Seção 2.2, uma opção viável para reduzir tal volume e assim facilitar o processamento. Porém essa abordagem pode ser insuficiente para gerar uma representação compacta de uma tomada de vídeo, a ser utilizada pelos sistemas de personalização. Uma alternativa para lidar com esse problema é o método RANSAC (Fischler \& Bolles, 1981). Tal método é frequentemente utilizado em aplicações de Visão Computacional, mas pode ser aplicado ao contexto de Processamento de Imagens, visando reduzir a quantidade de informações necessárias para descrever uma imagem ou um conjunto delas.

O RANSAC pode ser definido como um método para ajustar um modelo a dados experimentais. Para isso, utiliza um pequeno conjunto de dados iniciais, aumentando-o com dados consistentes, quando possível. Por exemplo, dada a tarefa de ajustar um círculo a conjunto de dados bidimensionais, a abordagem RANSAC seleciona um conjunto de três pontos, calcula o centro e o raio do círculo inferido e conta o número de pontos que são suficientemente próximos ao círculo para sugerir compatibilidade com ele (isto é, pontos com pequeno desvio). Se existir um número suficiente de pontos compatíveis, o RANSAC emprega um método, como o dos mínimos quadrados, para computar uma estimação aprimorada dos parâmetros do círculo, dado que um conjunto de pontos consistentes foi identificado. A seguir, descreve-se formalmente o algoritmo RANSAC.

Dado um modelo que requer um mínimo de $n$ pontos para instanciar seus parâmetros e um conjunto de $P$ pontos, sendo que o número de pontos em $P$ é maior que em $n$, seleciona-se aleatoriamente um subconjunto $S 1$ de $n$ pontos de $P$ e instancia-se o modelo. Utiliza-se, então, o modelo instanciado $M 1$ para determinar o subconjunto $S 1 *$ de pontos em $P$ que satisfaz o 
modelo $M 1$, com determinada margem de erro. O conjunto $S 1^{*}$ é chamado conjunto consenso de $S 1$.

Se o número de pontos em $S 1^{*}$ é maior que um limiar $t$, utiliza-se $S 1^{*}$ para computar (possivelmente usando o método dos mínimos quadrados) um novo modelo $M 1^{*}$.

Se o número de pontos é menor que $t$, seleciona-se aleatoriamente um novo subconjunto $S 2$ e repetem-se os passos acima descritos. Se, após um número pré-determinado de tentativas, não for encontrado um conjunto consenso com $t$ ou mais membros, o modelo é resolvido com o maior conjunto consenso encontrado ou termina-se o algoritmo com falha (Fischler \& Bolles, 1981).

Portanto, têm-se, como resultado do RANSAC, os pontos classificados como inliers ou outliers, sendo considerados outliers os pontos que não se ajustam ao modelo instanciado.

\subsection{Considerações Finais}

Neste capítulo, foram apresentadas técnicas para manipulação de imagens, que podem ser aplicadas ao contexto de vídeos digitais, com o objetivo de se obter uma representação compacta para um conjunto de quadros, isto é, uma tomada. Essa caracterização pode ser utilizada em estratégias de segmentação em cenas, facilitando a composição dos serviços de personalização. Foram discutidas abordagens para a descrição de imagens e respectivas medidas de similaridade a serem empregadas, além de técnicas que facilitam o processamento dos dados e contribuem para a compactação da representação, como os métodos de segmentação de imagens e o algoritmo RANSAC. No próximo capítulo são apresentadas técnicas de segmentação de vídeo em diferentes níveis hierárquicos e uma discussão das abordagens de caracterização de tomadas encontradas na literatura. 


\section{Capítulo 3: Segmentação de Vídeo}

Um procedimento fundamental para a composição dos serviços de personalização é a segmentação do conteúdo que, no domínio de vídeos digitais, pode ocorrer em diversos níveis. Em geral, a estrutura hierárquica do fluxo de vídeo é composta de quatro segmentos distintos (Zhao et al., 2001b), conforme explicado a seguir e ilustrado na Figura 5.

- Quadro, definido como uma única imagem estática (Richardson, 2002).

- Tomada, definida como um conjunto de quadros, representando uma ação contínua capturada por uma única câmera (Smeaton, 2007).

- Cena, comumente definida como um grupo de tomadas semanticamente relacionadas (Rui et al., 1999; Zhai \& Shah, 2006). Diversos autores associam a relação semântica entre tomadas ao local em que acontecem. Nesse caso, uma cena é definida como uma sequência de tomadas que ocorrem em um mesmo local (Corridoni \& Bimbo, 1998; Oh \& Hua, 2000; Rui et al., 1999; Yeung \& Liu, 1995). Tal definição foi adotada para o desenvolvimento deste trabalho.

- Vídeo completo.

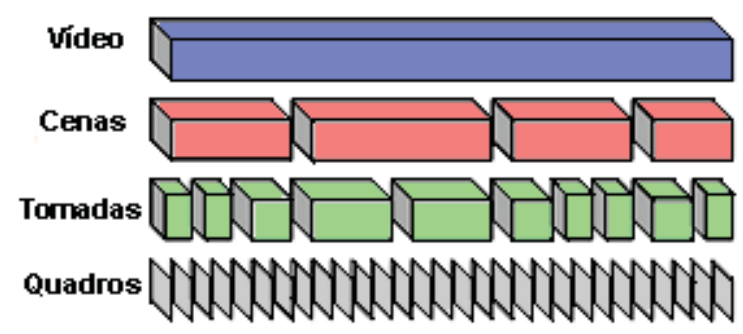

Figura 5. Estrutura do fluxo do vídeo digital.

Uma vez que os vídeos são, na verdade, uma sequência de imagens sendo exibidas a uma taxa constante e dando a ilusão de movimento (Richardson, 2002), a segmentação em quadros é considerada trivial. Existem ferramentas que obtém os quadros do vídeo e os armazenam em 
diferentes formatos de imagens. Um exemplo de ferramenta para segmentação nesse nível hierárquico é a FFmpeg ${ }^{6}$.

As tomadas, por sua vez, são caracterizadas por possuírem em comum algumas características visuais de baixo nível, por isso existem várias técnicas automáticas para identificá-las. Por outro lado, o agrupamento de tomadas em cenas depende do julgamento subjetivo da correlação semântica e, por isso, pode exigir a análise de outras características além das visuais de maneira a possibilitar a compreensão do conteúdo semântico (Fonseca, 2006).

Embora a representação da estrutura do vídeo apresentada na Figura 5 seja considerada um consenso na comunidade acadêmica (Oh et al., 2005; Sural et al., 2005; Zhao et al., 2001b), alguns autores utilizam outras representações. Mesmo não sendo iguais, há muita semelhança entre elas, havendo mudanças somente no acréscimo de uma camada na estrutura, seja entre as camadas de tomadas e cenas, seja entre as camadas de cenas e vídeo completo. No primeiro caso, é apresentada uma estrutura chamada Grupo, que representa uma etapa responsável pelo agrupamento de segmentos de tomadas (Rui et al., 1998). No segundo caso, é formada a camada Programa para representar possíveis episódios de uma série de TV, por exemplo (Al-Hames et al., 2006). Como o interesse deste trabalho são tomadas e cenas, as segmentações de vídeo nesses níveis hierárquicos são exploradas nas Seções 3.2 e 3.3.

Os sistemas de recuperação multimídia, em geral, e técnicas de segmentação, em particular, são avaliados quanto a sua eficácia. Para isso, é necessário utilizar medidas de avaliação, as quais, por constituírem conceitos fundamentais para o entendimento dos tópicos abordados neste capítulo, são apresentadas na Seção 3.1 .

\subsection{Avaliação}

A avaliação é um aspecto importante na pesquisa de sistemas de recuperação de vídeo. As medidas de avaliação descritas nesta seção originaram-se na área de recuperação de informação, mas foram adaptadas com sucesso para a área de recuperação de imagens por conteúdo, na qual os documentos são as imagens (Baeza-Yates \& Ribeiro-Neto, 2008).

Além disso, são medidas comumente utilizadas em trabalhos relacionados para aferir o desempenho de algoritmos e métodos. Assim, para tornar possível a comparação dos

${ }^{6}$ FFmpeg é uma solução multi-plataforma para gravar, converter e transmitir áudio e vídeo (http://ffmpeg.org/). 
resultados deste trabalho com outros da área de pesquisa, é necessário que as mesmas formas de avaliação sejam aplicadas.

Para entender as equações que serão apresentadas, é necessário primeiramente definir alguns termos. Assim, tem-se que:

- verdadeiros positivos (vp) são documentos que foram recuperados e são relevantes;

- verdadeiros negativos (vn) são documentos que não foram recuperados e não são relevantes;

- falsos positivos (fp) são documentos que foram recuperados, mas não são relevantes;

- falsos negativos (fn) são documentos que não foram recuperados, mas são relevantes.

A Tabela 1 mostra as definições apresentadas anteriormente de forma resumida.

Tabela 1. Definições de verdadeiros positivos e negativos, falsos positivos e negativos.

Retirado de (Manning et al., 2009).

\begin{tabular}{ccc}
\hline & Relevantes & Não relevantes \\
\hline Recuperados & Verdadeiros positivos (vp) & Falsos positivos (fp) \\
Não recuperados & Falsos negativos (fn) & Verdadeiros negativos (vn) \\
\hline
\end{tabular}

Precisão e abrangência (do inglês recall, também traduzida como revocação ou cobertura) são as duas medidas mais frequentemente utilizadas para aferir a eficácia de sistemas de recuperação de informações. A seguir, tais medidas são apresentadas, segundo Manning et al. (2009).

A precisão (P) é definida como a fração de documentos recuperados que são relevantes.

$$
\begin{gathered}
\mathrm{P}=\frac{\#(\text { itens relevantes recuperados })}{\#(\text { itens recuperados })} \\
\text { ou } \\
\mathrm{P}=\frac{v p}{(v p+f p)}
\end{gathered}
$$

A abrangência (A), por sua vez, é definida como a fração de documentos relevantes que foram recuperados.

$$
\begin{gathered}
\mathrm{A}=\frac{\#(\text { itens relevantes recuperados })}{\#(\text { itens relevantes })} \\
\mathrm{ou} \\
\mathrm{A}=\frac{v p}{(v p+f n)}
\end{gathered}
$$


Outra forma de avaliação comumente utilizada é a medida F, que compara precisão e abrangência usando a média harmônica ponderada. De acordo com Manning et al. (2009), é definida como:

$$
\begin{gathered}
\mathrm{F}=\frac{1}{\propto \frac{1}{P}+(1-\alpha) \frac{1}{A}}=\frac{\left(\beta^{2}+1\right) P A}{\beta^{2} P+A} \quad \text { onde } \beta^{2}=\frac{1-\alpha}{\alpha} \\
\text { sendo } \alpha \in[0,1] \text { e } \beta \in[0, \infty] .
\end{gathered}
$$

A medida $\mathrm{F}$ padrão atribui o mesmo peso para precisão e abrangência, o que significa $\alpha=$ $1 / 2$ ou $\beta=1$. Essa medida é comumente descrita como $F_{1}$, que é uma abreviação para $F_{\beta=1}$. Neste caso, a Equação 11 é simplificada para:

$$
\mathrm{F}_{1}=\frac{2 P A}{P+A}
$$

$\mathrm{O}$ cálculo da medida $\mathrm{F}$, a qual utiliza média harmônica, mostra-se mais interessante do que o cálculo de uma simples média aritmética entre precisão e abrangência, por exemplo. Isso porque é sempre possível alcançar 100\% de abrangência (basta que todos os documentos sejam retornados). Considerando-se essa situação, ao calcular a média aritmética sempre seria possível atingir, no mínimo, a taxa de 50\%, o que indica que o uso de tal medida é inadequado. Já a média harmônica é sempre menor ou igual à média aritmética e à média geométrica. Quando dois números diferem muito, a média harmônica é mais próxima ao menor dos valores do que à média aritmética de ambos.

\subsection{Segmentação em Tomadas}

A segmentação de um vídeo digital em tomadas, em geral, envolve a execução de alguns passos: primeiramente realiza-se a extração de características dos quadros do vídeo (utilizando-se histogramas, por exemplo). Então, define-se um método capaz de medir as diferenças entre o conteúdo dos quadros. Por fim, adota-se uma estratégia para determinar quando ocorre um corte entre tomadas. Tem-se que o espaço incontínuo entre duas tomadas é chamado corte (Ide et al., 2000). Sendo assim, as transições mais comuns e simples entre duas tomadas são as abruptas, também conhecidas como corte seco. Elas representam a transição sem nenhum efeito de edição, onde o último quadro da primeira tomada é seguido pelo primeiro quadro da segunda tomada. Existem também as transições graduais que resultam de 
combinações cromáticas ou espaciais de quadros das duas tomadas. Nesse caso, as principais são: dissolução, wipe e fade (Fonseca, 2006). Os diferentes tipos de transições são exemplificados nas Figuras 6 a 9.

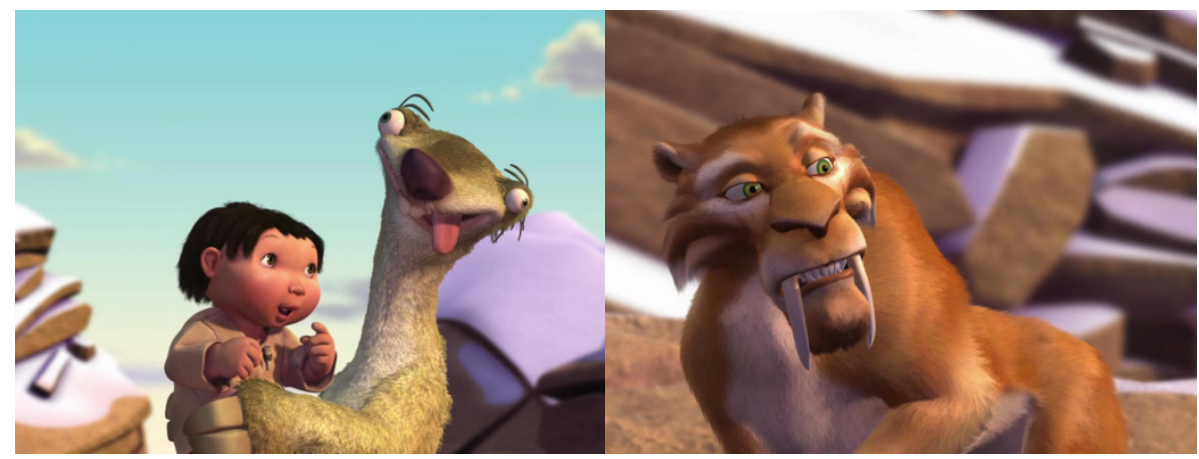

Figura 6. Exemplo de transição abrupta.

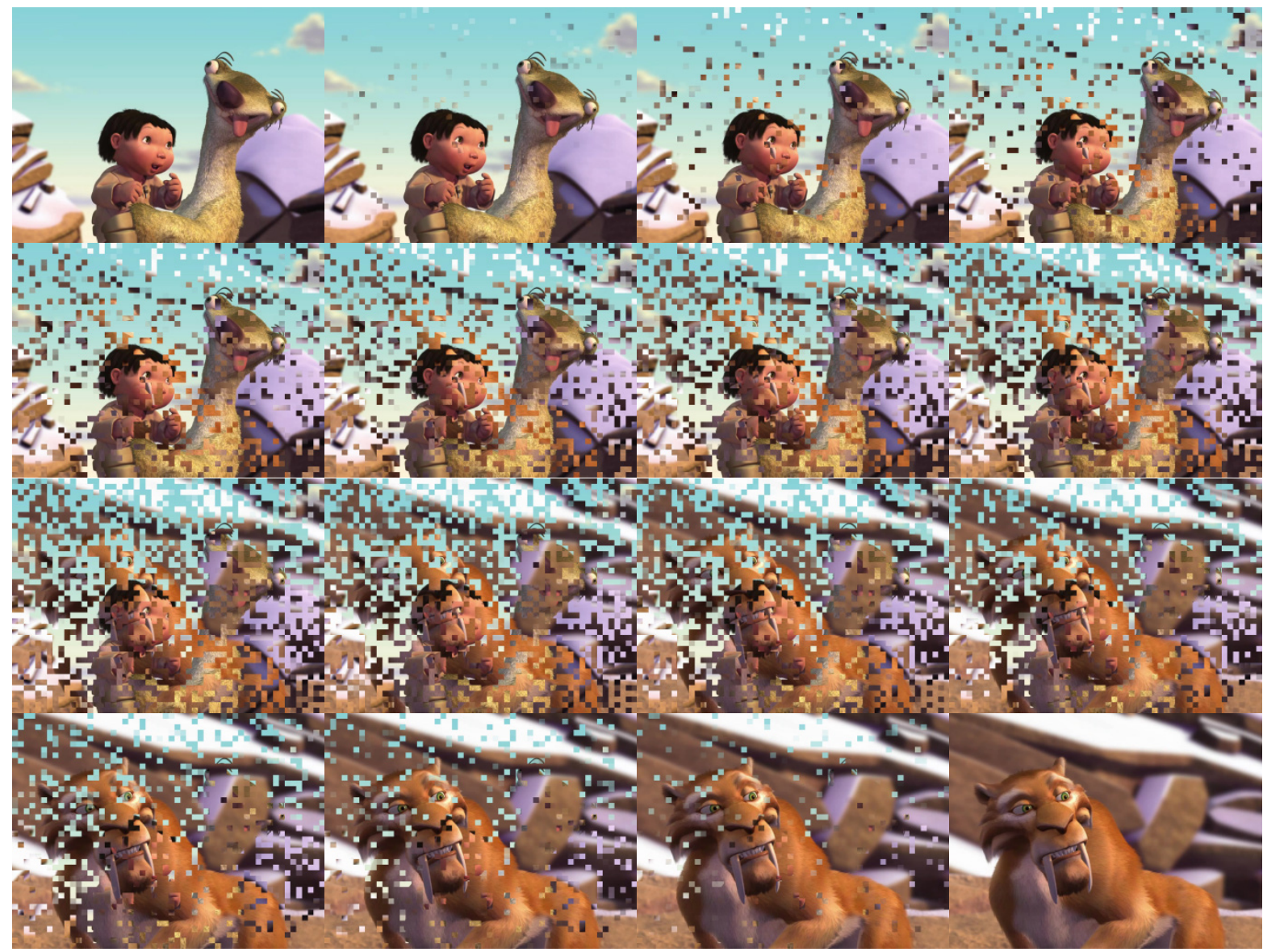

Figura 7. Exemplo de dissolução - transição gradual. 


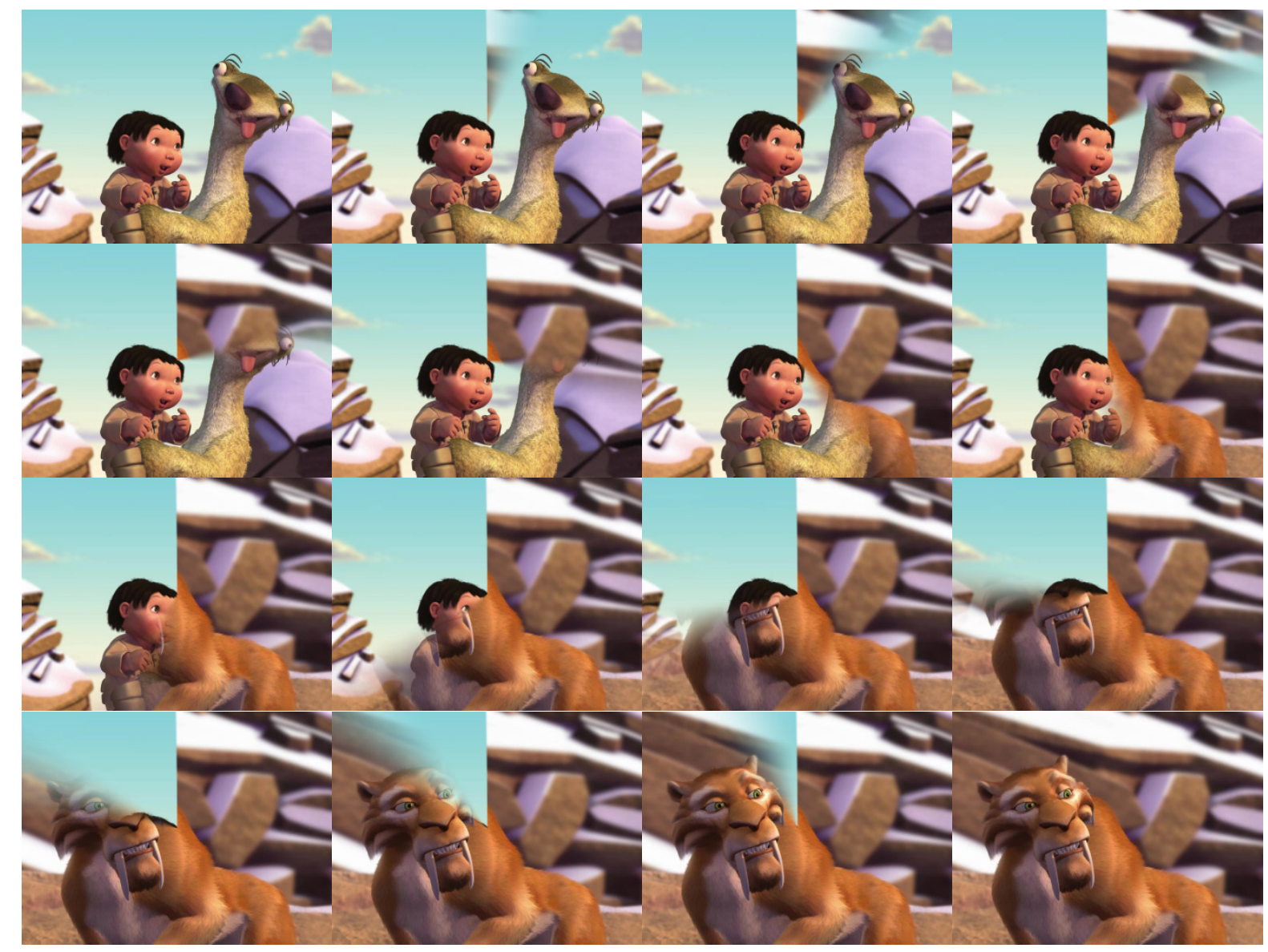

Figura 8. Exemplo de wipe - transição gradual.

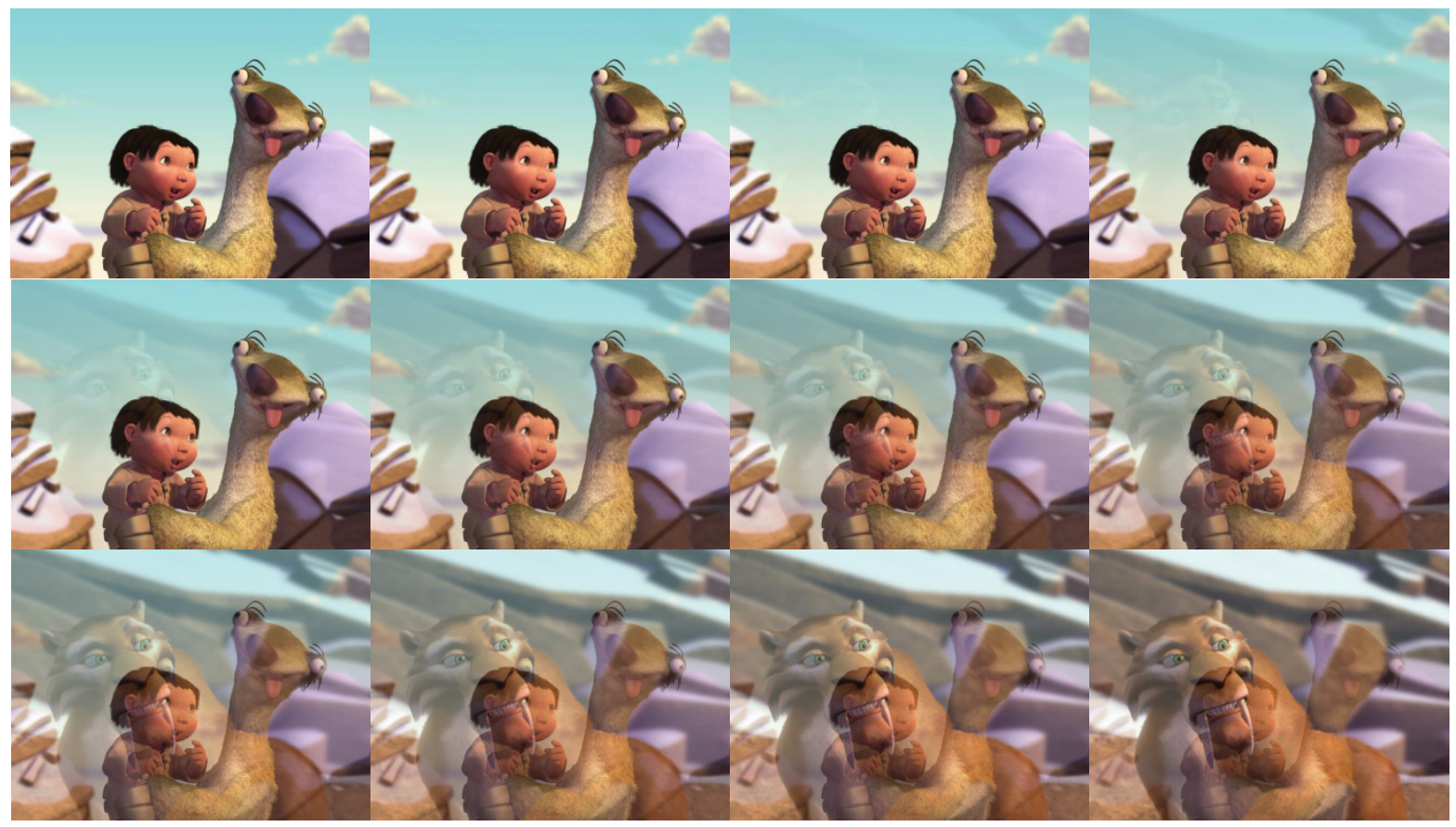




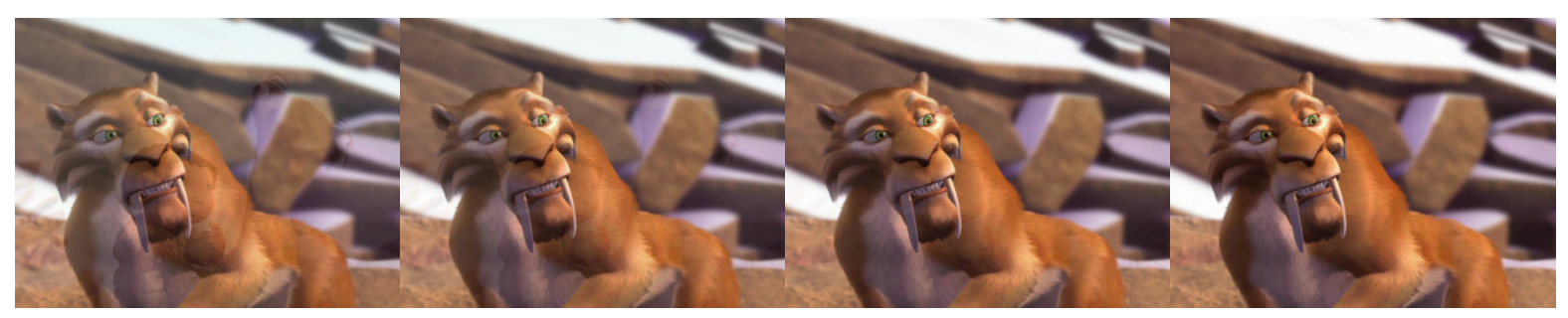

Figura 9. Exemplo de fade - transição gradual.

Vale ressaltar que as transições abruptas são mais simples de serem identificadas por técnicas automáticas do que as graduais. Smeaton et al. (2010) desenvolveram uma análise das abordagens mais significativas para detecção de tomadas que utilizam a base do TRECVID para avaliação. O TRECVID provê uma coleção de vídeos de teste e tem o objetivo de incentivar pesquisas relacionadas a recuperação de vídeo por conteúdo. Foram avaliados 10 trabalhos do ano de 2005 quanto à detecção de transições de tomadas. Os resultados indicaram que o desempenho para identificação de transições abruptas foi muito bom, com 7 técnicas apresentando medida F superior a 90\%. Já para a detecção de transições graduais, o desempenho dos métodos foi inferior, com medida $\mathrm{F}$ entre $69 \%$ e $79 \%$.

\subsection{Técnicas de Segmentação em Cenas}

Segundo Gu et al. (2007) as técnicas para a segmentação de vídeos digitais em cenas podem ser divididas em três abordagens de acordo com a forma de processamento: baseadas em agrupamento, baseadas em divisão e baseadas em modelos. Os métodos baseados em agrupamento tratam a segmentação como um processo bottom-up, no qual tomadas visualmente semelhantes são gradualmente agrupadas para compor uma cena (Rasheed \& Shah, 2003; Zhao et al., 2001a). Os métodos baseados em divisão, por sua vez, adotam o estilo top-down, no qual parte-se do vídeo como um todo e realiza-se a separação em cenas (Rasheed \& Shah, 2005; Yeung et al., 1998). Existem ainda as técnicas que se utilizam de modelos estatísticos para realizar a segmentação (Tan \& Lu, 2002; Zhai \& Shah, 2005).

$\mathrm{O}$ agrupamento de tomadas relacionadas é a abordagem mais comumente utilizada na literatura para segmentação em cenas, devido à boa relação oferecida entre eficiência e custo de processamento. Sendo assim, nesta seção, apresentam-se algumas técnicas que se utilizam do agrupamento de tomadas para a identificação de cenas. Elas são consideradas relevantes por serem citadas na literatura de modo recorrente ou por terem uma forte relação com o trabalho desenvolvido. 
Lin e Zhang (2000) apresentam uma abordagem que utiliza correlação entre tomadas, ao invés de similaridade, para agrupá-las em cenas. Para isso, foi desenvolvido um esquema para medir a correlação semântica de tomadas consecutivas utilizando agrupamento e monitoramento de cor dominante. A medida de correlação depende não somente de cores dominantes de quadros individuais, mas também da variação temporal. Então, um método de agrupamento foi projetado para unir tomadas consecutivas relacionadas em cenas. A técnica proposta supera outros métodos baseados em quadros-chave ou média de histogramas de cor, porém os autores afirmam que o desempenho poderia ser aprimorado se informações de áudio fossem integradas ao processo de detecção de cenas.

Rasheed e Shah (2003) desenvolveram um algoritmo de dois passos para detecção de limites de cenas. O vídeo é inicialmente dividido em tomadas pela identificação de cortes de câmeras. Cada tomada é então representada por um ou mais quadros-chave e calcula-se o número de quadros na mesma, bem como sua quantidade de movimento. No primeiro passo do algoritmo, uma medida de similaridade de cor das tomadas é computada, a qual é chamada BSC (Backward Shot Coherence). São encontrados vales nas medidas BSC e detectadas diversas potenciais fronteiras de cenas (do inglês, Potential Scene Boundaries - PSB), isto é, no início de uma nova cena, as primeiras tomadas não se assemelham às tomadas da cena anterior e nesses casos as medidas BSC são muito baixas. Porém, uma cena com mudanças no conteúdo, por exemplo, de ação, pode ser separada em muitas outras por não satisfazer a similaridade de cor. Por isso, as cenas são agrupadas durante o passo dois do algoritmo analisando-se a dinâmica das tomadas. O método proposto foi testado em filmes de Hollywood e em uma série de TV, com o objetivo de demonstrar que o algoritmo possui bom desempenho para diferentes gêneros de vídeos.

Chasanis et al. (2007) propuseram um método no qual as tomadas são agrupadas baseando-se apenas em suas características visuais. Então, rótulos são atribuídos a cada tomada de acordo com o grupo a que pertencem. Pares de rótulos de tomadas sucessivas são comparados em busca de padrões. Quando uma mudança nos padrões ocorre, uma transição de cena é detectada. Experimentos realizados com diversos vídeos indicaram que o método proposto detecta a maioria das transições de cenas e provê uma boa relação entre abrangência e precisão.

Coimbra (2011) propôs uma técnica que utiliza características multimodais para segmentar em cenas vídeos digitais no domínio de telejornais. No caso das características visuais foram aplicadas três técnicas a quadros-chave (primeiro quadro) extraídos das 
tomadas: histograma de cor global e local e wavelets. A identificação de transições foi realizada utilizando-se a intersecção de histogramas e a distância euclidiana para a wavelet. Já para a descrição de informações auditivas adotou-se a detecção de momentos de silêncio nas faixas de áudio. Quanto a características textuais foram utilizadas informações presentes nos closed-captions dos vídeos. Nesse caso, as transições de cenas foram detectadas por meio das falas dos âncoras dos telejornais. Então, os resultados obtidos com cada mídia separadamente foram integrados com o auxílio de um ranking que associa pesos pré-definidos a cada uma das técnicas, possibilitando verificar se uma determinada transição de cena foi identificada por diferentes métodos. Os resultados dos experimentos realizados mostraram que o uso da multimodalidade apresentou melhor desempenho que a aplicação das técnicas individualmente.

$\mathrm{Xu}$ et al. (2012) desenvolveram um método que integra em um único framework três esquemas, utilizando diferentes propriedades do vídeo para encontrar limites de cenas. Primeiramente, empregando um modelo de grafo, um sinal de coerência visual é calculado para representar as diferenças entre as tomadas. Para isso, quadros-chave são selecionados para descrever a tomada e divididos em 16 regiões de mesmo tamanho. Então, um histograma de cor normalizado, no espaço RGB, com 48 bins, é extraído de cada região. Um alto valor do sinal implica que existem diferenças visuais entre as tomadas, onde pode ocorrer mudança de cena. Porém, nem todos os pontos encontrados indicam troca de cena. Por isso, a análise de um grafo de transições de cenas é usada para aprimorar o desempenho do sinal de coerência. Os resultados experimentais em vídeos de diferentes gêneros indicaram que o método proposto detecta a maioria das transições de cenas, ao mesmo tempo em que provê bons resultados em abrangência, precisão e medida $\mathrm{F}$.

É possível perceber que os trabalhos apresentados nesta seção se utilizam de algum meio para representar e comparar as tomadas, visando obter a segmentação em cenas. Os meios utilizados são heterogêneos e a maioria se baseia em quadros-chave. Entretanto, o procedimento de escolha dos quadros-chave não é bem determinado e esses trabalhos não exploram ou propõem métodos diferentes para a representação das tomadas. Isso evidencia que ainda está aberta a questão de como caracterizar tomadas, discutida na Seção 3.4. 


\subsection{Caracterização de Tomadas}

Esta seção apresenta uma análise crítica dos resultados do mapeamento sistemático desenvolvido. As buscas por documentos foram realizadas nas bases de dados eletrônicas indexadas IEEE Xplore, ACM Digital Library e SpringerLink, utilizando a seguinte string: "shot representation" OR "shot characterization" OR "shot clustering" OR "scene detection" OR “scene segmentation”. Foram retornados 582 trabalhos, os quais foram submetidos ao processo de seleção preliminar, isto é, foram excluídos documentos repetidos e os que não estavam nos idiomas inglês ou português. Então, por meio da leitura do título e resumo foi avaliado se cada trabalho satisfazia algum critério de inclusão ou algum critério de exclusão definido. Especificou-se que seriam aceitas técnicas de segmentação de vídeos digitais em cenas por agrupamento de tomadas que utilizam métodos diferentes do histograma de cor para descrever tomadas. Isso porque, como a maioria dos trabalhos de segmentação em cenas se utiliza de histogramas, esse método de caracterização já é bem conhecido. Sendo assim, o foco do mapeamento era identificar outros extratores de características aplicados à representação de tomadas. Foram aceitos também estudos ou métodos de caracterização de tomadas.

Além disso, foram definidos os seguintes critérios de exclusão: técnicas de segmentação de vídeos digitais em cenas por agrupamento de tomadas que utilizam histogramas de cor para descrever as tomadas, segmentação de vídeos digitais em cenas por métodos diferentes do agrupamento de tomadas relacionadas, trabalhos não relacionados à segmentação de vídeos digitais em cenas e trabalhos sem PDF disponível. Ao todo, foram incluídos 26 trabalhos pelo processo de seleção preliminar.

Após essa etapa, realizou-se o processo de seleção final, que consistiu em ler integralmente os trabalhos considerados relevantes no processo de seleção preliminar e excluir os que não estavam de acordo com os critérios de inclusão. Depois dessa etapa, 22 artigos permaneceram aceitos, sendo 15 deles relacionados a técnicas de segmentação em cenas e 7 a métodos de caracterização de tomadas.

Então, foram criadas tabelas identificando, para cada documento analisado, os tópicos de interesse para o mapeamento sistemático e foram desenvolvidas análises críticas sobre os dados obtidos. As análises com foco nos métodos de caracterização de tomadas encontrados abrangem os dois tipos de trabalhos aceitos no processo, conforme descrito a seguir. 
- Técnicas de segmentação em cenas por agrupamento de tomadas. Nesse caso, o objetivo é analisar como tais trabalhos caracterizam as tomadas, para então comparálas e realizar a segmentação do vídeo digital (Subseção 3.4.1).

- Métodos de caracterização de tomadas. Nesse segundo caso, verificam-se as técnicas estudadas e/ou empregadas para caracterização das tomadas (Subseção 3.4.2).

\subsubsection{Trabalhos Relacionados a Técnicas de Segmentação em Cenas por Agrupamento de Tomadas}

Quanto aos trabalhos que abordam segmentação em cenas por agrupamento de tomadas pode-se concluir que a grande maioria, inclusive publicações recentes (Han \& Wu, 2011; Mezaris et al., 2011; Sidiropoulos et al., 2011; Tapu \& Zaharia, 2011b; Xu et al., 2012), utiliza histogramas de cor para caracterizar as tomadas. Isso porque, de 67 documentos relacionados ao tema desta subseção que foram recuperados pelas buscas, 52 foram excluídos por utilizarem histogramas na descrição das tomadas. As vantagens e desvantagens desse método de representação foram discutidas na Subseção 2.1.1.

Os demais trabalhos relacionados à segmentação em cenas que foram investigados revelaram outras características (principalmente visuais) utilizadas para descrever as tomadas. É possível observar que vários deles, apesar de não empregarem histogramas, ainda optam pela utilização da cor como característica para representar o conteúdo. Nesse caso, os métodos encontrados são: momento de cor no espaço de cor Lab (Brindha \& Kalaiarasan, 2010; Gu et al., 2007; Wang et al., 2008), CRG (Color Ratio Gradient) (Huang \& Chen, 2009), MPEG-7 color layout (Lee et al., 2005), color key (Cao et al., 2003; Tavanapong \& Zhou, 2004; Zhou \& Tavanapong, 2002) e histograma de variância de intensidade (Zhu \& Liu, 2008a, 2008b). Percebe-se que, de maneira semelhante aos histogramas, os demais métodos baseados em cor são escolhidos por sua simplicidade e capacidade de avaliar a distribuição de cores em uma tomada. Alguns deles possuem propriedades individuais que reforçam os argumentos para sua utilização. Por exemplo, o CRG é insensível à posição dos objetos, sombras e iluminações. O color key, por sua vez, tenta aproximar a representação do conteúdo à percepção humana e, para isso, aplica a extração de características em regiões pré-determinadas, evitando a inclusão de ruídos ou objetos ignorados pelas pessoas e considera que o sistema visual humano apresenta maior sensibilidade à luminância.

Outro método de destaque nos trabalhos investigados é o SIFT (Chu et al., 2010; Poulisse \& Moens, 2011; Tapu \& Zaharia, 2011a; Yamamoto \& Haseyama, 2009), classificado como 
um extrator de características locais. Uma importante propriedade é que cada um de seus vetores de características é invariante a translação, escala e rotação e parcialmente invariante a mudanças na iluminação ou projeção 3D. Além disso, o SIFT visa a identificação de objetos, conseguindo relacionar imagens que possuem planos de fundo similares, com pessoas ou objetos diferentes no primeiro plano ou, então, imagens com cores diferentes que apresentam o mesmo objeto. Entretanto, a construção de seus vetores de características apresenta um grande custo computacional. Uma alternativa à utilização do SIFT encontrada nos artigos analisados é o CCH (Contrast Context Histogram) (Huang \& Chen, 2009). Nesse caso, a extração de pontos-chave é robusta a rotação, escala e translação e a descrição desses pontos é realizada com histogramas de contraste, que são relativamente insensíveis a mudanças na iluminação e fáceis de computar.

Outro ponto importante observado é que, na maioria dos trabalhos, a representação de tomadas é feita por meio da seleção de quadros-chave, sendo as características extraídas de tais imagens. Essa abordagem tem a vantagem de possuir um baixo custo de processamento, uma vez que permite que se trabalhe com poucos quadros do vídeo. Porém, pode ocorrer o problema da baixa representatividade, ou seja, os quadros-chave escolhidos podem não sintetizar o conteúdo mais relevante da tomada.

Também é possível encontrar evidências de que várias das técnicas investigadas apresentam resultados que podem ser aprimorados. Por exemplo, o trabalho de Poulisse \& Moens (2011) apresenta medida F entre $42 \%$ e 54\% e o trabalho de Tapu \& Zaharia (2011a) entre $75 \%$ e $85 \%$, enquanto as técnicas de segmentação em tomadas em estado da arte conseguem alcançar valores de medida F superiores a 90\% (Smeaton et al., 2010). Isso indica que se trata de um campo de pesquisa ainda em aberto.

Após a análise dos trabalhos selecionados é possível concluir que não há um consenso na caracterização de tomadas utilizada em técnicas de segmentação em cenas por agrupamento de tomadas. Cada trabalho opta pela utilização do método que considera ser o mais promissor, nem sempre alcançando bons resultados. Percebe-se que a qualidade da segmentação em cenas obtida ainda pode ser aprimorada e a melhoria na caracterização das tomadas tem potencial para contribuir nesse sentido. 


\subsubsection{Trabalhos Relacionados a Métodos de Caracterização de Tomadas}

Quanto aos trabalhos relacionados a métodos de caracterização de tomadas, é possível verificar que a maioria utiliza histogramas de cor no espaço HSV (Chen et al., 2005; Galmar \& Huet, 2007; Souvannavong et al., 2004). Esse extrator é comumente utilizado para representar características de cor, por ser simples de calcular e possuir baixa complexidade computacional. Vale ressaltar também que, em geral, na quantização, são usados mais bins para a representação do H (Hue) do que do S (Saturation) ou V (Value), aproveitando características do sistema visual humano, que é mais sensível à tonalidade do que à saturação e valor. Porém, os histogramas não são capazes de capturar informações espaciais das cores, deixando a possibilidade de duas imagens com conteúdos diferentes possuírem representações bastante similares. A fim de amenizar essa deficiência, são extraídas outras características para serem empregadas em conjunto, por exemplo, características espaciais, como densidade e compactação da distribuição, dispersão e taxa de blocos ativos (Chen et al., 2005). Outros trabalhos (Galmar \& Huet, 2007; Souvannavong et al., 2004) optam pela utilização conjunta de características de textura (filtros de Gabor), as quais contêm informações importantes sobre a superfície de objetos e sua correlação com o ambiente ao redor, entretanto, podem ser aplicadas eficientemente em vídeos em que as informações de textura são salientes, o que não abrange todos os casos.

Outro método encontrado nos artigos analisados é o PCA-SIFT (Principal Component Analysis - SIFT) (Zhou et al., 2009), que se caracteriza por reduzir a dimensionalidade e a complexidade computacional do SIFT, sendo uma alternativa viável para aplicações que demandam processamento mais rápido.

Percebe-se também que, novamente, é comum o emprego de quadros-chave para representar o conteúdo de uma tomada. Nesse sentido, alguns trabalhos (Sze et al., 2004, 2005) propõem que ao invés de escolher um ou mais quadros, o ideal é construir esse quadrochave, de maneira que se garanta sua representatividade. Para isso, são consideradas informações espaciais e globais das imagens da tomada e extraídos os principais objetos. Espera-se, assim, que o resultado inclua o conteúdo mais significativo da tomada. Porém, essa abordagem envolve o processamento de todas as imagens de uma tomada, apresentando um custo computacional maior do que a escolha de quadros-chave em posições fixas (como selecionar o primeiro ou último quadro). 
Além disso, é possível concluir que há uma carência de trabalhos com foco na descrição de tomadas. Os poucos encontrados na literatura e discutidos nesta subseção reportam métodos de caracterização que não são aplicados ao contexto de segmentação de vídeos digitais em cenas, revelando uma lacuna a ser explorada.

Após o mapeamento sistemático desenvolvido e apresentado nesta seção, é possível verificar que os extratores de características visuais locais podem contribuir para a obtenção de representações de qualidade. Por isso, aprofundou-se o estudo em trabalhos que os empregam na caracterização de tomadas, os quais são discutidos na Seção 3.5.

\subsection{Métodos de Representação de Tomadas Baseados em Extratores de Características Visuais Locais}

Entre as diversas alternativas para caracterização de tomadas discutidas na Seção 3.4, os extratores de características locais destacam-se por possuírem potencial para aprimorar a qualidade das representações, o que pode ser verificado, por exemplo, no domínio de Recuperação de Imagens. Por isso, nesta seção, são discutidos métodos de representação de tomadas baseados em características visuais locais, encontrados em trabalhos pertencentes ao estado da arte da área de segmentação de vídeo.

Baber et al. (2011) descrevem cada tomada por meio de um quadro-chave, definido como o quadro mediano da tomada. Então, com o método SURF, vetores de características são extraídos de cada quadro-chave e utilizados no algoritmo de detecção de cenas desenvolvido pelos autores. Essa abordagem possui baixo custo computacional, uma vez que considera apenas uma pequena fração dos quadros disponíveis. Por outro lado, existe o problema de se selecionar uma imagem que não representa o conteúdo mais relevante da tomada. Em muitos casos, o quadro mediano pode não ser a escolha mais adequada.

Chergui et al. (2012) adotaram uma estratégia similar; eles também selecionam um único quadro-chave para representar cada tomada. Mas o método de extração de quadro-chave é menos rígido. Eles consideram que uma imagem relevante contém muitos detalhes visuais. Por isso, definem o quadro-chave como aquele com o maior número de pontos de interesse na tomada. Apesar de utilizarem o conteúdo das imagens, não é possível garantir que o quadro com o maior número de pontos de interesse é o mais representativo em todos os casos. Além disso, uma imagem pode não ser suficiente para descrever a variedade de conteúdo de algumas tomadas e informações importantes podem ser perdidas. Esse método também é mais 
custoso computacionalmente, pois a etapa de seleção envolve processar todos os quadros da tomada.

Chu et al. (2010) também utilizam uma abordagem baseada em quadros-chave. Eles automaticamente determinam o número mais apropriado de quadros-chave com o algoritmo global k-means. Primeiramente, os quadros de uma tomada são agrupados e aquele mais próximo ao centroide é selecionado como quadro-chave. Então, os resultados são filtrados e são eliminadas imagens com má qualidade, baseando-se na decomposição wavelet para detectar desfoques e em informações de iluminação para detectar condições de exposição excessiva ou insuficiente. Por fim, as imagens restantes são caracterizadas utilizando-se SIFT. A abordagem de seleção de quadros-chave evita o problema de se determinar um número fixo de quadros-chave por tomada, já que o método é capaz de escolher o número mais apropriado de imagens para representar a tomada considerando seu conteúdo. Entretanto, o processo utiliza um algoritmo de agrupamento e a transformada wavelet, aumentando o custo computacional.

Tapu \& Zaharia (2011a) desenvolveram uma abordagem para extrair um número variável de quadros-chave de cada tomada. Considerando uma janela de tamanho $N$, o primeiro quadro é selecionado $N$ quadros após a transição de tomadas. Então, são analisadas imagens localizadas em posições resultantes de multiplicadores inteiros aplicados sobre a janela $N$. Tais imagens são comparadas com o conjunto de quadros-chave já selecionado. Se a dissimilaridade visual (definida como a distância qui-quadrada dos histogramas de cor HSV) entre a imagem atual e os quadros-chave for significativa (acima de um limiar préestabelecido), ela é adicionada ao conjunto de quadros-chave. Após isso, quadros irrelevantes são descartados, computando-se os pontos de interesse com o método SIFT. Se o número de pontos de interesse for zero, a imagem é removida. Por fim, os quadros-chave são descritos com SIFT. Essa abordagem de seleção tem a vantagem de que nem todos os quadros da tomada são processados. Entretanto, muitos parâmetros precisam ser ajustados (janela $N$, limiar de dissimilaridade, quantização de histogramas), o que pode influenciar a qualidade da representação de tomadas.

Baber et al. (2013) extraem características locais de todos os quadros de uma tomada. Zhu \& Satoh (2012) utilizam uma abordagem similar. Eles extraem vetores de características com SIFT de quadros obtidos em um intervalo fixo (3 quadros por segundo). Esses dois métodos consideram todos, ou quase todos, os quadros do vídeo. Porém, as características obtidas não são processadas para redução de informações redundantes. Logo, o volume de dados para 
cada tomada é muito alto, o que dificulta passos posteriores, como avaliação de similaridade, devido ao custo computacional.

Os trabalhos relacionados apresentados nesta seção mostram que o uso de características locais pode ser uma alternativa para representação de tomadas. Porém, como discutido, as abordagens atuais apresentam problemas de representatividade e custo computacional.

\subsection{Considerações Finais}

Neste capítulo foram apresentadas técnicas de segmentação de vídeo digital em diferentes níveis hierárquicos. Além disso, foram analisadas estratégias de representação de tomadas encontradas na literatura e pertencentes ao estado da arte, que mostram que a caracterização de tomadas ainda é uma questão em aberto. Entre os problemas encontrados estão a carência de trabalhos com foco na descrição de tomadas e a baixa representatividade e/ou alto custo computacional das abordagens existentes. Por isso, neste trabalho, propõe-se um método de representação que visa explorar as lacunas identificadas. Tal método é detalhado no próximo capítulo. 


\section{Capítulo 4: Representação de Tomadas}

Este capítulo está organizado em três seções. A Seção 4.1 apresenta o método de representação de tomadas desenvolvido, que se utiliza de características visuais locais extraídas de todos os quadros de cada tomada e tem como objetivo principal aprimorar a caracterização obtida. A Seção 4.2 descreve um método de seleção de quadros-chave proposto a fim de obter uma representação de qualidade para as tomadas, com um menor custo de processamento. Por fim, a Seção 4.3 traz a técnica de segmentação em cenas desenvolvida para avaliar o método de representação de tomadas nesse contexto.

\subsection{Método de Representação de Tomadas Shot-HR (Shot High Representativeness)}

Desenvolveu-se um método de representação de tomadas baseado no extrator de características locais SIFT, que visa lidar com os principais problemas identificados em trabalhos relacionados (Seção 3.5), isto é, representatividade e volume de dados. O método proposto, denominado Shot-HR, pode ser dividido em três fases:

1. extração e redução de características em cada quadro;

2. redução de características em cada tomada;

3. identificação de correspondências entre tomadas.

A questão da representatividade é considerada nos processos realizados em todas as etapas e o problema do alto volume de dados é endereçado nas duas primeiras. Cada uma dessas fases é detalhada nas Subseções 4.1.1 a 4.1.3.

\subsubsection{Extração e Redução de Características em Cada Quadro}

O método Shot-HR utiliza todos os quadros da tomada, visando evitar o problema da escolha de quadros-chave que podem não representar seu conteúdo mais significativo. Além 
disso, a extração de características é realizada por meio do método SIFT (Subseção 2.1.2), o qual fornece mecanismos para extrair algum grau de semântica, ainda que de modo latente e de baixo nível, presente nas imagens. Isso porque se obtêm pontos de interesse de regiões importantes da imagem, como junções-T e bordas, as quais também são relevantes para os seres humanos no processo de compreensão de seu conteúdo. Porém, o método não atribui significado aos pontos obtidos.

Utilizando SIFT, tem-se, para cada imagem, um conjunto de pontos de interesse e seus respectivos vetores de características. Logo, percebe-se que o volume de dados obtido, apesar de ser menor do que o das imagens completas, ainda é alto, sendo necessário reduzi-lo de maneira a facilitar o processamento, mas mantendo-se a qualidade da caracterização.

Para endereçar esse problema, tem-se a primeira fase do método, composta por um conjunto de etapas apresentadas na Figura 10 e sumarizadas a seguir.

1. Extração de características: utilizando-se o método SIFT, extraem-se do quadro de vídeo pontos de interesse e respectivos vetores de características.

2. Binarização do quadro: torna-se o quadro binário com a aplicação do método de Otsu.

3. Identificação de regiões relevantes: segmenta-se o quadro por meio da técnica Quadtree com blocos mínimos de 8x8 pixels.

4. Redução de informações: obtém-se apenas um vetor de características por região resultante da aplicação da técnica Quadtree.

Esse processo é repetido para todos os quadros da tomada. Deve-se notar que a etapa 1 pode ser realizada em paralelo às etapas 2 e 3. A seguir explica-se, em detalhes, o raciocínio que levou ao estabelecimento desse processo.

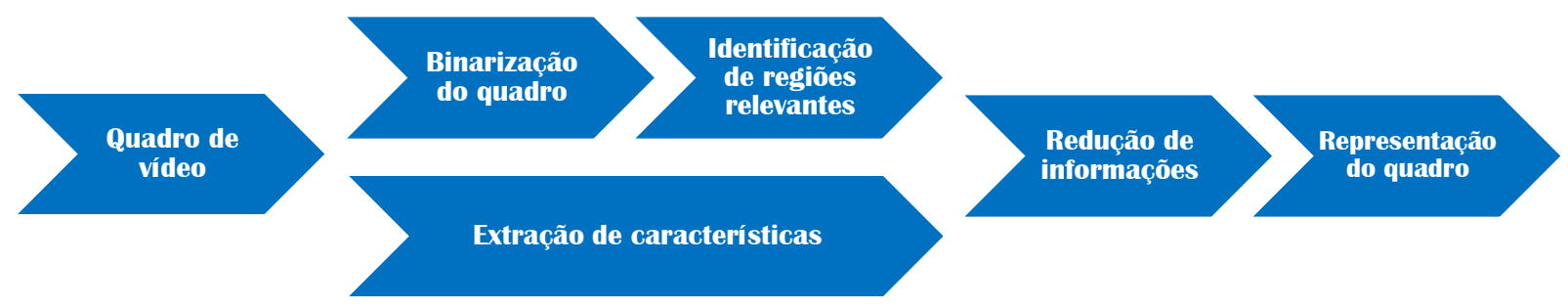

Figura 10. Resumo do processo de extração e redução de características em cada quadro.

Como mencionado anteriormente, para cada quadro da tomada, são obtidos com o método SIFT os pontos de interesse e respectivos vetores de características. Esses vetores são, então, reduzidos com base no seguinte raciocínio: pontos de interesse identificados em posições muito próximas na imagem representam características semelhantes, isto é, são redundantes. O problema de identificar pontos de interesse redundantes foi investigado por Pedrosa et al. 
(2012) com o uso de um raio fixo, percorrendo-se a imagem e considerando-se pontos interiores a tal raio como similares. Porém, a escolha do raio ideal depende do conteúdo de cada quadro. Sendo assim, com o objetivo de tornar a redução de pontos de interesse adequada à semântica das imagens, considerou-se que uma melhor abordagem seria segmentá-las, identificando as possíveis regiões semanticamente mais relevantes, de acordo com suas características. Para essa finalidade, optou-se pela utilização da técnica Quadtree (Subseção 2.2.2). Então, obtém-se, no máximo, um ponto de interesse e seu respectivo vetor de características por região resultante da segmentação, isto é, a Quadtree é utilizada para mapear as regiões da imagem de onde devem ser selecionados os pontos de interesse extraídos pelo método SIFT, como apresentado na Figura 10.

A técnica Quadtree divide uma imagem em quatro blocos quadrados de mesmo tamanho e verifica se cada bloco satisfaz um critério de homogeneidade, nesse caso, a cor dos pixels. Se o bloco satisfizer o critério, ele não é mais dividido. Caso contrário, é subdividido novamente em quatro regiões quadradas de mesmo tamanho. O processo é repetido até que todos os blocos satisfaçam o critério definido. Para imagens coloridas, no sistema RGB, por exemplo, mais de 16 milhões de tonalidades são possíveis. Essa variação dificulta que os blocos sejam homogêneos. Mesmo ao utilizar imagens em escala de cinza, com 256 níveis de cores, a variação ainda é grande e a técnica Quadtree gera como resultado uma grande quantidade de regiões pequenas, o que não é vantajoso para a redução de informações.

A solução direta para esse problema seria considerar que se as diferenças em um bloco fossem menores que um limiar estabelecido, então, o bloco seria tido como homogêneo. Porém, novamente a identificação do limiar mais adequado poderia variar de quadro para quadro. Uma melhor opção é utilizar o próprio conteúdo da imagem para torná-la binária, o que foi realizado por meio do método de Otsu (Subseção 2.2.1). Esse método automaticamente encontra o limiar global ótimo para cada imagem, fazendo com que o problema seja reduzido de 256 para 2 cores. Então, o critério de homogeneidade é mais facilmente satisfeito e têm-se, como resultado da técnica Quadtree, blocos maiores e em menor quantidade. As escolhas dos métodos de Otsu e Quadtree podem ser justificadas principalmente pela simplicidade das técnicas e pela baixa dependência de ajuste de parâmetros. 


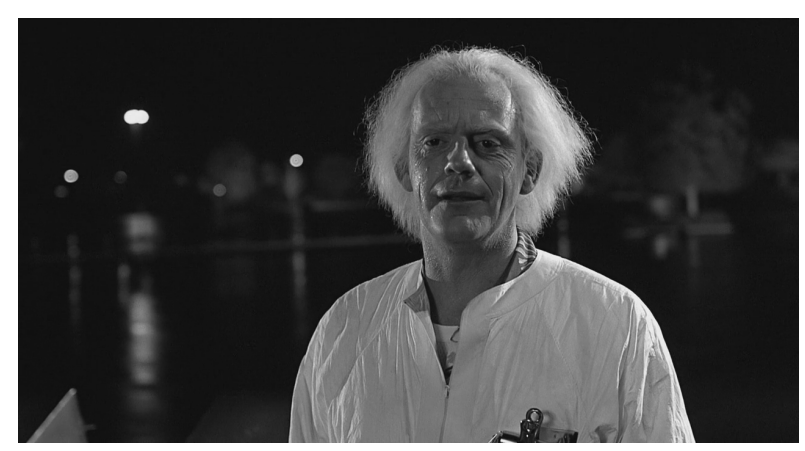

(a)

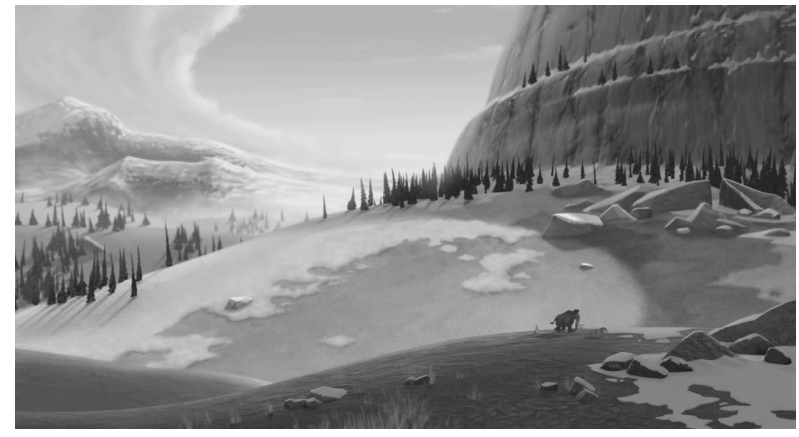

(c)

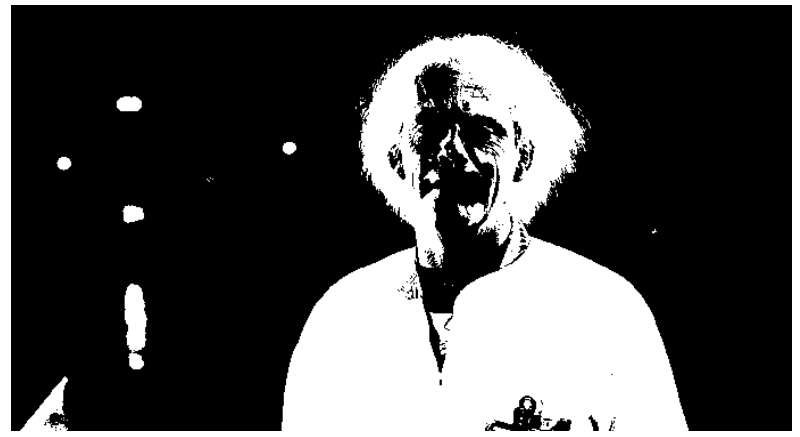

(b)

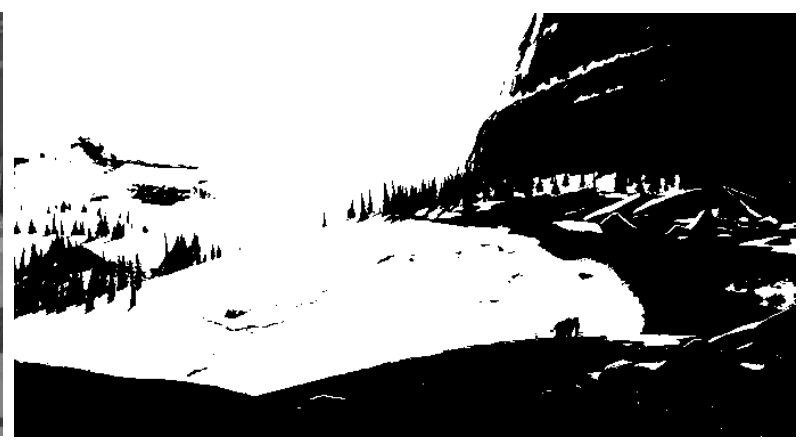

(d)

Figura 11. Exemplos de resultados do método de Otsu. Em (a) e (c), imagens em escala de cinza. Em (b) e (d), respectivas imagens binárias obtidas com o método de Otsu.

A Figura 11 mostra um exemplo do resultado da aplicação do método de Otsu em duas imagens em escala de cinza, extraídas dos filmes De Volta Para o Futuro (Figura 11a) e A Era do Gelo (Figura 11c). É possível observar que a transformação segue o conteúdo visual das imagens, mantendo as informações relevantes.

A Figura 12 ilustra os resultados da técnica Quadtree sobre as imagens em escala de cinza e respectivas imagens binárias da Figura 11. Pode-se perceber que quando a Quadtree é aplicada sobre uma imagem em escala de cinza, um grande número de blocos de tamanho pequeno é gerado, cobrindo quase toda a imagem. Entretanto, quando esse método de segmentação é aplicado em uma imagem binária, menos blocos são obtidos. Além disso, é importante observar que: 1) blocos menores e em maior número são gerados em regiões que concentram o conteúdo mais significativo da imagem; 2) blocos maiores e em menor quantidade são obtidos em regiões que contêm informações menos relevantes. Logo, pode-se deduzir que a redução de características também irá respeitar a semântica do quadro, mantendo mais pontos de interesse em suas regiões mais importantes. 


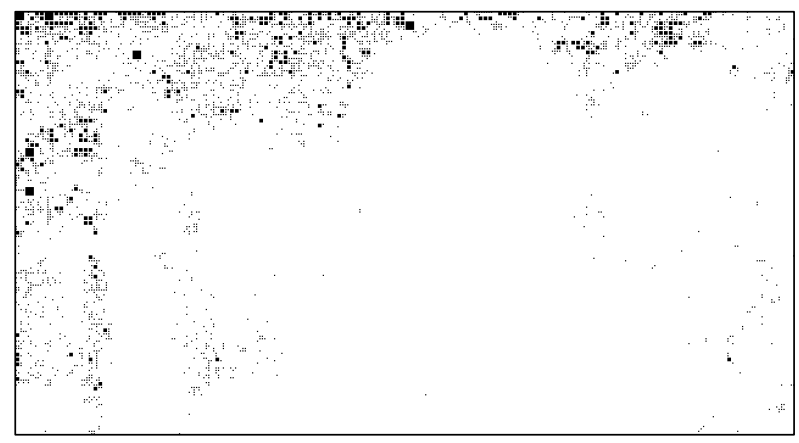

(a) Resultado da técnica Quadtree na imagem em escala de cinza da Figura 11a

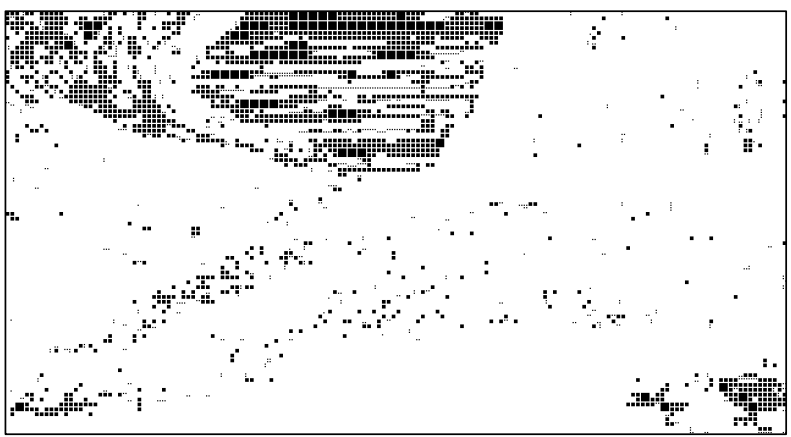

(c) Resultado da técnica Quadtree na imagem em escala de cinza da Figura 11c

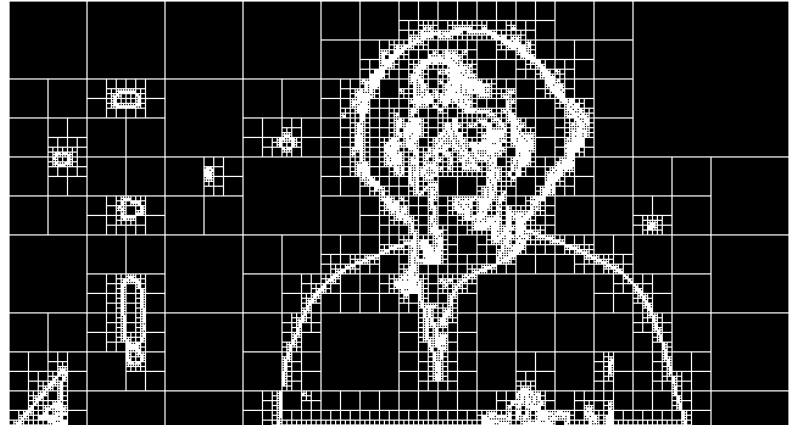

(b) Resultado da técnica Quadtree na imagem binária da Figura 11b

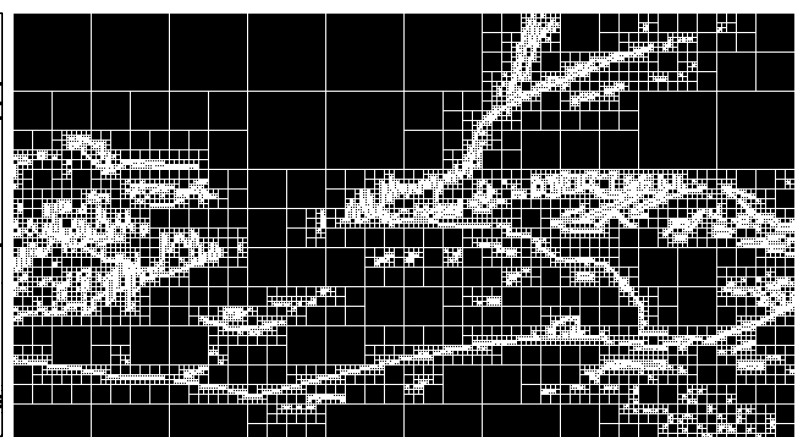

(d) Resultado da técnica Quadtree na imagem binária da Figura 11d

Figura 12. Exemplos de resultados da aplicação da técnica Quadtree.

Vale ressaltar que as características obtidas utilizando SIFT são extraídas das imagens originais, em escala de cinza. Os métodos Otsu e Quadtree são aplicados, de maneira combinada, apenas como um filtro, visando selecionar as características que melhor representam a imagem.

Observou-se que a redução de dados nos quadros ainda poderia ser aprimorada. A técnica Quadtree permite a definição de diferentes tamanhos mínimos para os blocos, o que pode influenciar no resultado do processo de redução de informações em cada quadro. Para a escolha do valor ideal a ser utilizado, dois fatores precisam ser ponderados: a taxa de redução e a qualidade da representação. Por isso, a fim de se determinar o tamanho mínimo de bloco mais apropriado para o método proposto, desenvolveu-se um estudo empírico, descrito na Seção 5.3, que culminou na escolha de blocos de 8x8 pixels.

O Algoritmo 2 sumariza a primeira fase do método Shot-HR, detalhada nesta subseção. $\mathrm{Na}$ linha 4, um quadro de vídeo é binarizado por meio do método de Otsu e, na linha 5, aplica-se a técnica Quadtree sobre o resultado obtido. Na linha 6, extraem-se características do quadro utilizando-se o método SIFT. Nas linhas 7 a 20, identificam-se os vetores de características contidos em cada bloco resultante da Quadtree, sendo que apenas um deles é 
mantido para caracterização do bloco. O conjunto $b R e p$ contém os vetores de características a serem eliminados da representação do quadro. O primeiro vetor identificado como pertencente ao bloco, não é adicionado ao conjunto $b R e p$ e, portanto, não é excluído da representação. Na linha 21, adiciona-se a representação do quadro, após o processamento, à representação da tomada.

\section{Algoritmo 2. Descrição da $1^{\text {a }}$ fase do método Shot-HR.}

Início

Entrada: conjunto de tomadas do vídeo, $V=\left\{\mathrm{t}_{1}, \mathrm{t}_{2}, \ldots, \mathrm{t}_{\mathrm{n}}\right\}$.

Saída: representação de cada tomada, $\mathrm{R}=\left\{\mathrm{t}_{1} \operatorname{Rep}, \mathrm{t}_{2} \mathrm{Rep}, \ldots, \mathrm{t}_{\mathrm{n}} \mathrm{Rep}\right\}$.

1: $\quad$ para i de 1 até $n$ faça

2: $\quad \mathrm{t}_{\mathrm{i}} \mathrm{Rep} \leftarrow \varnothing$;

3: $\quad$ para cada quadro $q \in t_{i}$ faça

4: $\quad$ qOtsu $\leftarrow$ Otsu $(\mathrm{q})$;

5: $\quad$ B $\quad$ Q Quadtree(qOtsu);

6: $\quad$ qRep $\leftarrow \operatorname{SIFT}(\mathrm{q})$;

7: $\quad$ para cada bloco $b \in \mathrm{B}$ faça

8: $\quad$ bRep $\leftarrow$;

9: $\quad$ 1o_vetor $\leftarrow$ verdadeiro;

10: $\quad$ para cada vetor de características $\mathrm{v} \in \mathrm{qRep}$ faça

11: $\quad$ se $(v \subset$ b $)$ então

12: $\quad$ se $\left(10_{-}\right.$vetor $==$falso $)$então

13: $\quad$ bRep $\leftarrow$ bRep U v;

14: $\quad$ senão

15: $\quad$ 1o_vetor $\leftarrow$ falso;

16: fim_se;

17: $\quad$ fim_se;

18: $\quad$ fim_para;

19: $\quad$ qRep $\leftarrow$ qRep - bRep;

20: fim_para;

21: $\quad t_{\mathrm{i}} \operatorname{Rep} \leftarrow \mathrm{t}_{\mathrm{i}} \operatorname{Rep} \mathrm{U}$ qRep;

22: fim_para;

23: fim_para;

Fim. 


\subsubsection{Redução de Características em Cada Tomada}

Mesmo com a redução de características em cada quadro, discutida na Subseção 4.1.1, o volume de dados na tomada como um todo ainda é alto. Nesse caso, reduzir a quantidade de dados sem comprometer a qualidade da representação implica em uma abordagem para selecionar os vetores de características mais representativos, entre todos os extraídos dos quadros de uma dada tomada. Neste trabalho, para viabilizar tal abordagem, utilizou-se o método PCA (Principal Component Analysis) (Jollife, 2002) para reduzir a dimensionalidade dos vetores de características e o método RANSAC (Seção 2.3) para selecionar os vetores mais relevantes, conforme ilustrado na Figura 13.

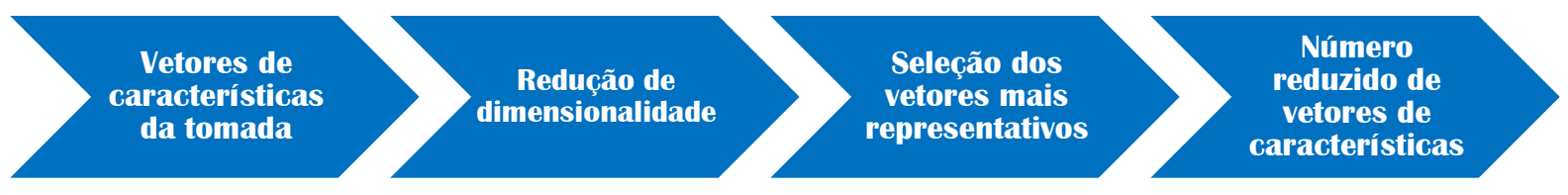

Figura 13. Resumo do processo de redução de características em cada tomada.

Em resumo, o método RANSAC ajusta um modelo a um conjunto de dados, classificando como outliers os pontos que não satisfazem o modelo instanciado. Considerou-se adequado para o problema ajustar os vetores de características obtidos utilizando SIFT a um plano. Essa escolha foi realizada levando-se em consideração que tal modelo não apresenta alta complexidade, sendo viável para aplicação em grandes volumes de dados.

Contudo, os vetores extraídos com SIFT apresentam 128 dimensões e o modelo (plano) trabalha com dados de 3 dimensões. Logo, para compatibilidade, utilizou-se o método PCA para reduzir os vetores a 3 dimensões. Então, o RANSAC foi aplicado nos dados transformados pelo PCA, identificando-se outliers. Para não prejudicar a caracterização devido à redução de dimensionalidade, foram excluídos os vetores de características de 128 dimensões correspondentes a cada outlier. Assim, tem-se como resultado dessa fase um conjunto menor de vetores resultantes do método SIFT, com suas dimensões originais.

Um estudo com 50 tomadas aleatoriamente selecionadas da base de vídeos utilizada nos experimentos (Seção 5.2) mostrou que a abordagem adotada possibilita a obtenção de uma representação compacta, apresentando uma taxa média de redução de vetores de características de $81.2 \%$ com desvio padrão de 5.8\%. O Gráfico 1 traz um exemplo dos resultados do método RANSAC sobre uma tomada do filme Uma Mente Brilhante. No gráfico, os inliers são representados pelos pontos ' $\mathrm{x}$ ' de cor verde e os outliers pelos pontos 
‘' vermelhos. É possível perceber que os dados ajustados ao plano correspondem a pontos distribuídos pelo espaço e não concentrados em uma única região. Isso contribui para manter a qualidade da caracterização, uma vez que vetores de diversos momentos da tomada são selecionados, representando sua diversidade de conteúdo. Também é possível observar que a abordagem é capaz de sintetizar os dados de maneira significativa: no exemplo, houve uma redução de $80.1 \%$.

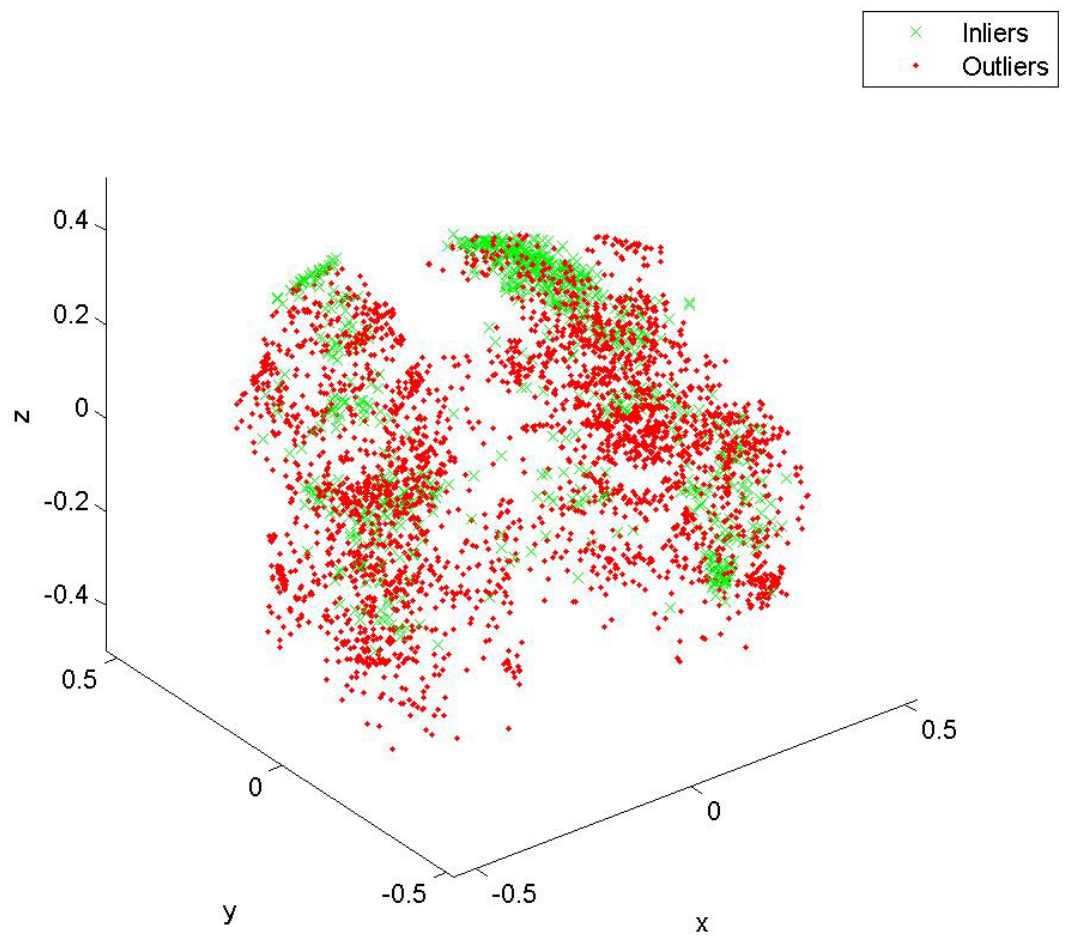

Gráfico 1. Exemplo de resultado da aplicação do método RANSAC.

O Algoritmo 3 apresenta a segunda fase do método Shot-HR, detalhada nesta subseção. $\mathrm{Na}$ linha 2, utiliza-se o método PCA para reduzir a dimensionalidade dos vetores de características pertencentes à representação da tomada. Na linha 3, aplica-se o método RANSAC para a identificação de outliers. Na linha 4, elimina-se da representação da tomada os vetores classificados como outliers.

Algoritmo 3. Descrição da $2^{\text {a }}$ fase do método Shot-HR.

Início

Entrada: representação de cada tomada obtida no Algoritmo 2, $R=\left\{t_{1} \operatorname{Rep}, t_{2} R e p, \ldots, t_{n} R e p\right\}$.

Saída: representação sintetizada de cada tomada. 
1: $\quad$ para cada representação tRep $\epsilon \mathrm{R}$ faça

2: $\quad$ tRepPCA $\leftarrow$ PCA(tRep);

3: $\quad$ outliers $\leftarrow$ RANSAC $($ tRepPCA);

4: $\quad$ tRep $\leftarrow$ tRep - outliers;

5: fim_para;

Fim.

\subsubsection{Identificação de Correspondências entre Tomadas}

Após as etapas explicadas nas Subseções 4.1.1 e 4.1.2, tem-se como resultado um conjunto de vetores de características representando cada tomada. Para ser possível comparar o grau de similaridade entre tomadas e verificar a adequação da caracterização desenvolvida no contexto de segmentação em cenas, uma medida de similaridade é necessária. Para viabilizar tal medida, adotou-se a técnica OOS (Subseção 2.1.3) para a identificação de correspondências entre vetores de características de dois conjuntos de dados (tomadas). A escolha justifica-se principalmente por essa técnica visar a otimização das correspondências e apresentar desempenho superior a outros métodos presentes na literatura, como descrito na Subseção 2.1.3.

Vale ressaltar que a técnica OOS permite a correspondência parcial, o que significa que apenas um subconjunto de vetores de características é mapeado. Para isso, utiliza-se um limiar que especifica a menor similaridade aceitável para uma possível correspondência e que, no caso deste trabalho, foi definido em 95\%. Tal valor foi determinado empiricamente e considerando-se as análises desenvolvidas em (Zhou et al., 2009).

Após a utilização da técnica OOS tem-se como medida de similaridade entre duas tomadas o número de vetores de características correspondentes entre elas.

O Algoritmo 4 descreve a técnica OOS, que foi implementada conforme descrito na Seção 5.1. Na linha 1, define-se a similaridade mínima para uma possível correspondência. Na linha 7, calcula-se a similaridade, dada pelo valor do cosseno, entre um vetor $v$ de uma dada tomada e todos os vetores da tomada subsequente. Na linha 8, identifica-se o vetor da tomada subsequente mais similar a $v$ e, na linha 9 , verifica-se se tal similaridade é maior que $95 \%$. Em caso positivo, tem-se uma possível correspondência entre o vetor $v$ e um dado vetor $v m$ da tomada seguinte. Até esse ponto tem-se que $v m$ é o mais similar a $v$. Para confirmar a correspondência, precisa-se verificar se o vetor $v$ é também o mais similar a $v m$. Por isso, nas linhas 11 a 13, repete-se o processo (cálculo do cosseno, busca pelo vetor mais similar e 
análise do valor da similaridade), porém no sentido contrário, isto é entre $v m$ e todos os vetores da tomada anterior. Caso exista um vetor correspondente a $v m$ na tomada anterior, verifica-se se o mesmo é o vetor $v$ (linha14). Se a condição for satisfeita, confirma-se a correspondência entre os vetores analisados (linha 15).

Algoritmo 4. Descrição da $3^{\text {a }}$ fase do método Shot-HR.

\section{Início}

Entrada: representação de cada tomada obtida no Algoritmo 3, $R=\left\{t_{1} R e p, t_{2} R e p, \ldots, t_{n} R e p\right\}$. Nesse algoritmo, os conjuntos tRep são utilizados na forma matricial.

Saída: número de vetores de características correspondentes entre cada par de tomadas consecutivas.

1: $\quad$ alfa $\leftarrow 0.95$;

2: $\quad$ para i de 1 até $n-1$ faça

3: $\quad \operatorname{match}(\mathrm{i}) \leftarrow 0$;

4: $\quad \mathrm{t}_{\mathrm{i}} \operatorname{RepT} \leftarrow \mathrm{t}_{\mathrm{i}} \operatorname{Rep}^{\mathrm{T}}$;

5: $\quad t_{i+1} \operatorname{RepT} \leftarrow t_{i+1} \operatorname{Rep}^{\mathrm{T}}$;

6: $\quad$ para cada vetor de características $\mathrm{v} \in \mathrm{t}_{\mathrm{i}}$ Rep faça

7: $\quad \operatorname{sim} \leftarrow v^{*} t_{i+1}$ RepT;

8: $\quad$ ind $\leftarrow$ buscalndiceMaiorValor $(\operatorname{sim})$;

9: $\quad$ se (sim(ind) $>=$ alfa) então

10: $\quad v m \leftarrow t_{i+1} \operatorname{Rep}($ ind);

11: $\quad \operatorname{sim}_{2} \leftarrow \mathrm{vm}^{*} \mathrm{t}_{\mathrm{i}} \mathrm{RepT}$;

12: $\quad \operatorname{ind}_{2} \leftarrow$ buscaIndiceMaiorValor $\left(\operatorname{sim}_{2}\right)$;

13: $\quad$ se $\left(\operatorname{sim}_{2}\left(\right.\right.$ ind $\left._{2}\right)>=$ alfa $)$ então

14: $\quad$ se $\left(t_{i} \operatorname{Rep}\left(\operatorname{ind}_{2}\right)==v\right)$ então

15: $\quad \operatorname{match}(\mathrm{i}) \leftarrow \operatorname{match}(\mathrm{i})+1$;

16: fim_se;

17: fim_se;

18: fim_se;

19: fim_para;

20: fim_para;

Fim. 


\subsection{Método de Seleção de Quadros-Chave KS-SIFT (Keyframe Set - SIFT)}

Se por um lado o uso de todos os quadros de uma tomada apresenta a vantagem de não se excluírem os que possam ser importantes para sua caracterização, por outro lado dois aspectos precisam ser considerados:

- no método Shot-HR, os quadros não são descartados, mas muitos vetores de características que os descrevem são. Por isso, não se conseguiria um melhor resultado selecionando-se os melhores quadros ao invés das melhores características para representar uma tomada?

- o custo de processamento ao se utilizar todos os quadros é bastante alto. Não seria possível atingir resultados similares com menos quadros?

Visando analisar os dois pontos apresentados anteriormente e devido às limitações das abordagens de seleção de quadros-chave encontradas na literatura (Seção 3.5), desenvolveu-se um novo método para esse propósito, denominado KS-SIFT. Nesta seção o método proposto é descrito e, na Seção 5.4, os aspectos citados são analisados.

O método KS-SIFT pode ser dividido em três etapas, descritas nas Subseções 4.2.1 a 4.2.3. A Subseção 4.2.4 apresenta exemplos de quadros-chave extraídos com o método proposto, bem como um algoritmo que o descreve.

\subsubsection{Primeiro Quadro-Chave}

O método KS-SIFT seleciona um conjunto de quadros-chave, cujo tamanho depende do teor dos quadros analisados. Isso porque, devido a grande variedade de conteúdo que pode ser encontrada em uma tomada, a escolha de um número fixo de quadros pode não resultar em uma representação de qualidade.

Com o objetivo de que todas as tomadas fossem representadas por, pelo menos, um quadro-chave, definiu-se que o primeiro quadro de cada tomada deve ser adicionado ao conjunto de quadros-chave.

Definiu-se também uma janela de tamanho $n$, e imagens localizadas nas posições $n+1$, $2 n+1,3 n+1$, e assim por diante, são analisadas visando definir se devem ou não ser incluídas no conjunto de quadros-chave. Considerou-se adequado utilizar o valor 25 para a janela. Esse valor foi definido considerando-se a taxa de quadros de vídeos no domínio de filmes, que 
usualmente é de 24 a 26 quadros/segundo. Logo, a amostragem utilizada corresponde a 1 quadro por segundo de vídeo. Além disso, o método de seleção desenvolvido é baseado no extrator de características locais SIFT, que apresenta alto custo computacional. Levando-se em consideração esse fator, é importante que não se avaliem todos os quadros.

Apesar do maior custo computacional de um extrator de características locais, em comparação, por exemplo, aos histogramas, optou-se pela sua utilização por ser capaz de encontrar pontos de interesse que identificam unicamente uma imagem, favorecendo a escolha dos quadros que melhor representam a variação de conteúdo dentro de uma tomada.

\subsubsection{Análise do Número de Pontos de Interesse}

Após a definição do primeiro quadro-chave, avaliam-se quais os demais quadros a serem adicionados ao conjunto, de modo a contribuir com a representação. Logo, o segundo passo do método KS-SIFT baseia-se no seguinte raciocínio: se o número de pontos de interesse do quadro sendo analisado, referenciado nesta seção como quadro atual, é suficientemente diferente do número de pontos de interesse de todos os quadros já selecionados, assume-se que o quadro atual é diferente dos demais já escolhidos e adiciona-se o mesmo ao conjunto de quadros-chave.

Mais especificamente, verifica-se se o módulo da diferença entre o número de pontos de interesse do quadro atual e do quadro-chave é maior ou igual a $60 \%$ do número de pontos do quadro-chave. É importante ressaltar que esse critério deve ser satisfeito entre o quadro atual e todos os quadros já pertencentes ao conjunto de quadros-chave para que ele seja inserido. Um exemplo de comparação do quadro atual com um quadro-chave é apresentado na Figura 14.

Quadro-chave: 10 pontos de interesse $60 \%=6$

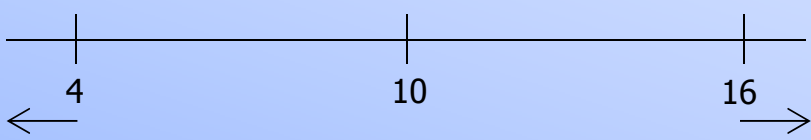

intervalo para considerar as imagens diferentes

Se o número de pontos de interesse do quadro atual for menor que 4 ou maior que 16 , ele é considerado diferente do quadro-chave

Figura 14. Exemplo de análise da diferença entre quadro atual e quadro-chave com base no número de pontos de interesse. 
A taxa de $60 \%$ foi definida empiricamente. Foram selecionadas tomadas da base de vídeos utilizada nos experimentos (Seção 5.2) e foram empregados no método KS-SIFT valores entre $10 \%$ e $90 \%$. Quanto menor o valor utilizado, maior foi o número de quadros-chave selecionados. Concluiu-se que a taxa de $60 \%$ é capaz de selecionar quadros que representam a variedade de conteúdo da tomada e que não contêm as mesmas informações. Assim, é possível obter um conjunto de quadros-chave representativo e compacto.

Além disso, optou-se pela utilização de um limiar calculado em função do quadro-chave, ao invés de um limiar fixo, pois o número de pontos de interesse identificado apresenta uma grande variação dependendo do conteúdo das imagens, tornando difícil encontrar um valor adequado para o vídeo como um todo.

\subsubsection{Análise dos Vetores de Características}

Se o critério descrito na Subseção 4.2.2 não for satisfeito, isto é, se o quadro atual apresenta um número de pontos de interesse semelhante ao dos quadros já selecionados, verifica-se se esses pontos são diferentes. Isso porque, duas imagens com conteúdos distintos podem possuir um número semelhante de pontos de interesse, porém, nesse caso, eles não representarão as mesmas informações. Para fazer essa avaliação, os vetores de características que descrevem os pontos de interesse são analisados com a técnica OOS.

Mais especificamente, com a OOS, faz-se a correspondência entre os vetores de características do quadro atual e do quadro-chave e verifica-se se o número de vetores correspondentes é menor que 10\% (valor definido empiricamente de maneira análoga ao limiar de $60 \%$ discutido na Subseção 4.2.2) do número de vetores do quadro-chave. O raciocínio é o seguinte: se muitos vetores de características do quadro-chave estão presentes no quadro atual, então esse quadro já está representado pelo quadro-chave, ou seja, é semelhante a ele e não precisa ser incluído no conjunto de imagens selecionadas. De maneira análoga, se poucos vetores de características do quadro-chave estão presentes no quadro atual, considera-se que as imagens são diferentes e o quadro atual deve ser inserido no conjunto. Novamente, o critério deve ser satisfeito entre o quadro atual e todos os quadros já selecionados para que o mesmo seja inserido no conjunto de quadros-chave. 


\subsubsection{Exemplo de Aplicação do Método KS-SIFT}

Como resultado do método KS-SIFT descrito nesta seção, tem-se um conjunto de imagens representando cada tomada. Esse conjunto apresenta tamanho variável, dependendo da diversidade de conteúdo presente nas tomadas. A Figura 15 apresenta exemplos de quadroschave selecionados com o método proposto para três tomadas do filme Uma Mente Brilhante. É possível perceber que as imagens pertencentes ao conjunto de quadros-chave possuem semântica diferente e representam diversos momentos da tomada.
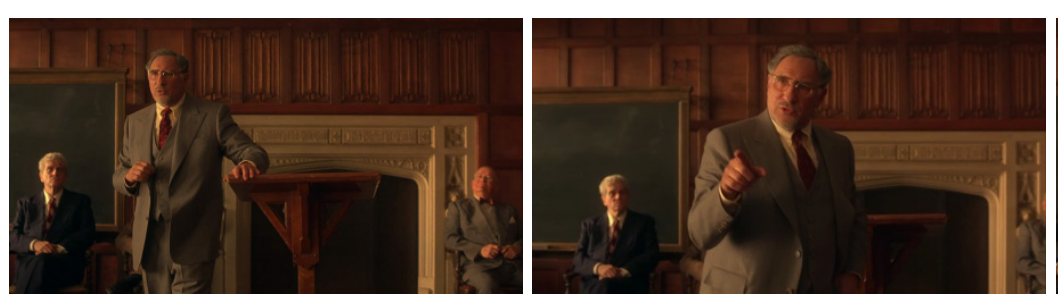

(a)
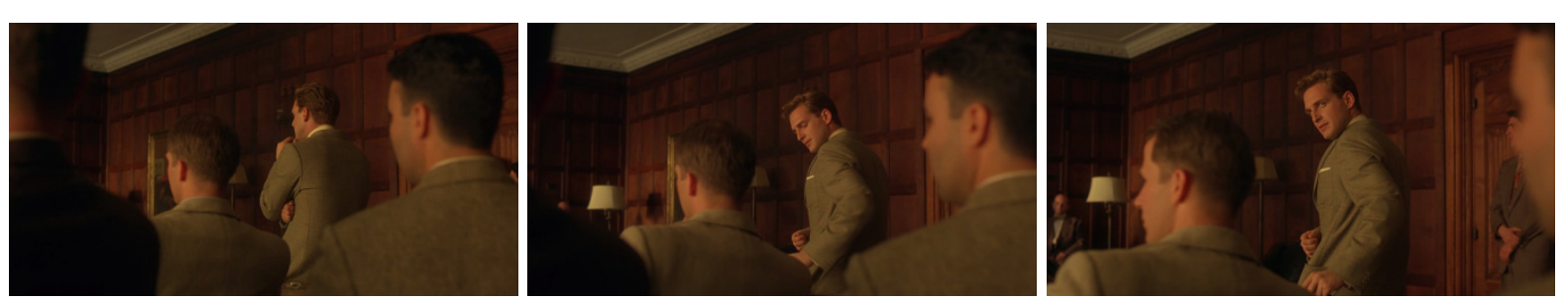

(b)
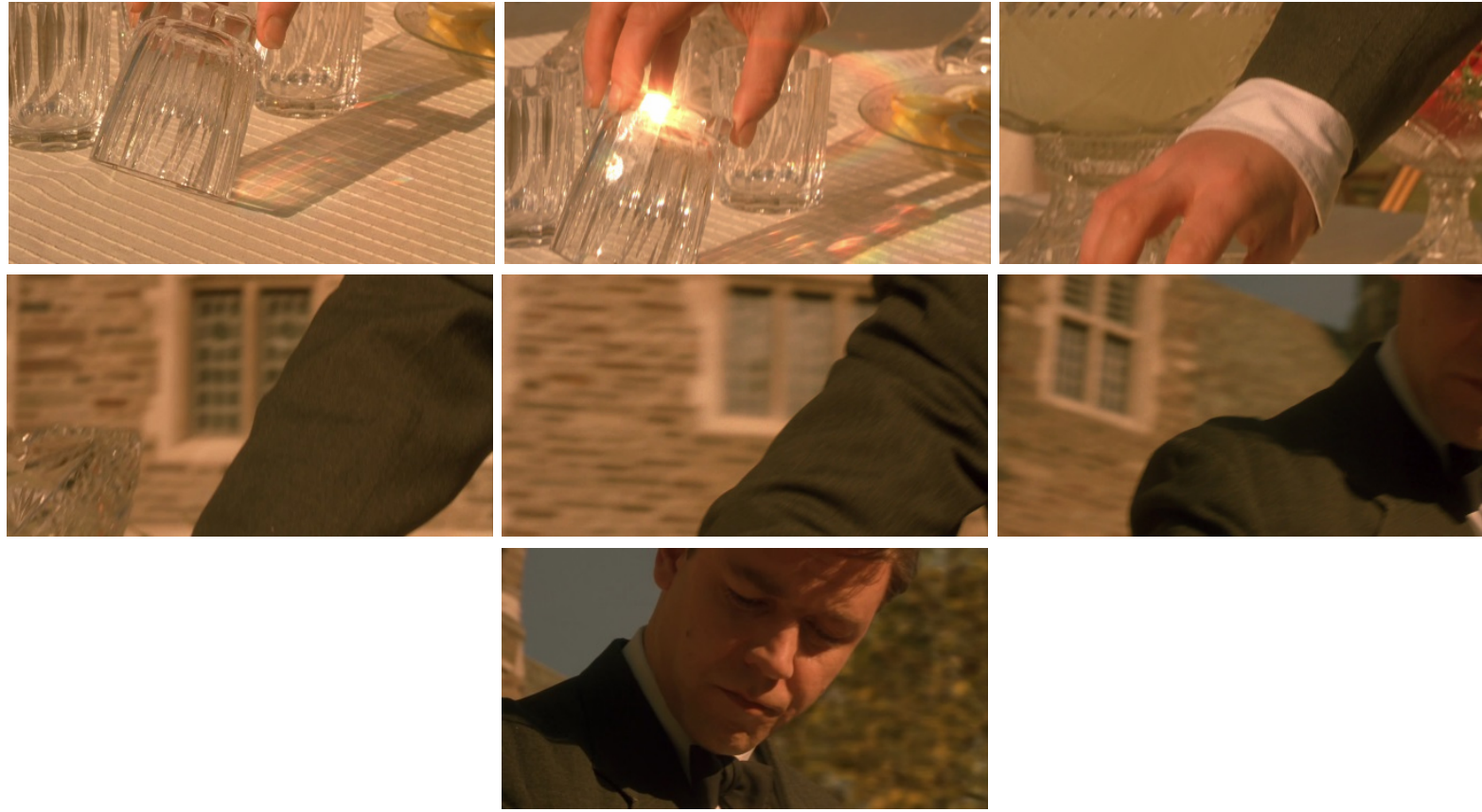

(c)

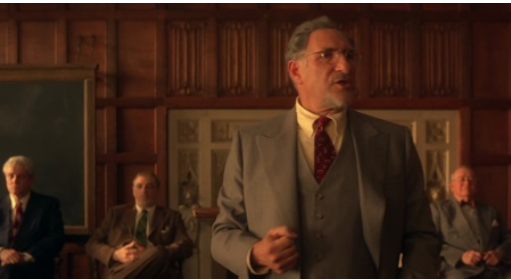

\section{.}

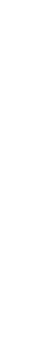 \\ (1)}

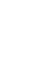




\section{Início}

Entrada: conjunto de tomadas do vídeo, $\mathrm{V}=\left\{\mathrm{t}_{1}, \mathrm{t}_{2}, \ldots, \mathrm{t}_{\mathrm{n}}\right\}$, sendo $\mathrm{t}_{\mathrm{k}}=\left\{\mathrm{q}_{\mathrm{k} 1}, \mathrm{q}_{\mathrm{k} 2}, \ldots, \mathrm{q}_{\mathrm{km}}\right\}$, para $\mathrm{k}=1 . . \mathrm{n}$.

Saída: quadros-chave de cada tomada.

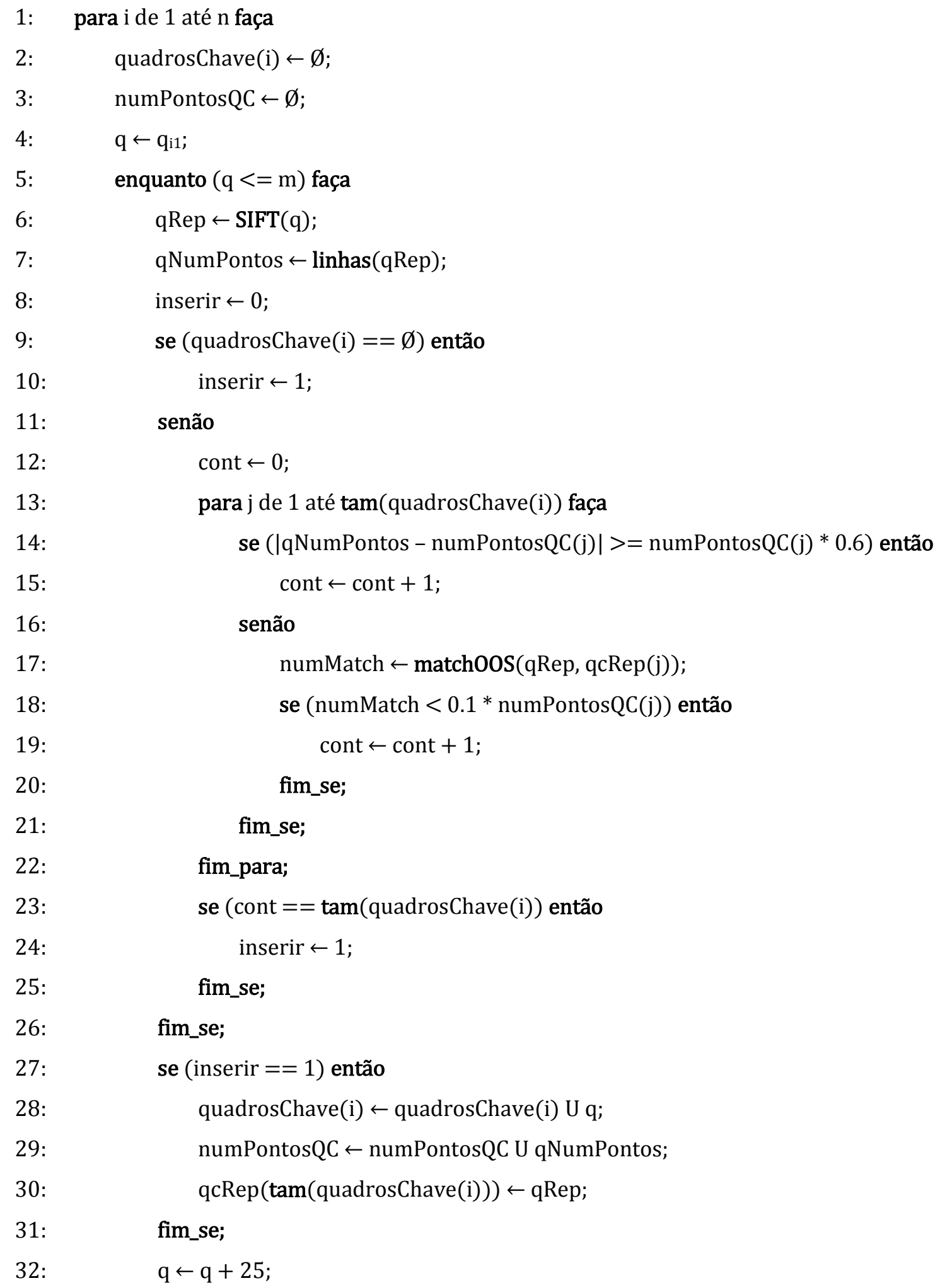


33: fim_enquanto;

34: fim_para;

Fim.

O Algoritmo 5 apresenta o método KS-SIFT. Na linha 6, extraem-se características do quadro atual utilizando-se o método SIFT e, na linha 7, obtém-se o número de pontos de interesse identificados. Caso o conjunto de quadros-chave esteja vazio, trata-se do primeiro quadro da tomada, que deve ser inserido no conjunto (linhas 9 e 10). Nas linhas 14 e 15, analisa-se a condição de inserção explicada na Subseção 4.2.2, isto é, verifica-se se a diferença entre o número de pontos de interesse do quadro atual e do quadro-chave é maior ou igual a $60 \%$ do número de pontos do quadro-chave. Nas linhas 17 a 20, analisa-se a condição de inserção explicada na Subseção 4.2.3, ou seja, realiza-se a correspondência entre os vetores de características do quadro atual e do quadro-chave utilizando-se a técnica OOS, descrita no Algoritmo 4 e, então, verifica-se se o número de vetores correspondentes é menor que $10 \%$ do número de vetores de características do quadro-chave. Nas linhas 23 a 25 , verifica-se se o quadro atual é suficientemente diferente de todos os já selecionados e, em caso positivo, indica-se que deve ser adicionado ao conjunto. Nas linhas 27 a 31, realiza-se, quando necessário, a inserção do quadro atual no conjunto de quadros-chave. Por fim, na linha 32, passa-se para o próximo quadro a ser analisado, respeitando a janela definida ( 25 quadros).

\subsection{Técnica de Segmentação em Cenas}

Desenvolveu-se uma técnica automática de segmentação em cenas para avaliar a representação de tomadas proposta aplicada a esse contexto. A técnica consiste em encontrar vales na medida de similaridade entre as tomadas, por exemplo, no número de vetores de características correspondentes. Porém, só se considera um vale quando a redução e respectivo aumento no valor de similaridade são significativos. Uma taxa de redução/aumento significativa depende das características do vídeo em questão, por isso, ao invés de utilizar um limiar fixo, desenvolveu-se um método para determiná-la. Logo, são computados todos os valores de quedas na medida de similaridade, considerando-se que a redução pode ocorrer em um intervalo de até 5 tomadas. Então, calcula-se a queda típica para o vídeo, excluindo-se as $10 \%$ maiores e menores quedas, para que situações particulares não influenciem no cálculo, e fazendo-se a média dos demais valores. O resultado é a taxa de redução/aumento significativa 
para o vídeo sendo analisado, isto é, trata-se da variação mínima necessária para a identificação de um vale.

O passo seguinte é a identificação de transições de cenas. Para isso, percorrem-se todos os valores de similaridade, verificando-se se em um intervalo de até 5 tomadas consecutivas houve uma queda maior ou igual à taxa de redução/aumento determinada anteriormente. Em caso positivo, verifica-se ainda se, em até 5 tomadas sucessivas, houve um aumento maior ou igual à essa mesma taxa. Se a condição for novamente satisfeita, determina-se um vale, ou seja, uma transição de cenas.

É importante destacar que o intervalo de 5 tomadas foi definido por considerar-se que a coerência entre as tomadas pode diminuir de forma gradativa no final de uma cena e, de maneira análoga, aumentar gradualmente no início da cena seguinte. Analisando-se esse aspecto na base de vídeos utilizada nos experimentos (Seção 5.2), estabeleceu-se o valor 5 por ser capaz de introduzir flexibilidade ao método. Isso porque, trata-se do intervalo máximo, não excluindo situações em que a queda/aumento na coesão entre as tomadas acontece em intervalos menores.

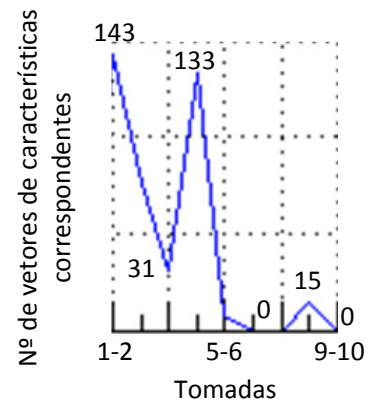

$1^{0}$ passo: Cálculo da taxa de redução/aumento significativa

$1^{\text {a }}$ queda (intervalo de 2 tomadas): $143-31=112$

$2^{\mathrm{a}}$ queda (intervalo de 2 tomadas): $133-0=133$

$3^{\mathrm{a}}$ queda (intervalo de 1 tomada): $15-0=15$

Exclusão das $10 \%$ maiores e $10 \%$ menores quedas: $\lfloor 0.1 * 3\rfloor=0$

Média das quedas restantes: $(112+133+15) / 3 \approx 87$

Taxa de redução/aumento: 87 vetores correspondentes

\section{$2^{0}$ passo: Identificação de vales}

Intervalo de 2 tomadas: queda de $112>$ taxa de redução/aumento Intervalo de 1 tomada: aumento de $102>$ taxa de redução/aumento Logo, um vale foi identificado e tomada 3-4 é uma transição de cenas

Intervalo de 2 tomadas: queda de $133>$ taxa de redução/aumento Intervalo de 2 tomadas: aumento de $15<$ taxa de redução/aumento Logo, um vale não foi identificado

Intervalo de 1 tomada: queda de 15 - Fim do vídeo

Figura 16. Simulação da execução da técnica de segmentação em cenas em um vídeo com 10 tomadas, no qual a medida de similaridade é o número de vetores de características correspondentes. 
A Figura 16 simula a execução da técnica de segmentação em cenas em um vídeo com 10 tomadas e no qual a medida de similaridade utilizada é o número de vetores de características correspondentes.

Vale ressaltar que a técnica de segmentação em cenas desenvolvida não está vinculada ao método de representação de tomadas. Ela não apresenta heurísticas nem análises adicionais (como detecção e tratamento de falsos positivos ou conhecimento do domínio/gênero do vídeo) para aprimorar os resultados obtidos com a abordagem de caracterização proposta. Logo, é possível alterar a representação de tomadas utilizada e realizar a segmentação em cenas da mesma maneira. Por exemplo, ao invés de utilizar uma representação baseada em SIFT e o número de vetores de características correspondentes como medida de similaridade, pode-se utilizar uma representação baseada em histogramas e intersecção de histogramas como medida de similaridade. Essa propriedade é importante pois torna possível comparar a qualidade da segmentação em cenas obtida utilizando-se diferentes métodos de caracterização de tomadas.

O Algoritmo 6 descreve a técnica de segmentação em cenas desenvolvida. Na linha 1, obtém-se o tamanho do conjunto, resultado do Algoritmo 4, que contém o número de vetores de características correspondentes entre os pares de tomadas consecutivas. Nas linhas 2 a 18 , calculam-se os valores de queda na medida de similaridade. Nas linhas 5 a 9 , percorrem-se os valores de similaridade até encontrar um mínimo local. Na linha 14, calcula-se a queda, considerando-se, no máximo, 5 tomadas anteriores ao ponto de mínimo. Nas linhas 15 a 17, percorrem-se os valores de similaridade até encontrar um máximo local. Na linha 19, calculase a taxa de redução/aumento significativa, desconsiderando-se as $10 \%$ maiores e $10 \%$ menores quedas e fazendo-se a média das demais. Nas linhas 20 a 46, buscam-se vales na medida de similaridade. Nas linhas 24 a 28, percorrem-se os valores de similaridade até encontrar um mínimo local. Nas linhas 32 a 34, verifica-se se em um intervalo de, no máximo, 5 tomadas anteriores ao ponto de mínimo local houve uma redução significativa. Em caso positivo, define-se um possível vale $v$. Nas linhas 35 a 39, percorrem-se os valores de similaridade até encontrar um máximo local. Nas linhas 43 a 45, se um possível vale havia sido determinado anteriormente, verifica-se se em um intervalo de, no máximo, 5 tomadas posteriores a $v$, houve um aumento significativo. Em caso positivo, determina-se uma transição de cenas. 


\section{Início}

Entrada: número de vetores de características correspondentes entre cada par de tomadas consecutivas, obtido no Algoritmo 4.

Saída: transições de cenas.

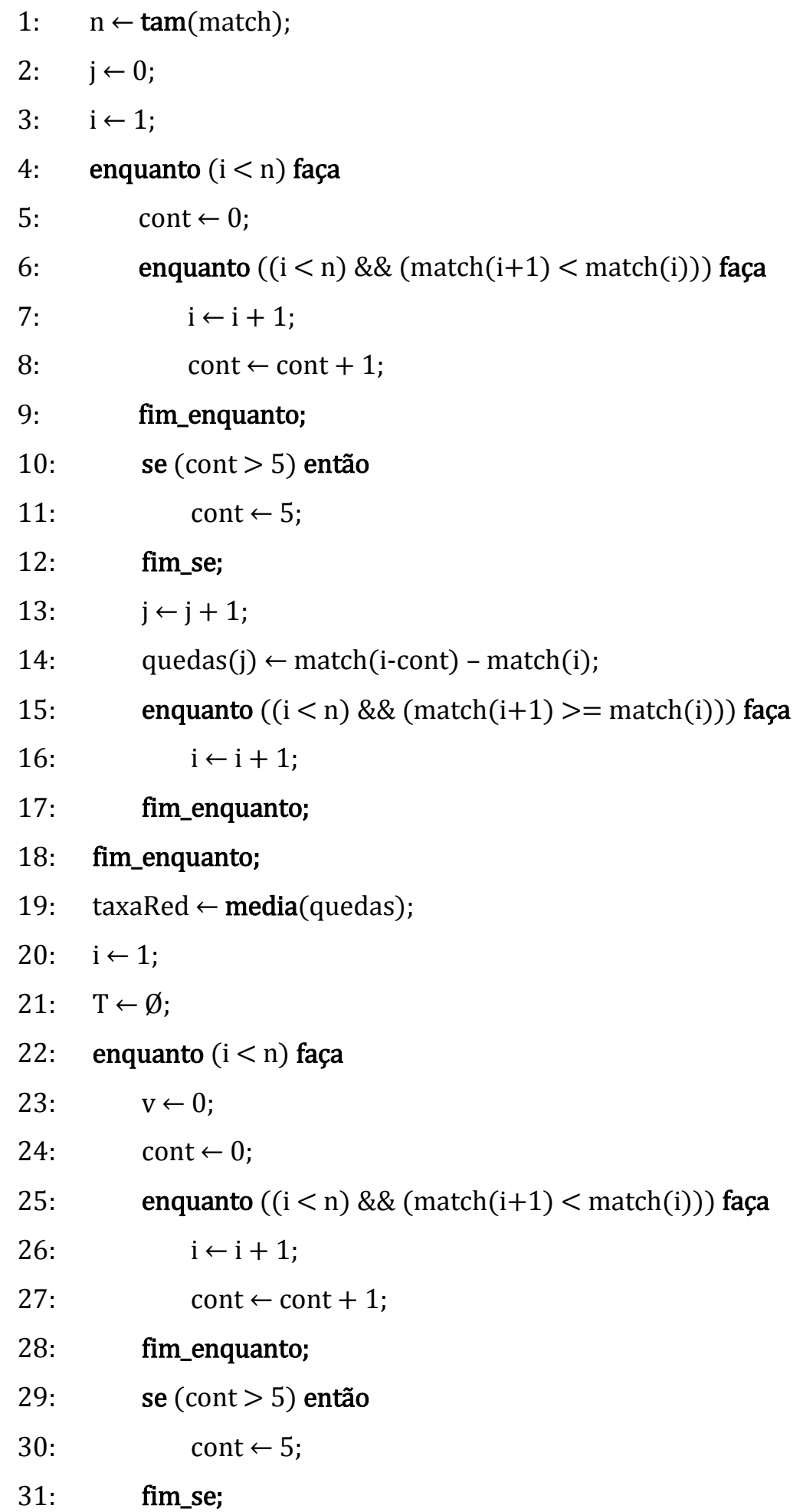




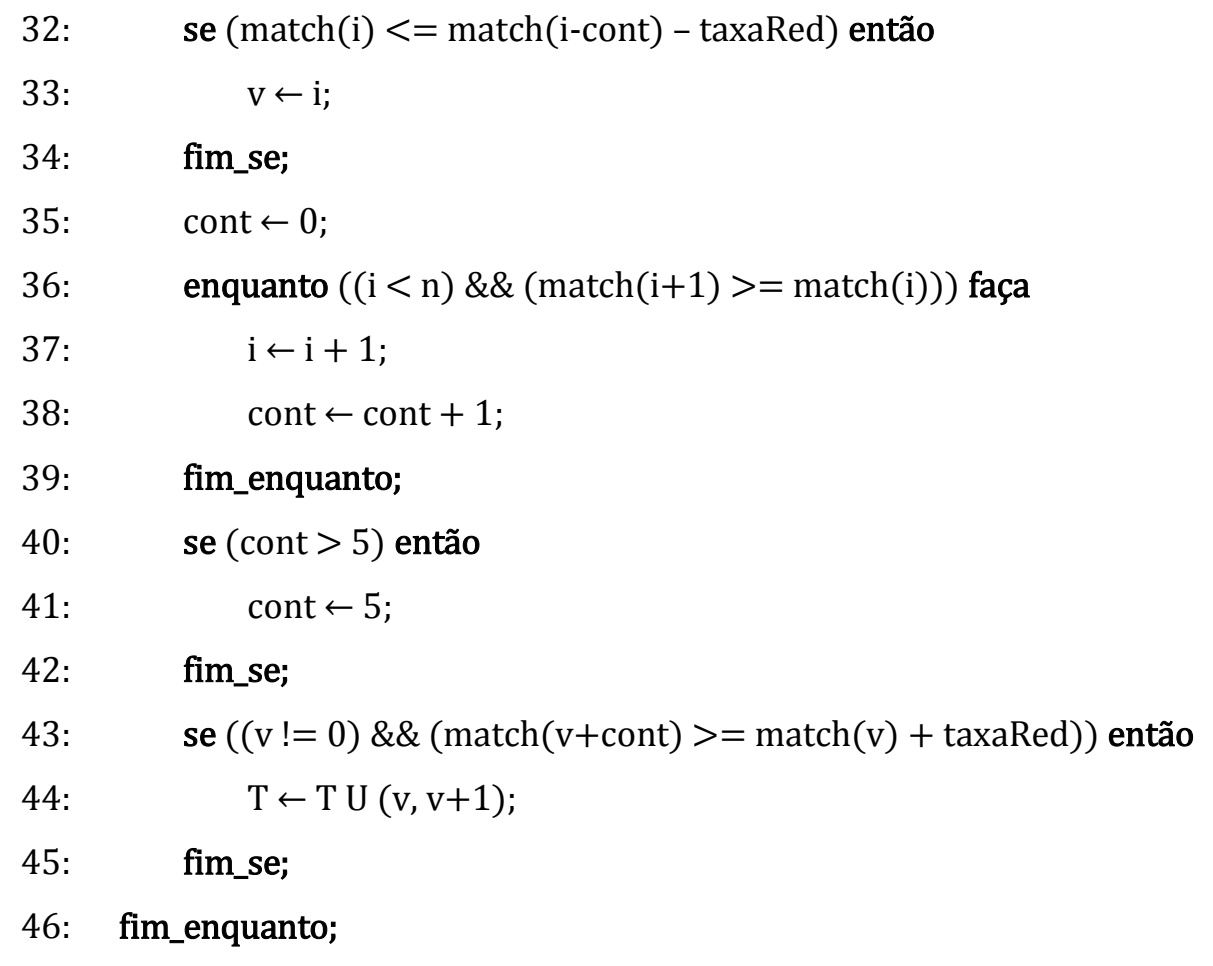

Fim.

\subsection{Considerações Finais}

Neste capítulo, detalhou-se o método de descrição de tomadas proposto (Shot-HR), que visa aprimorar a caracterização ao lidar com os problemas de representatividade e volume de dados. Discutiu-se também uma alternativa baseada na seleção de quadros-chave (KS-SIFT) e uma técnica de segmentação em cenas desenvolvida com o propósito de auxiliar na avaliação de métodos de representação de tomadas. No próximo capítulo são apresentados os experimentos e análises realizados para avaliar a qualidade e o tempo de processamento do método de caracterização proposto, aplicado ao contexto de segmentação em cenas. 


\section{Capítulo 5: Experimentos e Análises}

Este capítulo tem como objetivo apresentar os experimentos realizados para avaliar qualidade e tempo de processamento do método de representação de tomadas Shot-HR e do método de seleção de quadros-chave KS-SIFT descritos no capítulo 4. Nas Seções 5.1 e 5.2, descrevem-se, respectivamente, as ferramentas utilizadas nas implementações desenvolvidas e a base de vídeos. Na Seção 5.3, apresenta-se uma análise do tamanho mínimo de bloco mais adequado a ser utilizado como parâmetro para a técnica Quadtree durante a fase de extração e redução de características em cada quadro (Subseção 4.1.1). Na Seção 5.4, compara-se o uso de todos os quadros do vídeo (Shot-HR) com o uso de quadros-chave (KS-SIFT), no contexto de segmentação em cenas. Na Seção 5.5, compara-se o método Shot-HR e a abordagem baseada em quadros-chave com métodos de caracterização encontrados na literatura. $\mathrm{Na}$ Seção 5.6, apresenta-se uma análise do tempo de processamento dos métodos investigados.

\subsection{Ambientes e Ferramentas de Desenvolvimento}

Para avaliar o método de representação de tomadas proposto e compará-lo com outras abordagens encontradas na literatura, diversas implementações foram necessárias.

Os métodos Shot-HR, KS-SIFT e a técnica de segmentação em cenas, descritos, respectivamente, nas Seções 4.1, 4.2 e 4.3, foram implementados na ferramenta MATLAB (MATrix LABoratory ${ }^{7}$ ), versão R2012a. Para os métodos de Otsu, Quadtree e PCA foram utilizadas funções disponíveis nas bibliotecas padrão do MATLAB. Já para a técnica SIFT, utilizou-se uma implementação disponibilizada para propósitos de pesquisa, pelo autor da técnica (Lowe, 1999), que pode ser encontrada no seguinte endereço: www.cs.ubc.ca/ lowe/keypoints. No caso do método RANSAC, o código utilizado pode ser obtido acessando-se: github.com/RANSAC/RANSAC-Toolbox. A técnica OOS, por sua vez, foi implementada, em MATLAB, de acordo com o artigo de Zhao et al. (2007).

\footnotetext{
${ }^{7}$ www.mathworks.com
} 
Além disso, as abordagens de caracterização de tomadas pertencentes ao estado da arte, com as quais o método proposto foi comparado, também foram desenvolvidas na ferramenta MATLAB.

\subsection{Base de Vídeos}

Os experimentos foram realizados com cinco segmentos de vídeo do domínio de filmes. Esse domínio foi escolhido por conter uma grande quantidade e variedade de tomadas e cenas. Além disso, não se encontra na literatura uma base bem estabelecida e com vídeos de longa duração apropriada para o contexto deste trabalho. Por exemplo, a base do TRECVID ${ }^{8}$, uma das raras exceções em termos de benchmarks para vídeos, comumente citada em trabalhos relacionados, possui vídeos curtos e com um pequeno número de cenas, nos domínios de telejornais e documentários. Logo, não foi considerada apropriada para o processo de avaliação do método proposto por não conter vídeos com as características desejadas (variedade e quantidade de cenas e tomadas). Bases de vídeo adequadas para avaliações e comparações ainda são um problema em aberto no domínio de segmentação (Money \& Agius, 2008; Smeaton et al., 2010).

Devido às dificuldades citadas anteriormente, desenvolveu-se uma base de vídeos utilizada, neste trabalho, para propósitos de avaliação. Para isso, foram selecionados os 50 minutos iniciais de cinco filmes, desconsiderando-se os efeitos de abertura. Os vídeos foram convertidos para quadros com a ferramenta FFmpeg, versão para Windows, disponível em ffmpeg.org/download.html, utilizando-se a seguinte linha de comando:

\section{ffmpeg.exe -i nome_vídeo.ext -f image $2 \% 5 \mathrm{~d}$.ext}

onde:

- -i nome_vídeo.ext: corresponde ao nome do vídeo de entrada com sua respectiva extensão;

- -f image2 \%5d.ext: indica o nome e extensão das imagens de saída. No caso, a máscara "\%5d" indica numeração sequencial de 5 dígitos, ou seja, os arquivos serão nomeados "00001.ext", "00002.ext" e assim por diante. Dois formatos de imagens foram utilizados: PGM (Portable Gray Map), para extração de características com

\footnotetext{
${ }^{8}$ trecvid.nist.gov
} 
SIFT e PNG (Portable Network Graphics), para obtenção de histogramas de cor, usados por um dos métodos de seleção de quadros-chave encontrados na literatura.

Vale ressaltar que não foram definidas a taxa de quadros e a resolução das imagens. Foram obtidos todos os quadros do vídeo, seguindo suas dimensões originais.

Além disso, os métodos de representação de tomadas utilizados nos experimentos consideram que os vídeos foram previamente segmentados em tomadas, por isso, esse passo foi realizado manualmente para não influenciar a qualidade da caracterização. Os vídeos também foram segmentados manualmente em cenas, a fim de se criar uma base confiável (tradução livre do inglês ground truth) para comparar os resultados obtidos com a técnica de segmentação automática. Vale mencionar que os vídeos possuíam transições abruptas e graduais de cenas e, para os experimentos, as transições graduais foram consideradas tomadas individuais. A Tabela 2 apresenta as principais características dos vídeos pertencentes à base utilizada.

Tabela 2. Base de vídeos utilizada nos experimentos.

\begin{tabular}{|c|c|c|c|c|c|}
\hline Filme & $\begin{array}{c}\text { Quadro Inicial } \\
\text { do Segmento }\end{array}$ & $\begin{array}{c}\text { Número de } \\
\text { Quadros }\end{array}$ & $\begin{array}{c}\text { Número de } \\
\text { Tomadas }\end{array}$ & $\begin{array}{c}\text { Número } \\
\text { de Cenas }\end{array}$ & $\begin{array}{c}\text { Resolução dos } \\
\text { Quadros (pixels) }\end{array}$ \\
\hline Uma Mente Brilhante & 2152 & 69013 & 609 & 28 & $1280 \times 688$ \\
\hline A Era do Gelo & 685 & 72019 & 905 & 43 & $1280 \times 694$ \\
\hline 60 Segundos & 4836 & 72010 & 1047 & 72 & $1920 \times 816$ \\
\hline Piratas do Caribe & 396 & 72008 & 1041 & 57 & $1280 \times 528$ \\
\hline De Volta Para o Futuro & 4831 & 71970 & 572 & 37 & $1280 \times 696$ \\
\hline
\end{tabular}

As saídas da segmentação automática em cenas foram avaliadas com as medidas descritas na Seção 3.1: precisão, abrangência e F1. A Figura 17 apresenta um trecho da segmentação automática obtida para o filme Uma Mente Brilhante, utilizando-se o método de representação de tomadas Shot-HR. Pode-se observar que são identificadas as tomadas onde ocorrem as transições de cenas. Para comparar os resultados obtidos com a base confiável empregou-se o critério de Hanjalic et al. (1999), isto é, se a transição de cena detectada pelo método automático estiver a até quatro tomadas da transição detectada manualmente, ela é contada como um acerto. Esse critério é comumente adotado por trabalhos relacionados a segmentação em cenas (Zhu \& Liu, 2008a). 


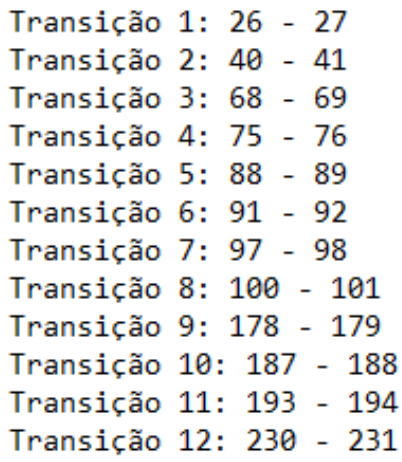

Figura 17. Exemplo de saída da segmentação automática em cenas. Trecho obtido para o filme Uma Mente Brilhante, utilizando-se o método de representação de tomadas Shot-HR.

\subsection{Análise do Tamanho Mínimo de Bloco}

Um dos pontos importantes da primeira fase do método Shot-HR (Subseção 4.1.1) é o tamanho mínimo de bloco utilizado como parâmetro pela técnica Quadtree. Esse aspecto tem influência na taxa de redução de vetores de características e também na qualidade da representação obtida. Para se determinar o tamanho mínimo de bloco ideal a ser utilizado desenvolveu-se um estudo empírico, detalhado nas Subseções 5.3.1 e 5.3.2.

\subsubsection{Análise da Taxa de Redução e Qualidade da Representação}

Para realizar o estudo, foram selecionadas aleatoriamente 50 imagens da base de vídeos (Seção 5.2) e dois aspectos foram verificados:

- a taxa média de redução no número de pontos de interesse para diferentes tamanhos mínimos de blocos;

- a qualidade da representação obtida. Realizou-se uma análise visual dos pontos de interesse resultantes do processo de redução.

A Tabela 3 apresenta a taxa média de redução de pontos de interesse, em comparação aos pontos originalmente obtidos com o método SIFT, e o desvio padrão para diferentes tamanhos mínimos de blocos utilizados na técnica Quadtree, considerando-se as 50 imagens selecionadas. É possível observar que, quanto maior o tamanho mínimo de bloco definido, maior é a taxa de redução de pontos de interesse obtida. 
Tabela 3. Comparação entre os diferentes tamanhos mínimos de bloco utilizados na técnica Quadtree quanto à taxa de redução do número de pontos de interesse em relação aos pontos originalmente obtidos com o método SIFT e desvio padrão.

\begin{tabular}{|ccc}
\hline & Taxa média de redução (\%) & Desvio padrão (\%) \\
\hline Blocos mínimos de 2x2 pixels & 26.8 & 10.7 \\
\hline Blocos mínimos de 4x4 pixels & 28.1 & 10.6 \\
\hline Blocos mínimos de 8x8 pixels & 37.1 & 11.5 \\
\hline Blocos mínimos de 16x16 pixels & 53.1 & 15.4 \\
\hline Blocos mínimos de 32x32 pixels & 69.1 & 17.7 \\
\hline Blocos mínimos de 64x64 pixels & 82.1 & 16.4 \\
\hline
\end{tabular}

As Figuras 18 e 19 exemplificam a análise visual realizada. Elas apresentam os pontos de interesse originalmente obtidos com o método SIFT para as Figuras 11a e 11c e os pontos remanescentes após o processo de redução de informações, considerando-se diferentes tamanhos mínimos de regiões definidos para a técnica Quadtree. Assim como na Tabela 3, é possível observar que ao aumentar o tamanho mínimo de bloco, consegue-se alcançar uma maior taxa de redução de pontos de interesse. Porém, a partir de blocos mínimos de 16x16 pixels, os pontos de interesse começam a tornar-se esparsos e perdem-se informações características das imagens. Por exemplo, pode-se observar na Figura 18e que regiões importantes do rosto, como os olhos e o nariz, deixam de ser bem representadas, o que pode influenciar negativamente na qualidade da caracterização. Esse aspecto também pode ser observado na Figura 19e, onde muitos pontos que representam as árvores ou o elefante, por exemplo, são descartados.

Entretanto, apesar dos argumentos apresentados anteriormente, ainda poder-se-ia haver dúvidas quanto à opção de se utilizar blocos de tamanho mínimo 8x8 ao invés de 16x16 pixels, já que a taxa média de redução obtida para o segundo caso é significativamente mais alta. Apesar do maior espaçamento entre os pontos no caso de regiões mínimas de 16x16 pixels, eles poderiam ser suficientes para representar as imagens com qualidade e as informações descartadas poderiam não ser tão importantes para a caracterização. Quando dados redundantes são eliminados, isso não impacta negativamente no poder de representação. Por isso, realizou-se o experimento descrito na Subseção 5.3.2, para avaliar a qualidade do resultado final obtido para ambos os tamanhos mínimos de blocos. 


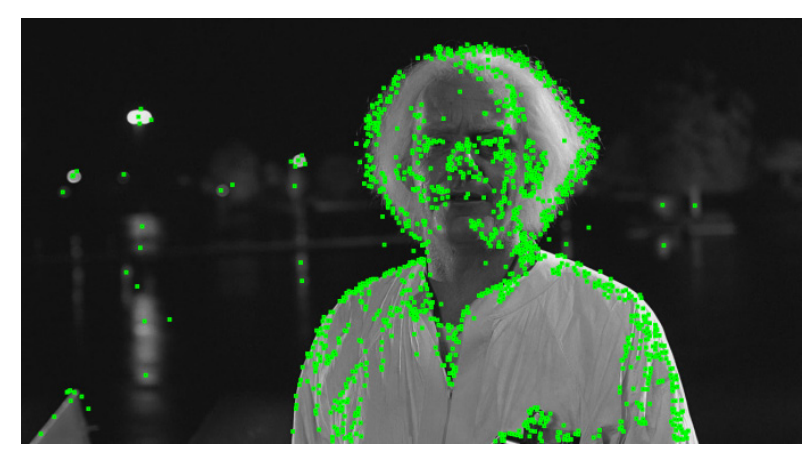

(a) 1554 pontos de interesse obtidos com SIFT (sem redução)

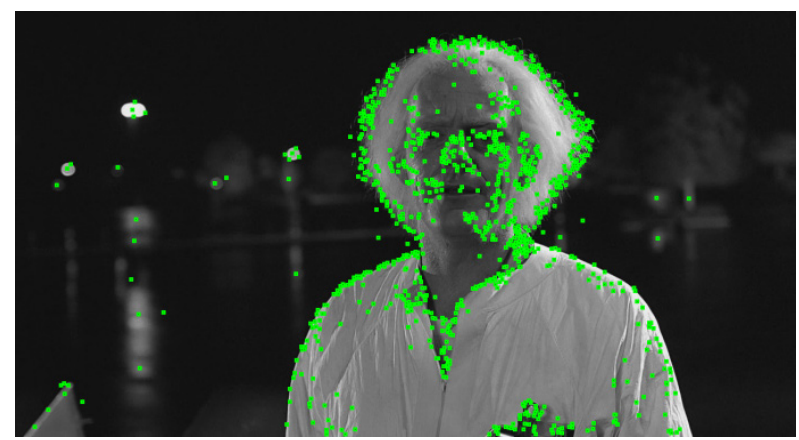

(c) Quadtree com blocos mínimos de 4x4 pixels 973 pontos de interesse após o processo de redução

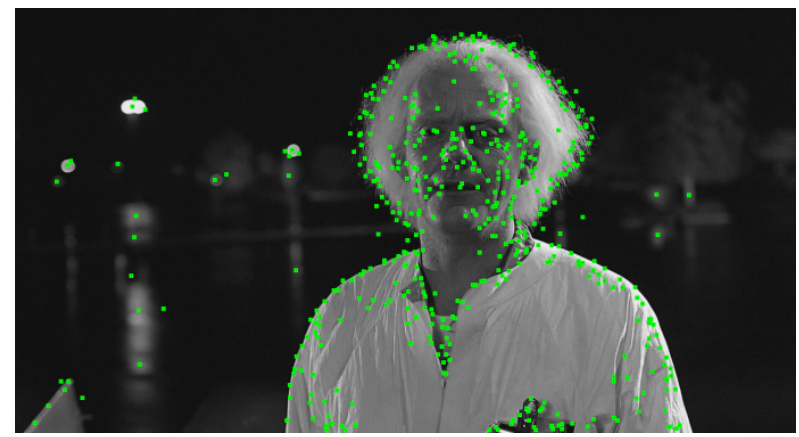

(e) Quadtree com blocos mínimos de 16x16 pixels 482 pontos de interesse após o processo de redução

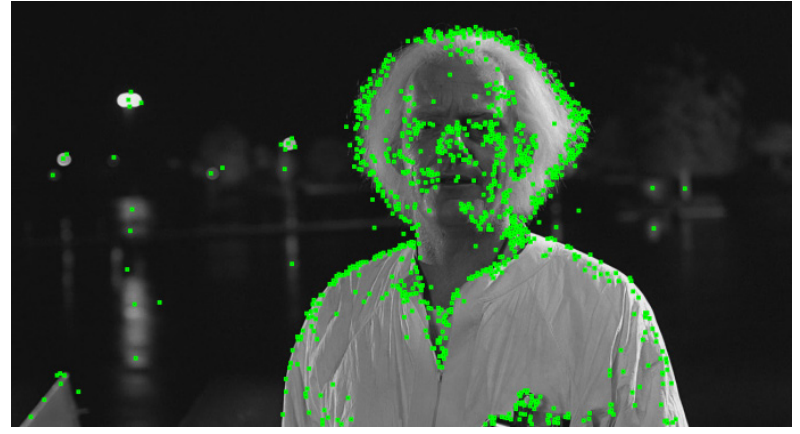

(b) Quadtree com blocos mínimos de 2x2 pixels 997 pontos de interesse após o processo de redução

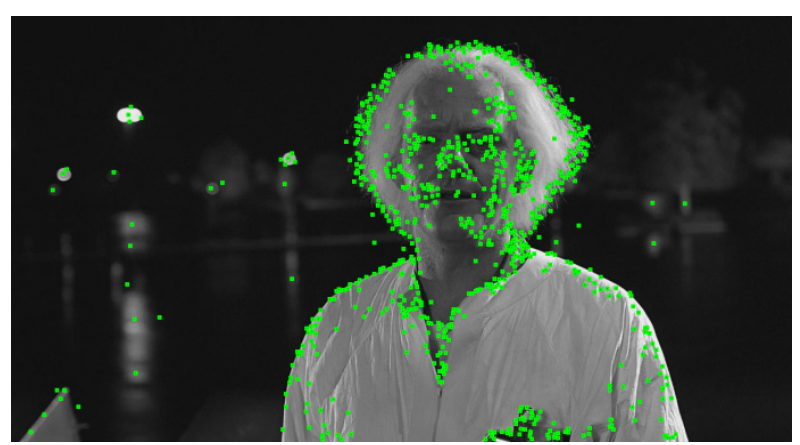

(d) Quadtree com blocos mínimos de 8x8 pixels 794 pontos de interesse após o processo de redução

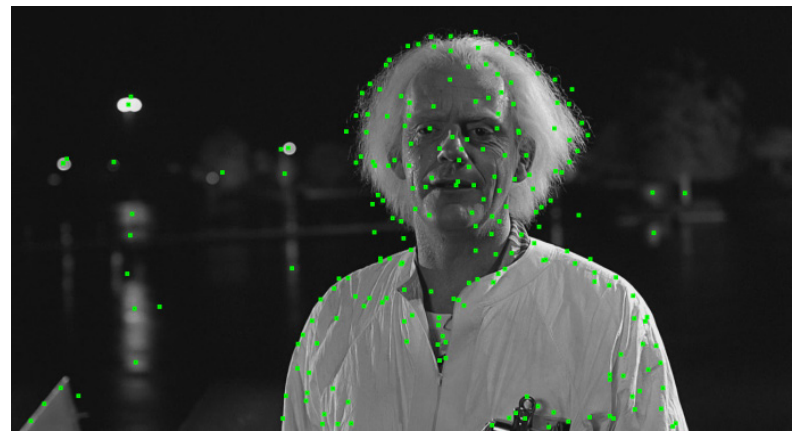

(f) Quadtree com blocos mínimos de 32x32 pixels 223 pontos de interesse após o processo de redução

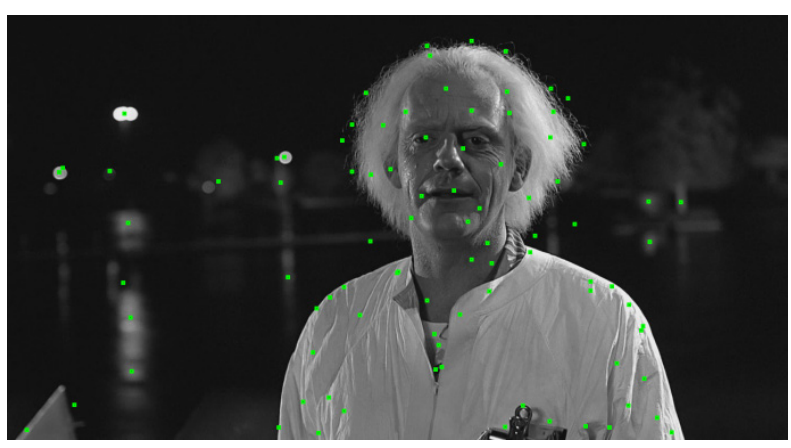

(g) Quadtree com blocos mínimos de 64x64 pixels

91 pontos de interesse após o processo de redução

Figura 18. Comparação entre os pontos de interesse resultantes do processo de redução para diferentes tamanhos mínimos de bloco na técnica Quadtree. Exemplo baseado na Figura 11a. 


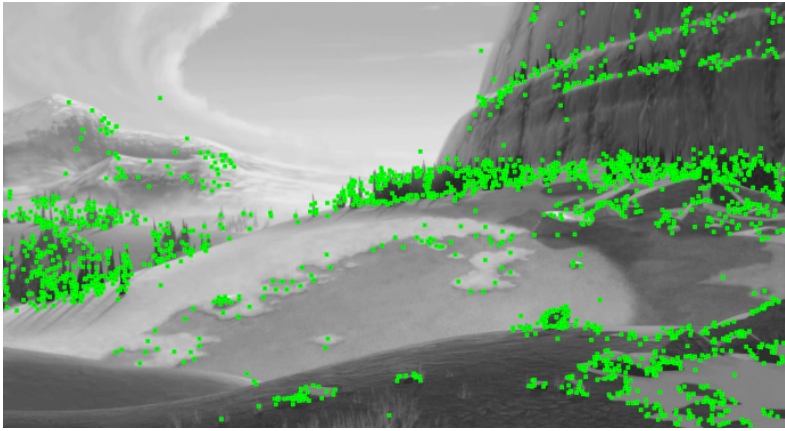

(a) 2271 pontos de interesse obtidos com SIFT (sem redução)

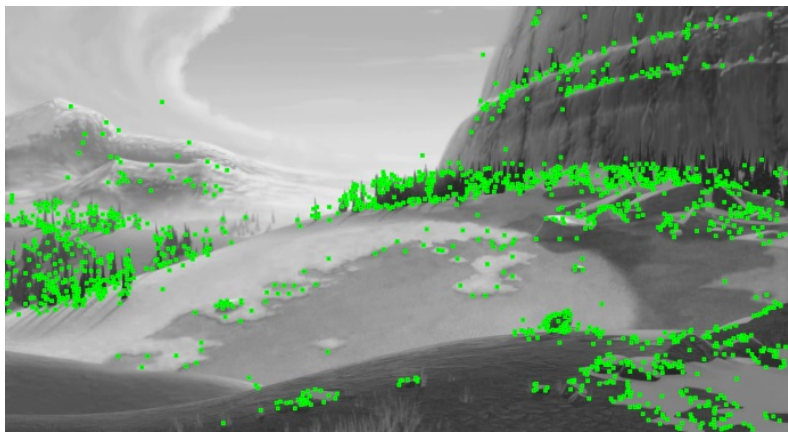

(c) Quadtree com blocos mínimos de 4x4 pixels 1456 pontos de interesse após o processo de redução

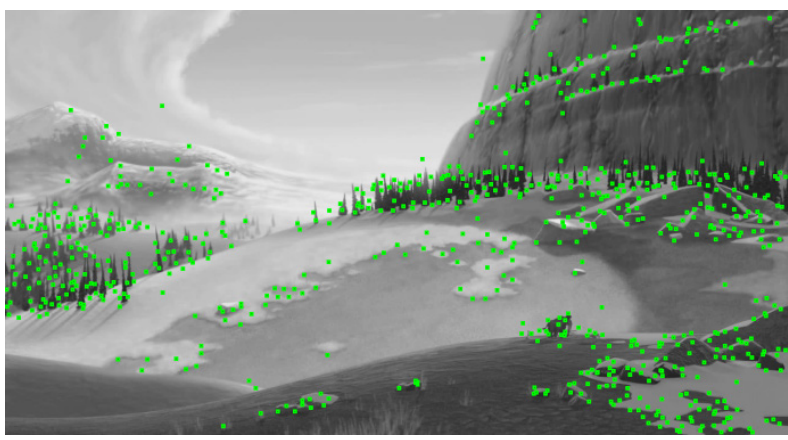

(e) Quadtree com blocos mínimos de 16x16 pixels 727 pontos de interesse após o processo de redução

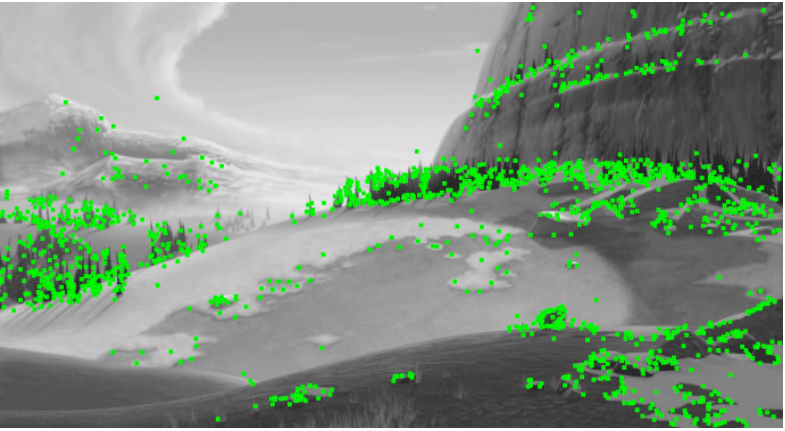

(b) Quadtree com blocos mínimos de 2x2 pixels 1476 pontos de interesse após o processo de redução

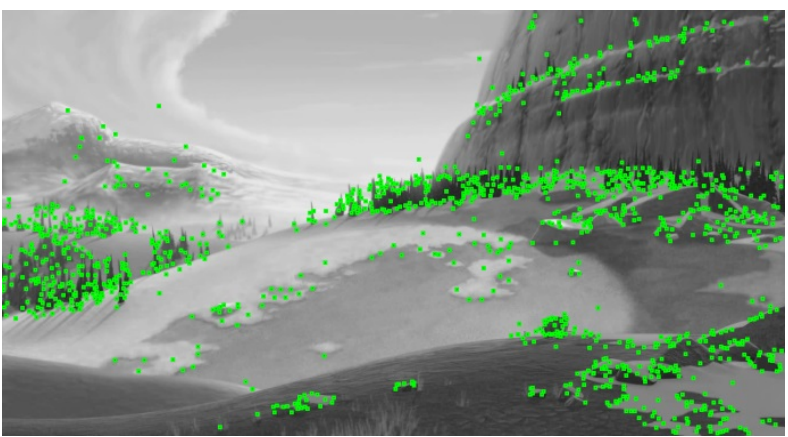

(d) Quadtree com blocos mínimos de 8x8 pixels 1211 pontos de interesse após o processo de redução

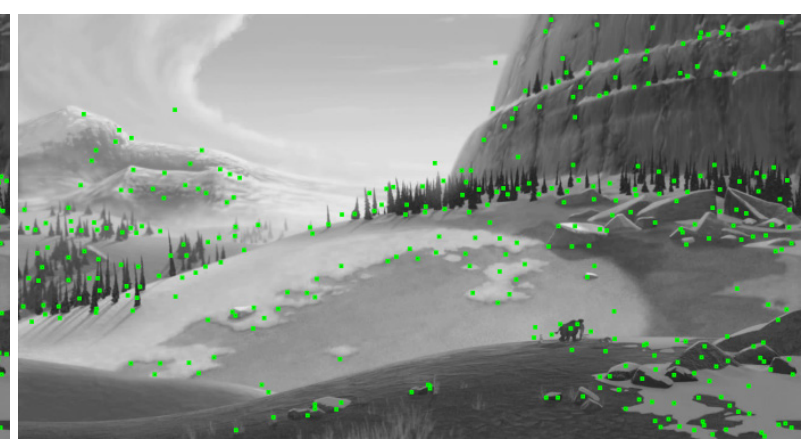

(f) Quadtree com blocos mínimos de 32x32 pixels 340 pontos de interesse após o processo de redução

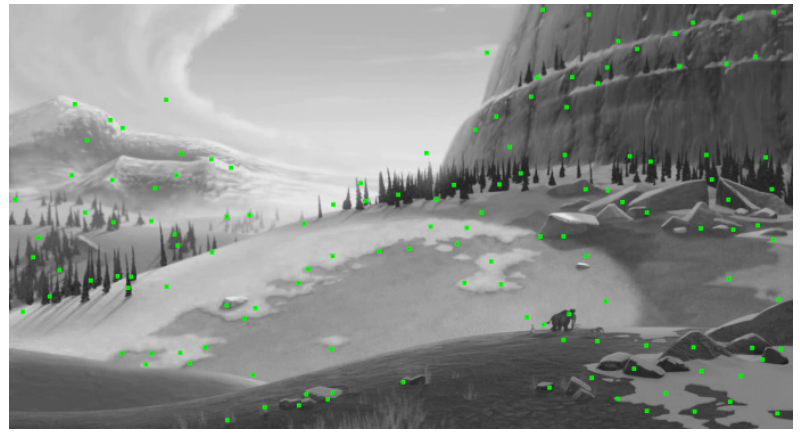

(g) Quadtree com blocos mínimos de 64x64 pixels 135 pontos de interesse após o processo de redução

Figura 19. Comparação entre os pontos de interesse resultantes do processo de redução para diferentes tamanhos mínimos de bloco na técnica Quadtree. Exemplo baseado na Figura 11c. 


\subsubsection{Avaliação de Blocos de $8 \times 8$ e $16 \times 16$ pixels}

A análise visual realizada aponta duas possibilidades de tamanho mínimo de bloco com bons compromissos entre redução de informação e caracterização: 8x8 e 16x16 pixels. Sendo assim, realizou-se um experimento para avaliar o impacto da utilização de cada configuração nos resultados finais obtidos. Para isso, aplicou-se o método Shot-HR nos cinco vídeos da base e realizou-se a segmentação em cenas com a técnica desenvolvida. A única diferença entre os dois testes realizados foi o tamanho mínimo de bloco empregado na Quadtree. A Tabela 4 apresenta os resultados.

Tabela 4. Resultados da segmentação em cenas utilizando-se o método Shot-HR com duas configurações de blocos mínimos para a técnica Quadtree.

\begin{tabular}{|c|c|c|c|c|c|c|}
\hline \multirow{2}{*}{ Filme } & \multicolumn{3}{|c|}{ Blocos mínimos de 8x8 pixels } & \multicolumn{3}{c|}{ Blocos mínimos de 16x16 pixels } \\
\cline { 2 - 7 } & $\mathbf{P ~ ( \% )}$ & $\mathbf{R}(\%)$ & $\mathbf{F 1 ~ ( \% ) ~}$ & $\mathbf{P ~ ( \% ) ~}$ & $\mathbf{R}(\%)$ & F1 (\%) \\
\hline Uma Mente Brilhante & 56 & 56 & 56 & 58 & 52 & 55 \\
\hline A Era do Gelo & 64 & 71 & 67 & 47 & 52 & 49 \\
\hline 60 Segundos & 69 & 47 & 56 & 63 & 42 & 50 \\
\hline Piratas do Caribe & 50 & 52 & 51 & 48 & 52 & 50 \\
\hline De Volta Para o Futuro & 57 & 56 & 57 & 69 & 50 & 58 \\
\hline Média & 59 & 56 & 57 & 57 & 50 & 52 \\
\hline
\end{tabular}

Observando-se os resultados, é possível perceber que o tamanho mínimo de bloco de 8x8 pixels, resulta em uma maior taxa de acertos na segmentação em cenas, na maioria dos casos, com medida F1, em média, 5 pontos percentuais maior. Para o vídeo A Era do Gelo, a diferença na medida F1 chega a 18 pontos percentuais. A única exceção é o filme De Volta Para o Futuro, para o qual os blocos mínimos de 16x16 pixels apresentaram medida F1 superior em 1 ponto percentual. Porém, mesmo nesse caso, é preciso ponderar que a diferença entre os valores de precisão e abrangência obtidos foi significativa. Para alcançar uma maior precisão, a abrangência foi prejudicada e, no contexto de segmentação em cenas, é interessante que ambas as medidas apresentem números elevados. Sendo assim, pode-se concluir que ao utilizar regiões de tamanho mínimo de 16x16 pixels, informações importantes das imagens são descartadas, prejudicando a caracterização das mesmas e impactando negativamente nos resultados finais. Logo, o uso de blocos mínimos de 8x8 pixels mostra-se o mais adequado e os experimentos apresentados nas próximas seções consideram que essa configuração foi utilizada ao aplicar a técnica Quadtree. 


\subsection{Todos os Quadros x Quadros-Chave}

Realizou-se um experimento para determinar se o uso de todos os quadros da tomada no método de representação é imprescindível para a obtenção de bons resultados, ou se valores similares nas medidas de avaliação podem ser alcançados com o uso de menos informações. Para isso, comparou-se o método Shot-HR com o método de seleção de quadros-chave KSSIFT, em três situações, descritas a seguir. Vale ressaltar que, nos casos 2 e 3, apresenta-se uma adaptação do método Shot-HR, combinando algumas de suas fases com o uso de quadros-chave.

- Caso 1:

○ seleção de quadros-chave com o método KS-SIFT;

- extração de características, com o método SIFT, dos quadros-chave selecionados;

Obs.: nenhum processamento adicional visando redução de informações é realizado.

- $\quad$ Caso 2:

○ seleção de quadros-chave com o método KS-SIFT;

- extração de características, com o método SIFT, dos quadros-chave selecionados;

○ emprego da primeira fase do método Shot-HR (Subseção 4.1.1), isto é, redução de características em cada quadro.

- Caso 3:

○ seleção de quadros-chave com o método KS-SIFT;

- extração de características, com o método SIFT, dos quadros-chave selecionados;

○ emprego da primeira fase do método Shot-HR (Subseção 4.1.1), isto é, redução de características em cada quadro;

○ emprego da segunda fase do método Shot-HR (Subseção 4.1.2), isto é, redução de características em cada tomada.

Em todas as configurações do experimento, a medida de similaridade utilizada foi o número de vetores de características correspondentes entre tomadas sucessivas e a segmentação em cenas foi realizada com a técnica descrita na Seção 4.3. 
A Tabela 5 apresenta os resultados do experimento. Primeiramente, analisando-se as diferentes configurações para o uso de quadros-chave, é possível verificar que, de forma geral, o caso 2 apresenta resultados superiores. Com a abordagem de quadros-chave, aplicar a exclusão de vetores de características em dois níveis (caso 3), mostra-se excessivo. Por as imagens terem sido selecionadas previamente, muitos dados que caracterizam a tomada não são redundantes e ao tentar sintetizar a representação, informações importantes são perdidas. Por outro lado, percebe-se que ainda há espaço para refinamento dos vetores de características originalmente obtidos das imagens (caso 1). A redução de informações apenas no interior de cada quadro (caso 2) mostra-se uma vantagem, uma vez que contribui para a compactação da representação e, ao mesmo tempo, aprimoramento dos resultados. Isso indica que encontrar os dados corretos a serem eliminados é um ponto essencial e que um grande volume de vetores de características não é sinônimo de qualidade da representação, pelo contrário, o excesso de informações pode atrapalhar na clareza da caracterização, implicando em perdas nos resultados finais.

Tabela 5. Resultados da segmentação em cenas utilizando-se todos os quadros e quadros-chave no método de representação de tomadas.

\begin{tabular}{|c|c|c|c|c|c|c|c|c|c|c|c|c|}
\hline \multirow{3}{*}{ Filme } & \multirow{2}{*}{\multicolumn{3}{|c|}{$\begin{array}{c}\text { Shot-HR } \\
\text { (Todos os quadros) }\end{array}$}} & \multicolumn{9}{|c|}{ KS-SIFT (Quadros-chave) } \\
\hline & & & & \multicolumn{3}{|c|}{ Caso 1} & \multicolumn{3}{|c|}{ Caso 2} & \multicolumn{3}{|c|}{ Caso 3} \\
\hline & $\begin{array}{l}P \\
(\%)\end{array}$ & $\begin{array}{c}R \\
\text { (\%) }\end{array}$ & $\begin{array}{l}\text { F1 } \\
\text { (\%) }\end{array}$ & $\begin{array}{l}P \\
(\%)\end{array}$ & $\begin{array}{l}R \\
(\%)\end{array}$ & $\begin{array}{l}F 1 \\
(\%)\end{array}$ & $\begin{array}{l}P \\
(\%)\end{array}$ & $\begin{array}{l}R \\
\text { (\%) }\end{array}$ & $\begin{array}{l}\text { F1 } \\
\text { (\%) }\end{array}$ & $\begin{array}{l}P \\
(\%)\end{array}$ & $\begin{array}{c}R \\
\text { (\%) }\end{array}$ & $\begin{array}{l}\text { F1 } \\
\text { (\%) }\end{array}$ \\
\hline Uma Mente Brilhante & 56 & 56 & 56 & 57 & 59 & 58 & 48 & 52 & 50 & 35 & 30 & 32 \\
\hline A Era do Gelo & 64 & 71 & 67 & 40 & 50 & 44 & 44 & 62 & 52 & 37 & 43 & 40 \\
\hline 60 Segundos & 69 & 47 & 56 & 56 & 45 & 50 & 60 & 48 & 53 & 65 & 37 & 47 \\
\hline Piratas do Caribe & 50 & 52 & 51 & 46 & 48 & 47 & 49 & 59 & 54 & 43 & 41 & 42 \\
\hline De Volta Para o Futuro & 57 & 56 & 57 & 54 & 53 & 54 & 58 & 58 & 58 & 42 & 44 & 43 \\
\hline
\end{tabular}

Comparando-se o uso de todos os quadros da tomada com o de quadros-chave, é possível observar que dependendo do vídeo analisado, um ou outro caso mostra-se mais vantajoso. Porém, pode-se afirmar que o emprego de quadros-chave é uma alternativa viável, por ser capaz de atingir resultados similares ou até mesmo superiores à abordagem que considera todos os quadros. Isso mostra que o método KS-SIFT consegue selecionar imagens que descrevem as informações mais importantes da tomada e sua variação de conteúdo. Além disso, tem-se também uma vantagem em termos de custo computacional. 


\subsection{Comparação com a Literatura}

O método de representação de tomadas Shot-HR e também a abordagem baseada em quadros-chave que apresentou os melhores resultados (KS-SIFT - caso 2), foram comparados com três esquemas de caracterização de tomadas encontrados na literatura e discutidos na Seção 3.5: Baber et al. (2011), Chergui et al. (2012) e Tapu e Zaharia (2011a). Esses trabalhos pertencem ao estado da arte e contribuem com resultados importantes para a área de segmentação em cenas. Para realizar o experimento, adotaram-se as estratégias de representação de tomadas presentes em tais trabalhos (implementadas conforme descrito na Seção 5.1) e foram extraídas características, com o método SIFT, dos quadros obtidos. Em todos os casos, considerou-se a mesma medida de similaridade, isto é, o número de vetores de características correspondentes entre tomadas e realizou-se a segmentação em cenas com a técnica apresentada na Seção 4.3. Assim, foi possível comparar o impacto das abordagens de representação de tomadas nos resultados.

Para o método de seleção de quadros-chave de Tapu e Zaharia, em particular, foi necessário ajustar alguns parâmetros. $\mathrm{O}$ primeiro deles foi o tamanho da janela $N$, como discutido na Seção 3.5. Analisando-se a base de vídeos utilizada nos experimentos, concluiuse que o melhor valor para $N$ era 10 , já que alguns dos filmes possuíam tomadas de curta duração, que poderiam não ser representadas se uma janela maior fosse escolhida. Além disso, como o método se baseia no uso de histogramas, seu custo computacional é mais baixo comparado, por exemplo, a um extrator de características locais, logo, não é um problema processar uma quantidade maior de quadros do vídeo. Também foi necessário estabelecer um limiar para definir se a dissimilaridade visual entre quadros era significativa. Nesse caso, determinou-se empiricamente que o valor mais apropriado era 0.3 , isto é, se a distância entre os quadros for maior ou igual a $30 \%$, eles são considerados diferentes. Para isso, selecionaram-se tomadas da base de vídeos utilizada nos experimentos (Seção 5.2) e testou-se um intervalo de $10 \%$ a $90 \%$, analisando os resultados quanto à capacidade de representar a diversidade de conteúdo das tomadas e à repetição de informações nos quadros.

A Figura 20 apresenta exemplos de quadros-chave selecionados com o método de Tapu e Zaharia para três tomadas do filme Uma Mente Brilhante. É possível observar que os parâmetros ajustados fornecem resultados consistentes, uma vez que as imagens selecionadas apresentam dissimilaridade visual e são capazes de capturar certa variedade de conteúdo. 


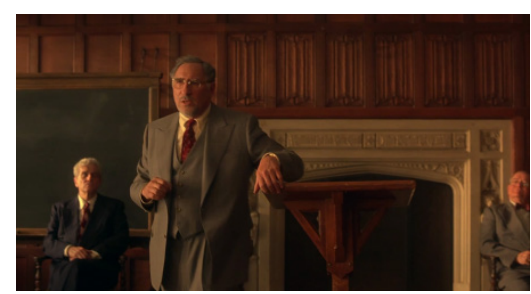

(a)

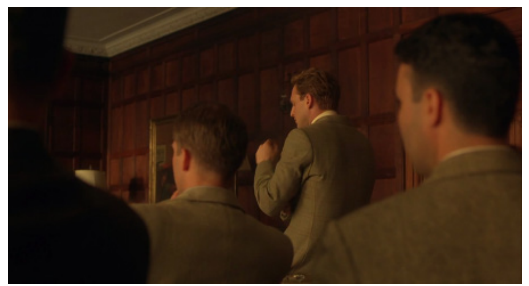

(b)
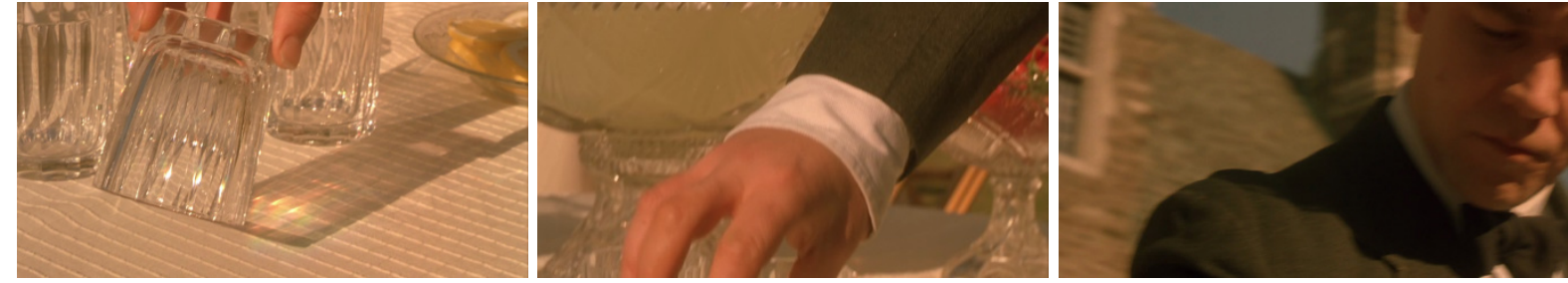

(c)

Figura 20. Exemplos de quadros-chave selecionados utilizando-se o método proposto por Tapu \& Zaharia.

A Tabela 6 mostra os resultados da segmentação em cenas obtidos usando diferentes estratégias para a descrição das tomadas. Analisando-os, é possível observar que os métodos de representação propostos apresentam desempenho superior às abordagens encontradas na literatura. A caracterização que utiliza todos os quadros (Shot-HR) consegue atingir medida F1, em média, 12 pontos percentuais superior em comparação às da literatura e a estratégia baseada em quadros-chave desenvolvida (KS-SIFT - caso2) apresenta medida F1, em média, 8 pontos percentuais mais alta.

Tabela 6. Resultados da segmentação em cenas utilizando-se os métodos de representação de tomadas propostos e abordagens encontradas na literatura.

\begin{tabular}{|c|c|c|c|c|c|c|c|c|c|c|c|c|c|c|c|}
\hline \multirow{3}{*}{ Filme } & \multicolumn{6}{|c|}{ Métodos Propostos } & \multicolumn{9}{|c|}{ Literatura } \\
\hline & \multicolumn{3}{|c|}{ Shot-HR } & \multicolumn{3}{|c|}{$\begin{array}{c}\text { KS-SIFT } \\
\text { caso } 2\end{array}$} & \multicolumn{3}{|c|}{ Baber et al. } & \multicolumn{3}{|c|}{ Chergui et al. } & \multicolumn{3}{|c|}{ Tapu \& Zaharia } \\
\hline & $\begin{array}{c}P \\
(\%)\end{array}$ & $\begin{array}{c}R \\
(\%)\end{array}$ & $\begin{array}{l}\text { F1 } \\
(\%)\end{array}$ & $\begin{array}{c}P \\
(\%)\end{array}$ & $\begin{array}{c}R \\
(\%)\end{array}$ & $\begin{array}{l}\text { F1 } \\
(\%)\end{array}$ & $\begin{array}{c}P \\
(\%)\end{array}$ & $\begin{array}{c}R \\
(\%)\end{array}$ & $\begin{array}{l}\text { F1 } \\
\text { (\%) }\end{array}$ & $\begin{array}{c}P \\
(\%)\end{array}$ & $\begin{array}{c}R \\
(\%)\end{array}$ & $\begin{array}{l}\text { F1 } \\
\text { (\%) }\end{array}$ & $\begin{array}{c}P \\
(\%)\end{array}$ & $\begin{array}{c}R \\
(\%)\end{array}$ & $\begin{array}{l}\text { F1 } \\
\text { (\%) }\end{array}$ \\
\hline $\begin{array}{c}\text { Uma Mente } \\
\text { Brilhante }\end{array}$ & 56 & 56 & 56 & 48 & 52 & 50 & 53 & 37 & 44 & 39 & 44 & 41 & 42 & 41 & 42 \\
\hline $\begin{array}{l}\text { A Era do } \\
\text { Gelo }\end{array}$ & 64 & 71 & 67 & 44 & 62 & 52 & 46 & 62 & 53 & 42 & 52 & 47 & 47 & 57 & 52 \\
\hline $\begin{array}{c}60 \\
\text { Segundos }\end{array}$ & 69 & 47 & 56 & 60 & 48 & 53 & 47 & 37 & 41 & 58 & 42 & 49 & 52 & 39 & 45 \\
\hline $\begin{array}{l}\text { Piratas do } \\
\text { Caribe }\end{array}$ & 50 & 52 & 51 & 49 & 59 & 54 & 38 & 41 & 39 & 40 & 48 & 44 & 46 & 54 & 50 \\
\hline $\begin{array}{c}\text { De Volta Para } \\
\text { o Futuro }\end{array}$ & 57 & 56 & 57 & 58 & 58 & 58 & 53 & 44 & 48 & 46 & 44 & 45 & 41 & 39 & 40 \\
\hline
\end{tabular}


Além disso, em especial para o método Shot-HR, é possível observar que se atingem valores similares de precisão e abrangência. Tal comportamento é relevante, uma vez que tão importante quanto identificar somente transições de cenas corretas é garantir que todas as cenas da base confiável sejam cobertas. Os resultados com o filme 60 Segundos não respeitam esse padrão, mas isso pode ser explicado pelas características do vídeo. Esse filme possui muitas cenas curtas consecutivas, compostas por apenas uma tomada, as quais são mais difíceis de serem identificadas por uma técnica de segmentação simples, como a utilizada. Porém, ressalta-se que o objetivo do experimento é avaliar a representação de tomadas e não a segmentação em cenas.

Considerando-se as abordagens baseadas em quadros-chave pertencentes ao estado da arte, não é evidente um padrão de comportamento. Algumas delas provêm resultados melhores para alguns vídeos, mas piores para outros e, de forma geral, as medidas de avaliação obtidas nos três casos são similares.

Pode-se afirmar que o método de seleção de quadros-chave tem um papel fundamental na qualidade da caracterização obtida. Os resultados indicam que o uso de apenas um quadro (Baber et al. e Chergui et al.) não é suficiente para representar a variedade de conteúdo presente em uma tomada e informações semanticamente relevantes são perdidas. Além disso, mesmo ao utilizar um conjunto de quadros-chave (Tapu e Zaharia), é importante que o método de seleção seja capaz de escolher imagens que sintetizem o conteúdo mais relevante da tomada. As Figuras 15 e 20 exemplificam a diferença na qualidade das imagens obtidas, sendo que o método KS-SIFT (Figura 15) é capaz de descrever melhor as informações presentes na tomada e o seu desenvolvimento, já que elementos diferentes podem ser observados em cada quadro-chave selecionado. Além disso, pode-se verificar que, na Figura 20 (Tapu e Zaharia), há ações não representadas. Isso se reflete nos resultados da detecção de cenas.

Também é possível comprovar que valores altos de precisão e abrangência reportados pelas técnicas de segmentação em cenas que utilizam um dos três tipos de representação de tomadas pertencentes ao estado da arte e avaliados nesse experimento, devem-se a melhorias ou heurísticas aplicadas ao processo de segmentação e não à qualidade da caracterização de tomadas, como esperado. Assim, dados os resultados dos experimentos, evidencia-se que a caracterização de tomadas proposta tem potencial para melhorar o desempenho de técnicas de segmentação em cenas. 


\subsection{Análise de Tempo de Processamento}

Além da qualidade dos resultados, analisou-se também o tempo de processamento para a obtenção das representações de tomadas com cada um dos métodos. Foram selecionadas aleatoriamente 50 tomadas da base de vídeos e os testes foram realizados em um computador com processador Intel Core i5 - 3.1GHz, memória RAM de $8 \mathrm{~GB}$ e sistema operacional Windows 8. Os tempos analisados foram medidos em segundos, adicionando-se aos códigos desenvolvidos as funções $\operatorname{clock}($ ) e etime(), disponíveis nas bibliotecas padrão da ferramenta MATLAB.

Primeiramente, mediu-se o tempo gasto com cada processo realizado nas duas primeiras fases do método Shot-HR. O Gráfico 2 apresenta os resultados para a primeira fase, isto é, extração e redução de características em cada quadro e o Gráfico 3 os resultados para a segunda fase, que consiste na redução de informações em cada tomada.

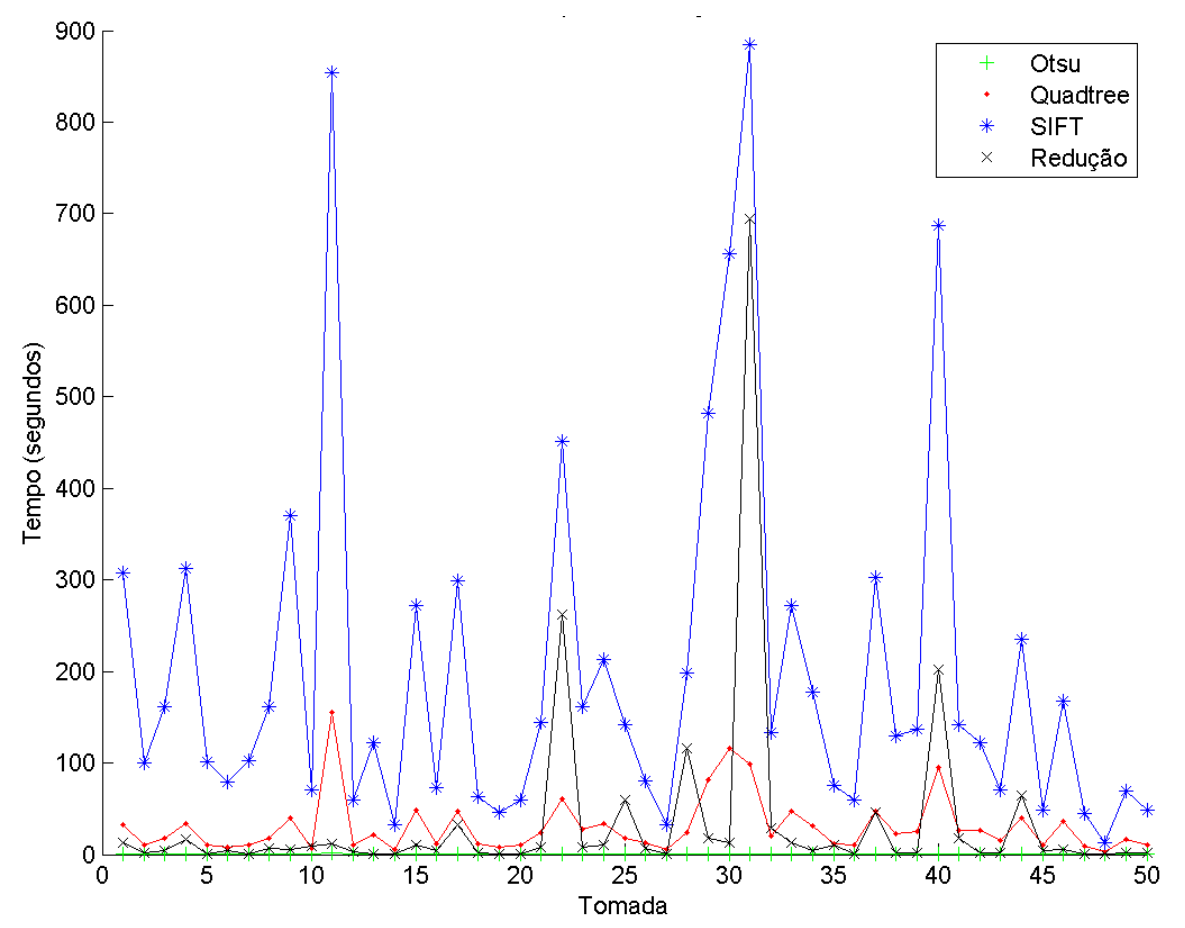

Gráfico 2. Comparação entre os tempos de execução de cada processo na fase de extração e redução de características nos quadros.

Analisando-se o Gráfico 2, é possível perceber que a etapa que demanda mais tempo é a extração de características com o método SIFT, cujo tempo de processamento corresponde a, em média, $71 \%$ do tempo total requerido pela primeira fase do método Shot-HR. Como o processamento com Otsu-Quadtree e a obtenção dos vetores de características são aplicados à 
imagem original, esses processos podem ser realizados em paralelo. Logo, pode-se verificar que segmentar os quadros não é um problema, já que o tempo gasto pela extração de características é, em média, 6.5 vezes superior ao tempo dos métodos Otsu e Quadtree somados.

Além disso, também é possível observar alguns picos nos tempos obtidos na etapa de redução de informações que, em alguns casos, aproximam-se do tempo necessário à extração de características. Isso acontece porque, para cada bloco resultante da técnica Quadtree, realiza-se uma busca pelos pontos de interesse presentes em seu interior, mantendo-se apenas um. Logo, quanto maior o número de regiões obtidas com a segmentação, maior é o tempo necessário para a conclusão desse processo. Por exemplo, no Gráfico 2, a tomada 31, que apresentou o tempo de redução mais elevado no teste realizado (695 segundos), possui, em média, por imagem, 9707 blocos de tamanho 9x9 pixels gerados pela Quadtree, enquanto a tomada 11, que apresenta uma redução rápida (12 segundos), possui, em média, por imagem, 1426 regiões de tamanho $16 \times 16$ pixels.

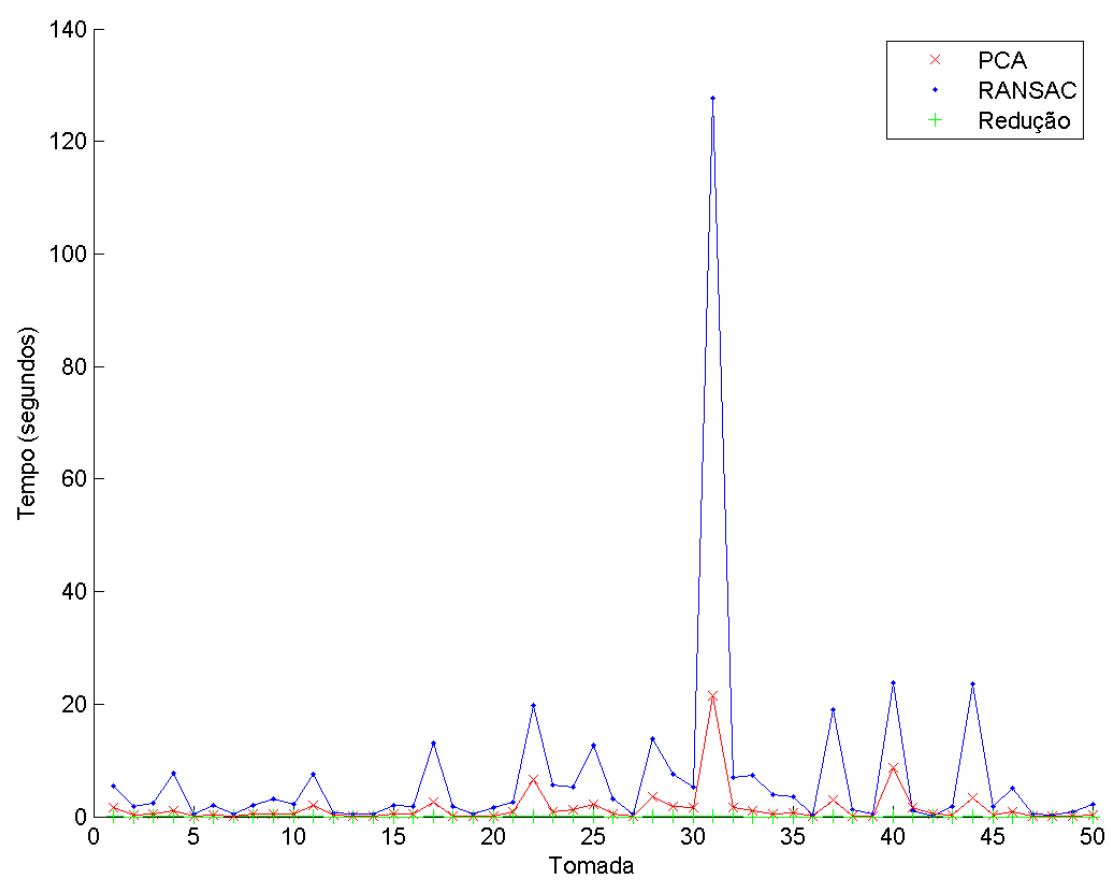

Gráfico 3. Comparação entre os tempos de execução de cada processo na fase de redução de características nas tomadas.

Já para o Gráfico 3, pode-se verificar que o RANSAC é o método que demanda mais tempo de processamento, em média, 4.8 vezes superior ao do PCA e do processo de redução unidos. Porém, é importante destacar que, comparativamente ao SIFT, o custo do RANSAC é baixo, isto é, em média, 27.5 vezes menor. 
O Gráfico 4 apresenta uma comparação entre os tempos totais de execução de cada uma das fases do método Shot-HR. Os valores indicados abrangem, além das técnicas avaliadas separadamente nos gráficos anteriores, outras operações necessárias, como leitura e gravação de dados em arquivo, carregamento da imagem, inicializações, entre outras. A fase 1 corresponde à extração e redução de características em cada quadro, a fase 2 à eliminação de informações em cada tomada e a fase 3 à identificação dos vetores correspondentes entre tomadas sucessivas. Analisando-se o Gráfico 4 fica evidente que o custo de processamento concentra-se na primeira fase, com tempos de, em média, 282 segundos por tomada e deve-se principalmente ao método SIFT, como já discutido. As fases 2 e 3 apresentam tempos similares e mais baixos, em média, 17 e 14 segundos por tomada, respectivamente.

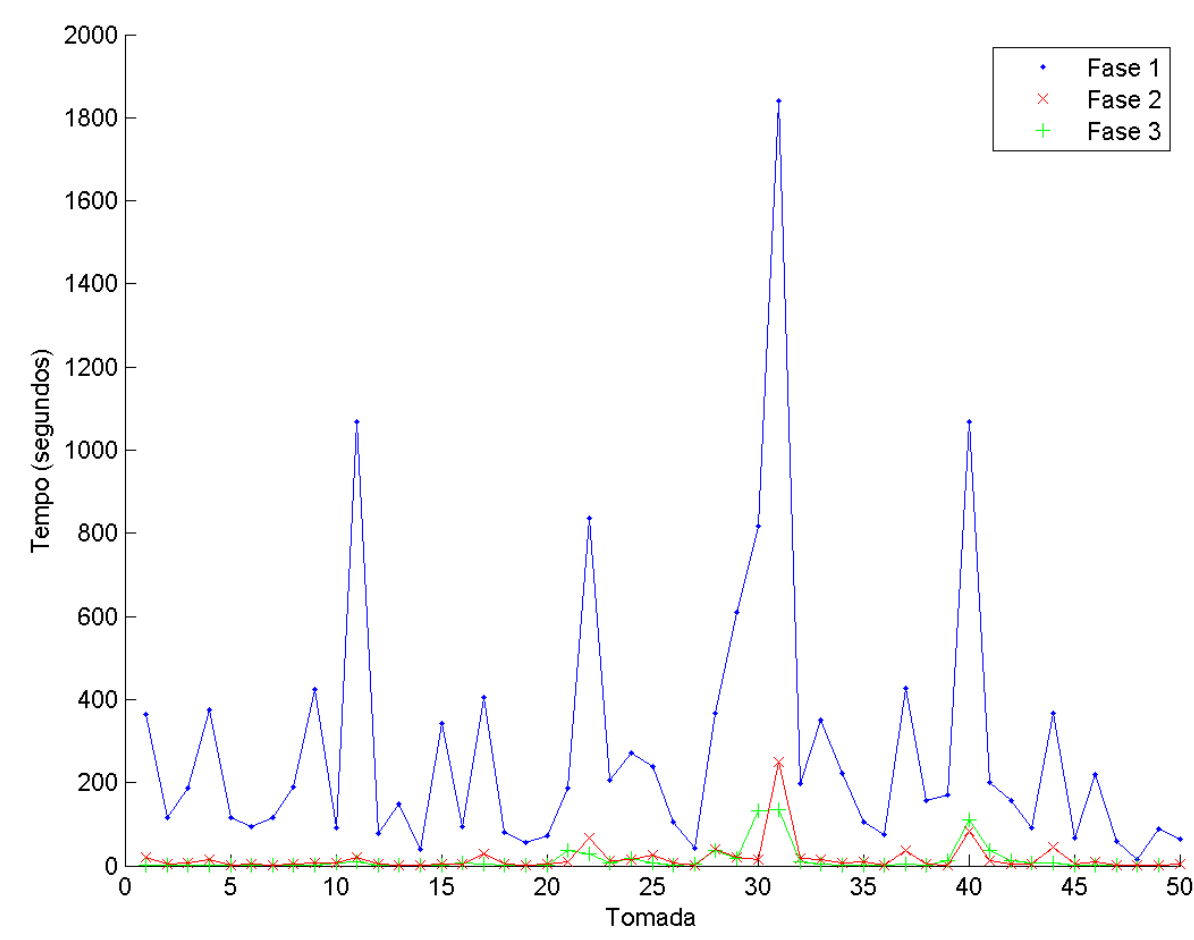

Gráfico 4. Comparação do tempo de execução das três fases do método Shot-HR.

Além disso, verificou-se o tempo necessário para a obtenção da representação de tomadas utilizando-se os métodos baseados em quadros-chave. Os Gráficos 5, 6, 7 e 8 apresentam os resultados para o método KS-SIFT, método de Chergui et al., Baber et al. e Tapu e Zaharia, respectivamente. Nos gráficos, a legenda "Representação" indica o tempo gasto para a seleção de quadros-chave e extração de características utilizando SIFT e o termo "Match" refere-se ao processo de identificação de vetores correspondentes entre tomadas sucessivas. Vale mencionar que, para o método KS-SIFT, avaliou-se o tempo de processamento do caso com os melhores resultados, isto é, extração de características combinada com redução de 
informações em cada quadro (caso 2 - Seção 5.4). Logo, nessa situação, o termo "Representação" inclui também o tempo necessário ao processo de redução de características nas imagens.

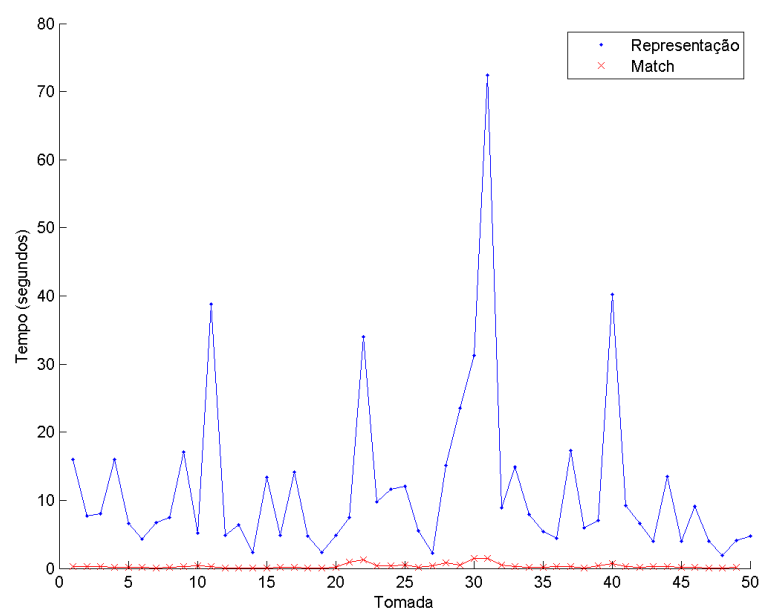

Gráfico 5. Tempos de execução para o método KS-SIFT (caso 2)

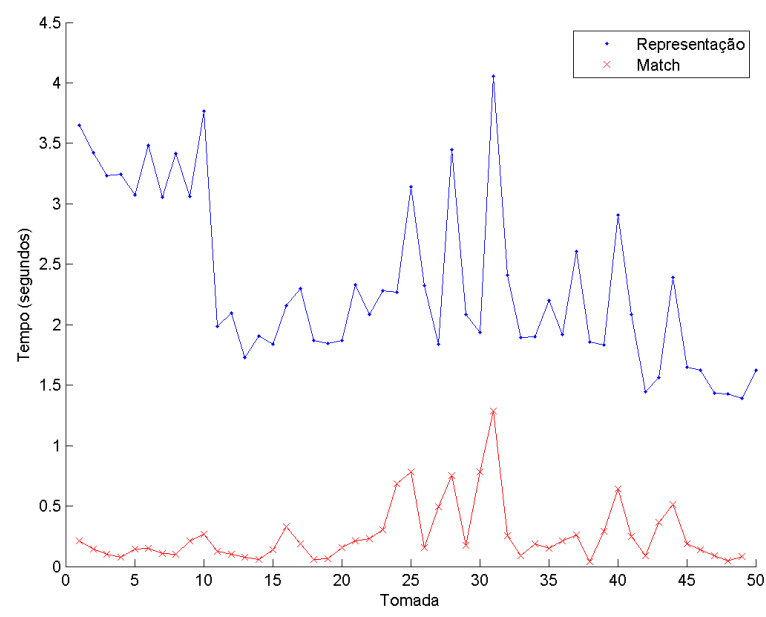

Gráfico 7. Tempos de execução para o método de Baber et al.

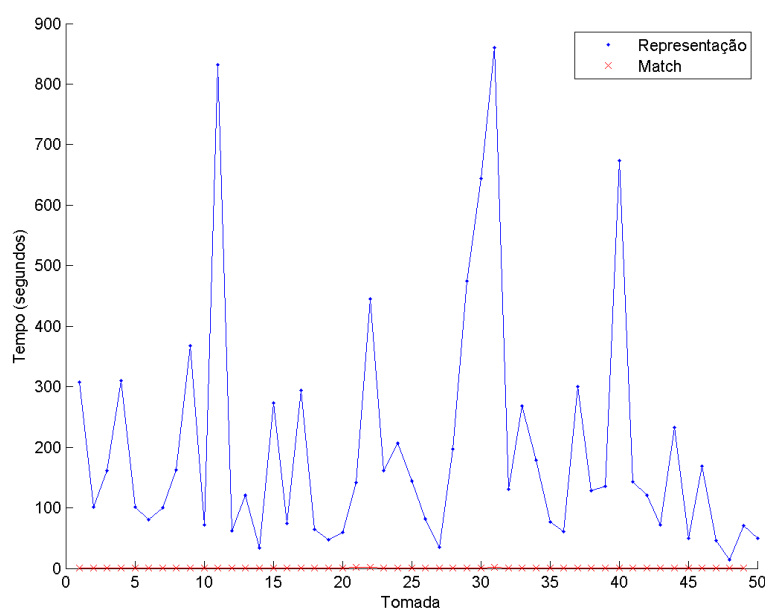

Gráfico 6. Tempos de execução para o método de Chegui et al.

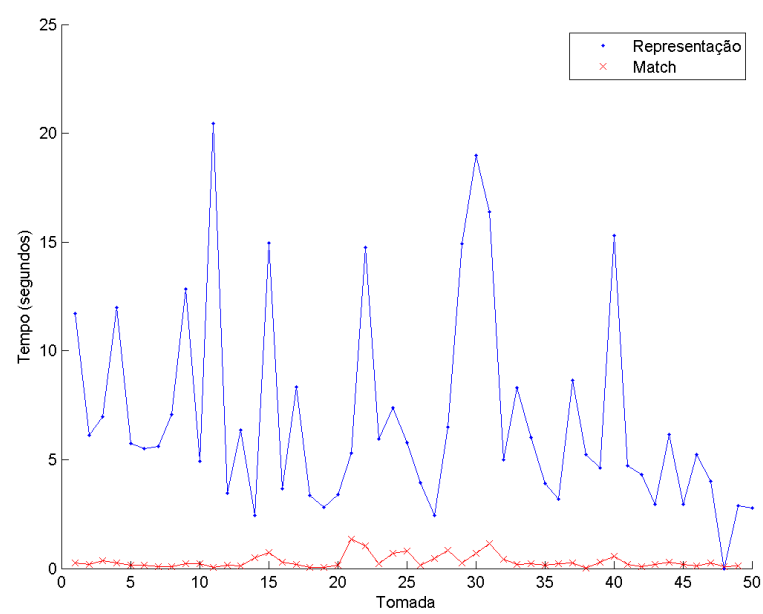

Gráfico 8. Tempos de execução para o método de Tapu e Zaharia

A análise dos Gráficos 5 a 8 permite concluir que, para todos os métodos analisados, o tempo necessário para a obtenção da representação de tomadas é superior ao tempo gasto com a medida de similaridade. Percebe-se ainda que, apesar de todas as abordagens serem baseadas em quadros-chave, elas possuem custos diferentes, sendo o método de Baber et al. o mais eficiente. Porém, vale lembrar que tal método é também o mais simples, por considerar como representante da tomada seu quadro mediano. 


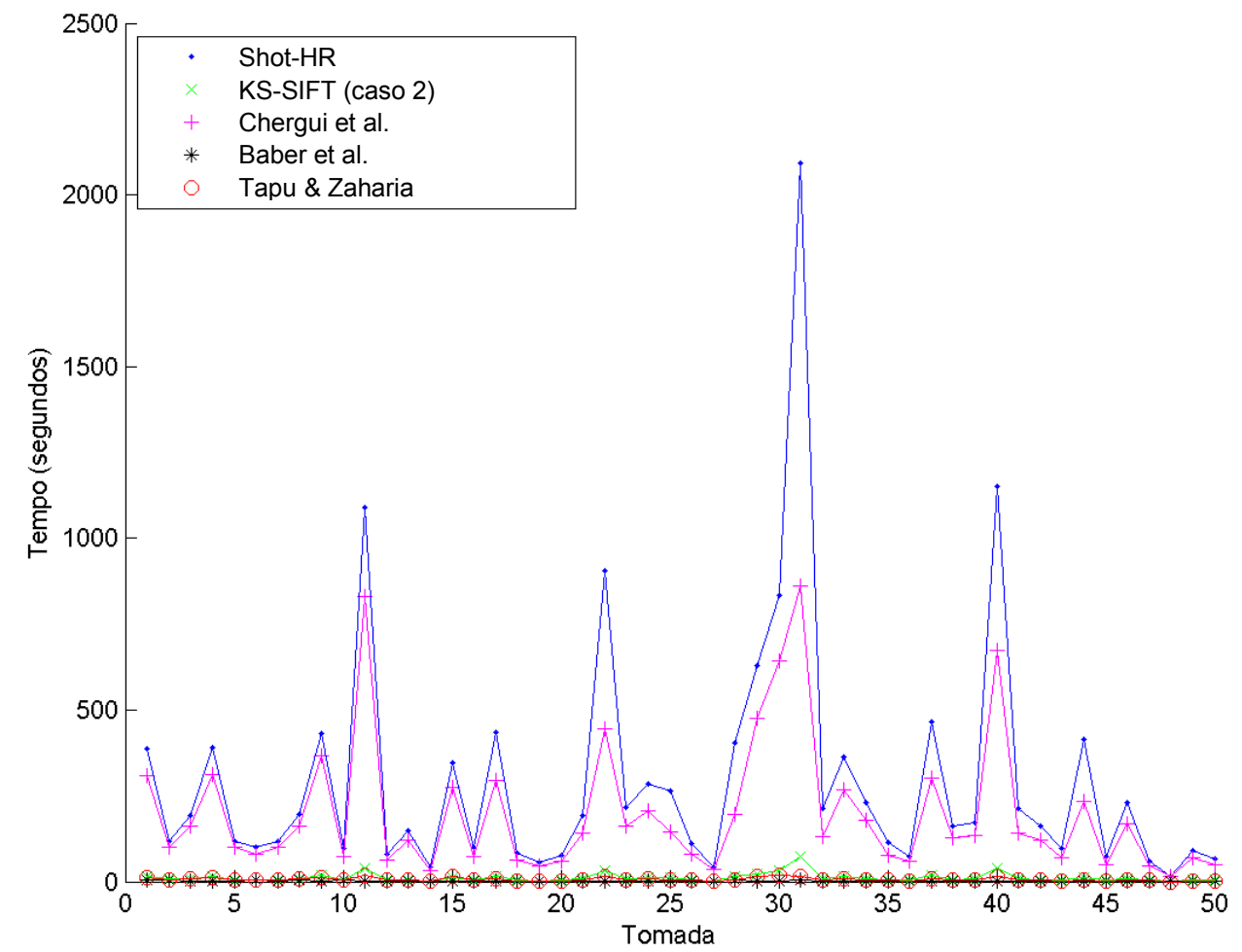

(a) Tempos de execução dos métodos de representação de tomadas propostos e dos métodos da literatura.

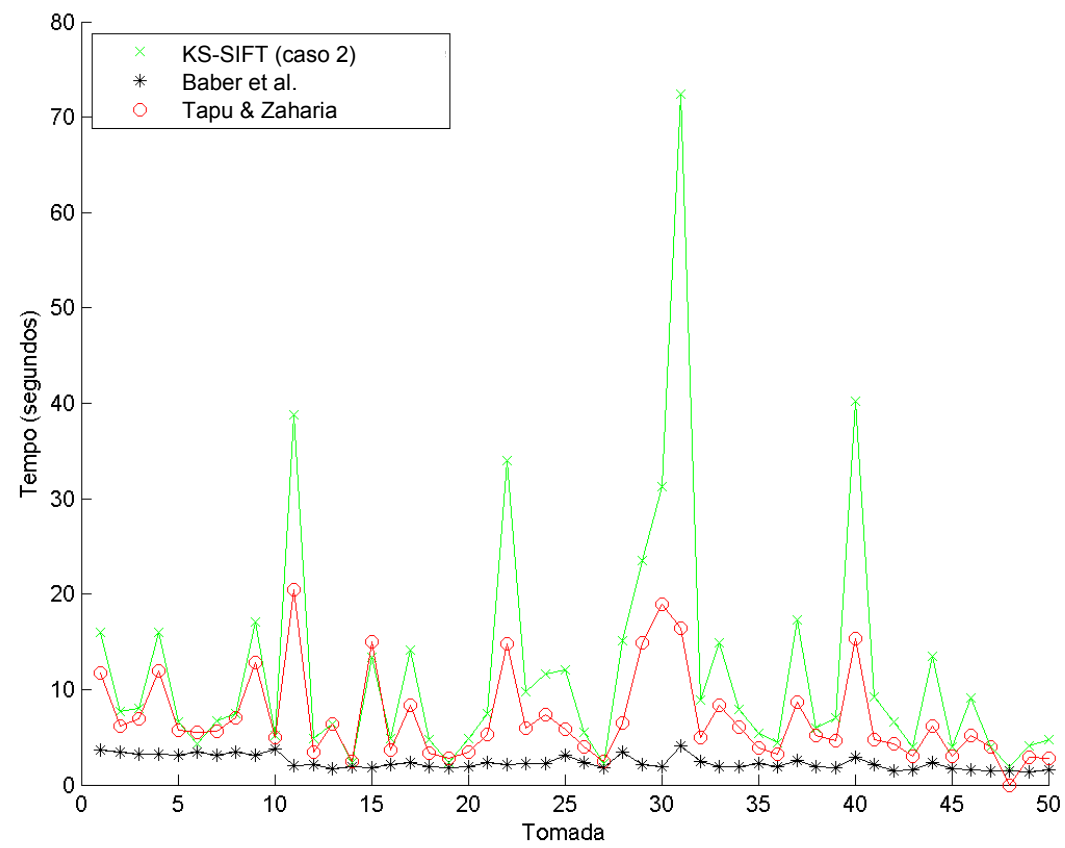

(b) Zoom-in nos dados dos métodos de menor tempo de execução.

Gráfico 9. Comparação entre os tempos de execução de diferentes métodos de representação de tomadas. 
O Gráfico 9 apresenta uma comparação entre os métodos utilizados quanto ao tempo para a obtenção das representações de tomadas. Nesse caso, não se considerou o tempo gasto com a medida de similaridade. Para o método Shot-HR, o tempo engloba as fases 1 e 2 (extração e redução de características em cada quadro e redução de informações em cada tomada) e para o método KS-SIFT (caso 2), engloba o processo de seleção, extração de características e redução de informações nas imagens. No caso das estratégias da literatura, o valor correponde ao processo de seleção de quadros-chave e extração de características.

Observando-se o Gráfico 9 é possível perceber que o método Shot-HR é o que apresenta o maior custo em termos de tempo. Isso porque exige o processamento de um grande volume de dados, porém, como discutido nas Seções 5.4 e 5.5, é capaz de prover bons resultados aplicado à segmentação em cenas. O método de Chergui et al. apesar de ser baseado no uso de quadros-chave também apresenta um custo elevado e, em alguns casos, comparável ao emprego de todas as imagens. Tal fato pode ser explicado pelo processo de seleção desenvolvido pelos autores. A identificação do quadro-chave é feita pela análise do número de pontos de interesse, logo, apesar de não utilizar informações de todas as imagens, todas são processadas com um extrator de características locais.

O método de Baber et al. apresenta baixo custo, com tempos de execução de, em média, 2 segundos por tomada, o que se deve principalmente à sua simplicidade, como discutido anteriormente. A abordagem de Tapu e Zaharia também se encontra entre as mais eficientes computacionalmente, com tempos de, em média, 7 segundos por tomada. Isso se justifica pelo processo de seleção ser baseado em histogramas, que possuem menor custo de processamento, sendo que características locais são extraídas somente dos quadros já escolhidos. Por fim, o método KS-SIFT (caso 2) apresenta tempos de, em média, 12 segundos por tomada, possuindo custo superior à estratégia de Tapu e Zaharia, porém muito inferior à de Chergui et al. (tempo médio de 199 segundos por tomada) e ao método Shot-HR (tempo médio de 299 segundos por tomada), sendo que seu processo de seleção utiliza-se de características extraídas com SIFT. Além disso, vale destacar que a grande vantagem do método de quadros-chave desenvolvido é conseguir reduzir os custos de tempo, mantendo-se a qualidade da representação obtida.

Avaliou-se também o tempo necessário para realizar a segmentação em cenas, utilizandose as representações resultantes dos diferentes métodos e o número de vetores de características correspondentes como medida de similaridade. A Tabela 7 apresenta os resultados. Pode-se perceber que a técnica desenvolvida é eficiente em termos de tempo 
computacional, realizando a segmentação em 0.046 segundos, em média. Esse processo mostra-se 44 vezes mais eficiente que o método mais rápido de representação de tomadas (Baber et al.). Porém, como já discutido, trata-se de uma técnica de segmentação em cenas simples, ou seja, que não apresenta heurísticas ou informações de domínio, mas que por esse mesmo motivo, mostra-se uma opção viável para comparações de diferentes métodos de representação.

Tabela 7. Tempos para a realização da segmentação em cenas.

\begin{tabular}{cc}
\hline Método de Representação & Tempo (segundos) \\
\hline Shot-HR & 0.078 \\
KS-SIFT (caso 2) & 0.038 \\
\hline Chergui et al. & 0.037 \\
Baber et al. & 0.040 \\
Tapu \& Zaharia & 0.036 \\
\hline
\end{tabular}

\subsection{Considerações Finais}

Este capítulo apresentou os resultados dos experimentos realizados, no contexto de segmentação em cenas, para avaliar a qualidade e o tempo de processamento dos métodos de representação de tomadas propostos comparados a abordagens da literatura. Pode-se concluir que o método Shot-HR apresenta resultados superiores às estratégias consideradas estado da arte e, em média, superiores também ao método KS-SIFT, porém possui o maior tempo de processamento. Logo, a abordagem baseada em quadros-chave proposta mostra-se uma alternativa, por superar às da literatura em termos de qualidade e destacar-se quanto ao tempo de execução. Algumas estratégias estado da arte, como a de Baber et al. ou de Tapu e Zaharia apresentam tempo de processamento ainda inferior ao método KS-SIFT (caso 2), porém com perdas na qualidade da representação. 


\section{Capítulo 6: Conclusões}

O objetivo deste trabalho é o desenvolvimento de um método de representação de tomadas, que possibilite aprimorar a caracterização das mesmas ao lidar com problemas identificados em trabalhos relacionados, isto é, representatividade e volume de dados. Tal objetivo foi alcançado, já que, como demonstrado no Capítulo 5, os métodos propostos superam as abordagens consideradas estado da arte. Para endereçar os problemas mencionados anteriormente, desenvolveram-se dois métodos: Shot-HR, baseado no emprego de todos os quadros da tomada e KS-SIFT, que visa a identificação de quadros-chave. Para o método Shot-HR, propôs-se utilizar o extrator SIFT e selecionar os vetores de características mais relevantes para a representação, realizando-se redução de informações em dois níveis: quadro e tomada. Para o método KS-SIFT, a estratégia adotada também se baseia no uso de SIFT, porém para a seleção dos quadros que melhor representam o conteúdo de uma tomada. Os resultados comparativos, no domínio de segmentação em cenas, evidenciaram que o uso de um conjunto maior que um ou poucos quadros é importante para a construção de uma representação relevante. Além disso, demonstraram que as estratégias propostas são viáveis: no caso do método Shot-HR, superando as abordagens da literatura em 12 pontos percentuais, apesar do maior custo de processamento e, para o melhor caso do experimento realizado com o método KS-SIFT, apresentando desempenho 8 pontos percentuais superior às estratégias consideradas estado da arte, com tempo de execução similar.

\subsection{Contribuições}

Como principal contribuição do trabalho realizado tem-se o método Shot-HR, que lida com os problemas de representatividade e volume de dados, aperfeiçoando a caracterização das tomadas. Ainda como contribuições diretas da pesquisa têm-se: o método de seleção de quadros-chave KS-SIFT, que apresenta desempenho superior a abordagens da literatura, ao selecionar quadros capazes de representar a diversidade de conteúdo em uma tomada; e a 
técnica de segmentação em cenas proposta, que apesar de não apresentar heurísticas que aprimorem os resultados é uma ferramenta importante para a realização de experimentos que comparam diferentes métodos de caracterização de tomadas.

De maneira abrangente, pode-se dizer que o método de representação pode contribuir com a área de Personalização de Conteúdo ao evidenciar que a caracterização de tomadas ainda é um problema em aberto e seu aprimoramento tem potencial para melhorar a qualidade dos resultados obtidos com técnicas de segmentação em cenas. Apesar de diversas técnicas relacionadas utilizarem estratégias simples de caracterização com foco no processo de segmentação, mostrou-se que com uma representação de tomadas bem planejada é possível diminuir a complexidade das técnicas de segmentação em cenas, com potencial para superar os resultados presentes na literatura.

Além disso, o trabalho contribuiu para aprimorar os conhecimentos do grupo de pesquisa SWMI na área de representação de tomadas e segmentação em cenas. Os métodos propostos podem ser aproveitados por trabalhos sendo desenvolvidos por outros alunos e diversos resultados provenientes desta pesquisa fazem parte de materiais didáticos utilizados em disciplinas do ICMC.

Os resultados parciais obtidos neste trabalho resultaram em um artigo (Souza \& Goularte, 2013) publicado e apresentado no SAC (Symposium on Applied Computing) 2013, evento Qualis A1 e em um artigo (Barbieri \& Goularte, 2014) aceito para publicação no ISM (International Symposium on Multimedia) 2014, evento Qualis B2. Submeteu-se também um artigo ao SAC 2015 e outro está em desenvolvimento, com os resultados completos, para ser submetido a um journal da área.

Além disso, o desenvolvimento do trabalho possibilitou que a autora obtivesse uma maior familiaridade com a área de pesquisa e pudesse se preparar para um doutorado. A autora também ganhou experiência em docência, com dois estágios PAE (Programa de Aperfeiçoamento de Ensino) realizados. Os estágios foram desenvolvidos $\operatorname{nos} 1^{\mathrm{o}}$ e $2^{\mathrm{o}}$ semestres de 2013, respectivamente nas disciplinas Introdução à Ciência da Computação e Multimídia e Hipermídia, ambos sob supervisão do Prof. Dr. Rudinei Goularte. Essa experiência foi importante para se vivenciar e entender melhor a vida acadêmica, sendo fundamental para quem deseja seguir na área. 


\subsection{Limitações}

Uma limitação do trabalho desenvolvido é o tempo de execução do método de representação de tomadas Shot-HR. Além disso, tem-se o fato de ter sido empregada uma técnica simples para a segmentação em cenas. Melhores resultados poderiam ser obtidos com técnicas mais elaboradas. Porém, vale destacar que a decisão de não investir esforços nesse aspecto baseou-se no objetivo do trabalho, que era o desenvolvimento de um método de representação de tomadas, sendo a segmentação em cenas utilizada com propósitos de avaliação. Também se pode citar como limitação, o fato do método de representação ter sido avaliado apenas no contexto de segmentação em cenas. Aplicá-lo em outras tarefas poderia mostrar sua qualidade de maneira mais abrangente.

\subsection{Trabalhos Futuros}

O trabalho desenvolvido apresenta diversas oportunidades de pesquisa a serem exploradas em trabalhos futuros. A primeira delas é implementar de maneira paralela o método de representação de tomadas Shot-HR. Isso pode contribuir com grandes ganhos em termos de tempo de processamento. Pode-se também utilizar outro extrator de características visuais locais dos quadros do vídeo, em substituição ao SIFT. Outra possibilidade é, ao invés de utilizar o RANSAC, empregar outras técnicas ou desenvolver um método para seleção dos vetores de características mais relevantes para caracterizar cada tomada. Também se pode verificar se o uso de outras medidas de similaridade seria mais vantajoso.

É possível ainda desenvolver uma técnica de segmentação em cenas mais elaborada, visando aprimorar os resultados obtidos nesse contexto ou aplicar o método de representação proposto a técnicas de segmentação reportadas na literatura e consideradas estado da arte. Por fim, pode-se avaliar a abordagem de caracterização desenvolvida de maneira mais abrangente, aplicando-a em outros domínios, como sumarização de vídeo. 


\section{Referências Bibliográficas}

(Adomavicius \& Tuzhilin, 2005)

(Al-Hames et al., 2006)

(Almeida et al., 2012)

(Baber et al., 2011)

(Baber et al., 2013)

(Baeza-Yates \&

Ribeiro-Neto, 2008)

(Barbieri \& Goularte, 2014)

(Barrios et al., 2005)
Adomavicius, G., \& Tuzhilin, A. (2005). Toward the next generation of recommender systems: a survey of the state-of-the-art and possible extensions. Knowledge and Data Engineering, IEEE Transactions on, 17(6), 734-749. doi:10.1109/TKDE.2005.99

Al-Hames, M., Zettl, S., Wallhoff, F., Reiter, S., Schuller, B., \& Rigoll, G. (2006). A Two-Layer Graphical Model for Combined Video Shot and Scene Boundary Detection. In Multimedia and Expo, 2006 IEEE International Conference on (pp. 261-264). doi:10.1109/ICME.2006.262432

Almeida, J., Leite, N. J., \& Torres, R. D. S. (2012). Online video summarization on compressed domain. Journal of Visual Communication and Image Representation, 1-10. doi:10.1016/j.jvcir.2012.01.009

Baber, J, Afzulpurkar, N., \& Bakhtyar, M. (2011). Video segmentation into scenes using entropy and SURF. In Emerging Technologies (ICET), 2011 7th International Conference on (pp. 1-6). doi:10.1109/ICET.2011.6048496

Baber, Junaid, Satoh, S., Afzulpurkar, N., \& Keatmanee, C. (2013). Bag of Visual Words Model for Videos Segmentation into Scenes. In Proceedings of the Fifth International Conference on Internet Multimedia Computing and Service (pp. 191-194). New York, NY, USA: ACM. doi:10.1145/2499788.2499814

Baeza-Yates, R., \& Ribeiro-Neto, B. (2008). Modern Information Retrieval (2nd ed.). USA: Addison-Wesley Publishing Company.

Barbieri, T. T. S., \& Goularte, R. (2014). KS-SIFT: a keyframe extraction method based on local features. In Proceedings of IEEE International Symposium on Multimedia (pp. 1-5). Taichung, Taiwan (Aceito para publicação).

Barrios, V. M. G., Mödritscher, F., \& Gütl, C. (2005).

Personalization versus Adaptation? A User-centred Model Approach and its Application. In Proceedings of I-KNOW '05 
(pp. 120-127). Graz, Austria.

(Bay et al., 2006)

Bay, H., Tuytelaars, T., \& Van Gool, L. (2006). SURF: Speeded Up Robust Features. In A. Leonardis, H. Bischof, \& A. Pinz (Eds.), Computer Vision - ECCV 2006 (Vol. 3951, pp. 404-417). Springer Berlin / Heidelberg.

(Blanken et al., 2010) Blanken, H. M., Vries, A. P., Blok, H. E., \& Feng, L. (2010). Multimedia Retrieval (390 p.). Springer.

(Bouyakoub \&

Belkhir, 2008)

Bouyakoub, F. M., \& Belkhir, A. (2008). AdaMS: An Adaptation Multimedia System for Heterogeneous Environments. In New Technologies, Mobility and Security, 2008. NTMS '08. (pp. 15). Tangier. doi:10.1109/NTMS.2008.ECP.15

(Brindha \&

Kalaiarasan, 2010)

Brindha, N., \& Kalaiarasan, C. (2010). Certain investigations on video scene segementaion techniques. In Computational Intelligence and Computing Research (ICCIC), 2010 IEEE International Conference on (pp. 1-4). doi:10.1109/ICCIC.2010.5705735

(Cao et al., 2003)

Cao, Y., Tavanapong, W., Kim, K., \& Oh, J. (2003). Audio-Assisted Scene Segmentation for Story Browsing. In E. Bakker, M. Lew, T. Huang, N. Sebe, \& X. Zhou (Eds.), Image and Video Retrieval (Vol. 2728, pp. 446-455). Springer Berlin / Heidelberg.

(Chasanis et al., 2007) Chasanis, V., Likas, A., \& Galatsanos, N. (2007). Scene Detection in Videos Using Shot Clustering and Symbolic Sequence Segmentation. In Multimedia Signal Processing, 2007. MMSP 2007. IEEE 9th Workshop on (pp. 187-190). Crete. doi:10.1109/MMSP.2007.4412849

(Chen et al., 2005)

Chen, L.-H., Chin, K.-H., \& Liao, H.-Y. M. (2005). On the query of video database. In Proceedings of the 5th WSEAS international conference on Multimedia, internet \& video technologies (pp. 213-218). Stevens Point, Wisconsin, USA: World Scientific and Engineering Academy and Society (WSEAS).

(Chergui et al., 2012) Chergui, A., Bekkhoucha, A., \& Sabbar, W. (2012). Video scene segmentation using the shot transition detection by local characterization of the points of interest. In Sciences of Electronics, Technologies of Information and Telecommunications (SETIT), 2012 6th International Conference on (pp. 404-411). doi:10.1109/SETIT.2012.6481949

(Chu et al., 2010) Chu, W.-T., Li, C.-J., \& Lin, T.-C. (2010). Travel Video Scene Detection by Search. In Image and Video Technology (PSIVT), 2010 Fourth Pacific-Rim Symposium on (pp. 180-185). 
doi:10.1109/PSIVT.2010.37

(Coimbra, 2011)

Coimbra, D. B. (2011). Segmentação de cenas em telejornais: uma abordagem multimodal. Universidade de São Paulo. Dissertação de mestrado (107 p.).

(Corridoni \& Bimbo, 1998)

Corridoni, J. M., \& Bimbo, A. D. (1998). Structured representation and automatic indexing of movie information content. Pattern Recognition, 31(12), 2027-2045. doi:10.1016/S00313203(98)00061-2

(Faloutsos, 1999)

Faloutsos, C. (1999). Multimedia IR: Indexing and Searching. In Modern Information Retrieval (1st ed., pp. 345-499). Addison Wesley.

(Fischler \& Bolles, 1981)

Fischler, M. A., \& Bolles, R. C. (1981). Random sample consensus: a paradigm for model fitting with applications to image analysis and automated cartography. Commun. ACM, 24(6), 381-395. doi:10.1145/358669.358692

(Fonseca, 2006)

Fonseca, M. S. (2006). Combinando Imagem e Som para Detecção de Transições em Videos Digitais. Universidade Federal Fluminense (121 p.).

(Galmar \& Huet, 2007)

Galmar, E., \& Huet, B. (2007). Analysis of vector space model and spatiotemporal segmentation for video indexing and retrieval. In Proceedings of the 6th ACM international conference on Image and video retrieval (pp. 433-440). New York, NY, USA: ACM. doi:10.1145/1282280.1282344

(Gonzalez \& Woods, Gonzalez, R. C., \& Woods, R. E. (2010). Processamento Digital de 2010)

(Gu et al., 2007) Imagens (3rd ed., 640 p.). Pearson Prentice Hall.

Gu, Z., Mei, T., Hua, X.-S., Wu, X., \& Li, S. (2007). EMS: Energy Minimization Based Video Scene Segmentation. In Multimedia and Expo, 2007 IEEE International Conference on (pp. 520523). doi:10.1109/ICME.2007.4284701

(Han \& Wu, 2011) Han, B., \& Wu, W. (2011). Video scene segmentation using a novel boundary evaluation criterion and dynamic programming. In Proceedings of the 2011 IEEE International Conference on Multimedia and Expo (pp. 1-6). Washington, DC, USA: IEEE Computer Society. doi:10.1109/ICME.2011.6012001

(Hanjalic et al., 1999) Hanjalic, A., Lagendijk, R. L., \& Biemond, J. (1999). Automated high-level movie segmentation for advanced video-retrieval systems. Circuits and Systems for Video Technology, IEEE Transactions on, 9(4), 580-588. doi:10.1109/76.767124 
(Hu et al., 2011)

(Huang \& Chen, 2009)

(Huang et al., 2011)

(Ide et al., 2000)

(Jollife, 2002)

(Koprinska \& Carrato, 2001)

(Lee et al., 2005)

(Li et al., 2001)

(Lin \& Zhang, 2000)

(Lindeberg, 1998)
Hu, W., Xie, N., Li, L., Zeng, X., \& Maybank, S. (2011). A Survey on Visual Content-Based Video Indexing and Retrieval. Systems, Man, and Cybernetics, Part C: Applications and Reviews, IEEE Transactions on, 41(6), 797-819. doi:10.1109/TSMCC.2011.2109710

Huang, C.-R., \& Chen, C.-S. (2009). Video scene detection by linkconstrained affinity-propagation. In Circuits and Systems, 2009. ISCAS 2009. IEEE International Symposium on (pp. 28342837). doi:10.1109/ISCAS.2009.5118392

Huang, X., Wang, J., Zhang, M., \& Zhai, J. (2011). Gradual-SURF. In Image and Signal Processing (CISP), 2011 4th International Congress on (Vol. 2, pp. 906-909). doi:10.1109/CISP.2011.6100375

Ide, I., Hamada, R., Sakai, S., \& Tanaka, H. (2000). Scene identification in news video by character region segmentation. In Proceedings of the 2000 ACM workshops on Multimedia (pp. 195-200). New York, NY, USA: ACM. doi: $10.1145 / 357744.357933$

Jollife, I. T. (2002). Principal Component Analysis (2nd ed., 487 p.). Springer.

Koprinska, I., \& Carrato, S. (2001). Temporal video segmentation: A survey. Signal Processing: Image Communication, 16(5), 477500. doi:http://dx.doi.org/10.1016/S0923-5965(00)00011-4

Lee, G.-G., Kim, E.-J., Kang, J., Kim, J.-G., \& Kim, W.-Y. (2005). A Method of Generating Table of Contents for Educational Videos. In Y.-S. Ho \& H.-J. Kim (Eds.), Advances in Multimedia Information Processing - PCM 2005 (Vol. 3768, pp. 129-140). Springer Berlin / Heidelberg.

Li, Y., Ming, W., \& Kuo, C.-C. J. (2001). Semantic video content abstraction based on multiple cues. In Multimedia and Expo, 2001. ICME 2001. IEEE International Conference on (pp. 623626). doi:10.1109/ICME.2001.1237797

Lin, T., \& Zhang, H.-J. (2000). Automatic video scene extraction by shot grouping. In Pattern Recognition, 2000. Proceedings. 15th International Conference on (Vol. 4, pp. 39-42). Barcelona. doi:10.1109/ICPR.2000.902860

Lindeberg, T. (1998). Feature Detection with Automatic Scale Selection. International Journal of Computer Vision, 30(2), 79116. doi:10.1023/A:1008045108935 
(Liu et al., 2009)

(Lowe, 1999)

(Lowe, 2004)

(Lu et al., 1998)

(Lu et al., 2011)

(Lum \& Lau, 2002)

(Magalhães \&

Pereira, 2004)

(Manning et al., 2009)

(Manzato, 2011)

(Marques Filho \&

Vieira Neto, 1999)

(Marques, 2011)

(Mezaris et al., 2011)
Liu, W., Yang, G., \& Huang, X. (2009). Semantic features based news stories segmentation for news retrieval. In Wavelet Analysis and Pattern Recognition, 2009. ICWAPR 2009. International Conference on (pp. 258-265). Baoding. doi:10.1109/ICWAPR.2009.5207491

Lowe, D. G. (1999). Object recognition from local scale-invariant features. In Computer Vision, 1999. The Proceedings of the Seventh IEEE International Conference on (Vol. 2, pp. 1150 1157). Kerkyra, Greece. doi:10.1109/ICCV.1999.790410

Lowe, D. G. (2004). Distinctive Image Features from Scale-Invariant Keypoints. International Journal of Computer Vision, 60(2), 91-110.

Lu, Q., Eichstaedt, M., \& Ford, D. (1998). Efficient profile matching for large scale Webcasting. Computer Networks and ISDN Systems, 30(1-7), 443-455. doi:10.1016/S0169-7552(98)001123

Lu, Y., Sebe, N., Hytnen, R., \& Tian, Q. (2011). Personalization in multimedia retrieval: A survey. Multimedia Tools Appl., 51(1), 247-277. doi:10.1007/s11042-010-0621-0

Lum, W. Y., \& Lau, F. C. M. (2002). A context-aware decision engine for content adaptation. Pervasive Computing, IEEE, 1(3), 41-49. doi:10.1109/MPRV.2002.1037721

Magalhães, J., \& Pereira, F. (2004). Using MPEG standards for multimedia customization. Signal Processing: Image Communication, 19(5), 437-456. doi:10.1016/j.image.2004.02.004

Manning, C. D., Raghavan, P., \& Schütze, H. (2009). An Introduction to Information Retrieval (544 p.). Cambridge University Press.

Manzato, M. G. (2011). Uma arquitetura de personalização baseada em anotações do usuário. Universidade de São Paulo. Tese de doutorado (172 p.).

Marques Filho, O., \& Vieira Neto, H. (1999). Processamento digital de imagens (1st ed., 406 p.). Rio de Janeiro: Brasport.

Marques, O. (2011). Practical Image and Video Processing Using $M A T L A B(696$ p.). Wiley, IEEE Press.

Mezaris, V., Sidiropoulos, P., \& Kompatsiaris, I. (2011). Improving Interactive Video Retrieval by Exploiting AutomaticallyExtracted Video Structural Semantics. In Semantic Computing 
(ICSC), 2011 Fifth IEEE International Conference on (pp. 224 227). doi:10.1109/ICSC.2011.29

(Mikolajczyk \&

Schmid, 2001)

(Mohan et al., 1999)

(Money \& Agius, 2008)

(Nixon \& Aguado, 2008)

(Oh et al., 2005)

(Oh \& Hua, 2000)

(Otsu, 1979)

(Pedrosa et al., 2012)

(Petrou \& Petrou, 2010)

(Poulisse \& Moens, 2011)
Mikolajczyk, K., \& Schmid, C. (2001). Indexing based on scale invariant interest points. In Computer Vision, 2001. ICCV 2001. Proceedings. Eighth IEEE International Conference on (Vol. 1, pp. 525-531). doi:10.1109/ICCV.2001.937561

Mohan, R., Smith, J. R., \& Li, C.-S. (1999). Adapting multimedia Internet content for universal access. Multimedia, IEEE Transactions on, 1(1), 104-114. doi:10.1109/6046.748175

Money, A. G., \& Agius, H. (2008). Video summarisation: A conceptual framework and survey of the state of the art. Journal of Visual Communication and Image Representation, 19(2), 121-143. doi:10.1016/j.jvcir.2007.04.002

Nixon, M., \& Aguado, A. (2008). Feature Extraction \& Image Processing (2nd ed., 424 p.). Academic Press (AP).

Oh, J. H., Wen, Q., Hwang, S., \& Lee, J. (2005). Video Abstraction. In Video Data Management and Information Retrieval. IRM Press.

Oh, J., \& Hua, K. A. (2000). Efficient and cost-effective techniques for browsing and indexing large video databases. In Proceedings of the 2000 ACM SIGMOD international conference on Management of data (pp. 415-426). New York, NY, USA: ACM. doi:10.1145/342009.335436

Otsu, N. (1979). A Threshold Selection Method from Gray-Level Histograms. IEEE Transactions on Systems, Man and Cybernetics, 9(1), 62-66.

Pedrosa, G. V., Rezende, S. O., \& Traina, A. J. M. (2012). Reducing the Dimensionality of the SIFT Descriptor and Increasing Its Effectiveness and Efficiency in Image Retrieval via Bag-offeatures. In Proceedings of the 18th Brazilian Symposium on Multimedia and the Web (pp. 139-142). New York, NY, USA: ACM. doi:10.1145/2382636.2382668

Petrou, M., \& Petrou, C. (2010). Image Processing: The Fundamentals (2nd ed., 818 p.). Wiley.

Poulisse, G., \& Moens, M. (2011). Unsupervised scene detection in Olympic video using multi-modal chains. In Content-Based Multimedia Indexing (CBMI), 2011 9th International Workshop on (pp. 103-108). doi:10.1109/CBMI.2011.5972529 
(Rasheed \& Shah, 2003)

(Rasheed \& Shah, 2005)

(Richardson, 2002)

(Rui et al., 1998)

(Rui et al., 1999)

(Sakarya \& Telatar, 2010)

(Sidiropoulos et al., 2011)

(Smeaton, 2007)

(Smeaton et al., 2010)

(Smeulders et al., 2000)

(Sonka et al., 1998)
Rasheed, Z., \& Shah, M. (2003). Scene detection in Hollywood movies and TV shows. In Computer Vision and Pattern Recognition, 2003. Proceedings. 2003 IEEE Computer Society Conference on (Vol. 2, pp. 343-348). doi:10.1109/CVPR.2003.1211489

Rasheed, Z., \& Shah, M. (2005). Detection and representation of scenes in videos. Multimedia, IEEE Transactions on, 7(6), 1097-1105. doi:10.1109/TMM.2005.858392

Richardson, I. E. G. (2002). Video Codec Design (303 p.). Wiley.

Rui, Y., Huang, T. S., \& Mehrotra, S. (1998). Exploring video structure beyond the shots. In Multimedia Computing and Systems, 1998. Proceedings. IEEE International Conference on (pp. 237-240). doi:10.1109/MMCS.1998.693648

Rui, Y., Huang, T. S., \& Mehrotra, S. (1999). Constructing table-ofcontent for videos. Multimedia Systems, 7(5), 359-368.

Sakarya, U., \& Telatar, Z. (2010). Video scene detection using graph-based representations. Signal Processing: Image Communication, 25(10), 774-783. doi:10.1016/j.image.2010.10.001

Sidiropoulos, P., Mezaris, V., Kompatsiaris, I., Meinedo, H., Bugalho, M., \& Trancoso, I. (2011). Temporal Video Segmentation to Scenes Using High-Level Audiovisual Features. IEEE Trans. Cir. and Sys. for Video Technol., 21(8), 1163-1177. doi:10.1109/TCSVT.2011.2138830

Smeaton, A. F. (2007). Techniques used and open challenges to the analysis, indexing and retrieval of digital video. Information Systems, 32(4), 545-559. doi:10.1016/j.is.2006.09.001

Smeaton, A. F., Over, P., \& Doherty, A. R. (2010). Video shot boundary detection: Seven years of TRECVid activity. Computer Vision and Image Understanding, 114(4), 411-418. doi:10.1016/j.cviu.2009.03.011

Smeulders, A. W. M., Worring, M., Santini, S., Gupta, A., \& Jain, R. (2000). Content-based image retrieval at the end of the early years. Pattern Analysis and Machine Intelligence, IEEE Transactions on, 22(12), 1349-1380. doi:10.1109/34.895972

Sonka, M., Hlavac, V., \& Boyle, R. (1998). Image Processing, Analysis and Machine Vision (2nd ed., 770 p.). International Thomson Publishing. 
(Souvannavong et al., 2004)

(Souza \& Goularte, 2013)

(Stehling et al., 2002)

(Sural et al., 2005)

(Sze et al., 2004)

(Sze et al., 2005)

(Tan \& Lu, 2002)

(Tapu \& Zaharia, 2011a)

(Tapu \& Zaharia, 2011b)
Souvannavong, F., Merialdo, B., \& Huet, B. (2004). Latent semantic analysis for an effective region-based video shot retrieval system. In Proceedings of the 6th ACM SIGMM international workshop on Multimedia information retrieval (pp. 243-250). New York, NY, USA: ACM. doi:10.1145/1026711.1026751

Souza, T. T., \& Goularte, R. (2013). Video Shot Representation Based on Histograms. In Proceedings of the 28th ACM Symposium on Applied Computing (pp. 961-966). Coimbra, Portugal: ACM.

Stehling, R. O., Nascimento, M. A., \& Falcão, A. X. (2002). A compact and efficient image retrieval approach based on border/interior pixel classification. In Proceedings of the eleventh international conference on Information and knowledge management (pp. 102-109). New York, NY, USA: ACM. doi:10.1145/584792.584812

Sural, S., Mohan, M., \& Majumdar, A. K. (2005). A Soft-Decision Histogram from the HSV Color Space for Video Shot Detection. In Video Data Management and Information Retrieval (pp. 237-252). IRM Press.

Sze, K.-W., Lam, K.-M., \& Qiu, G. (2004). An optimal key frame representation for video shot retrieval. In Intelligent Multimedia, Video and Speech Processing, 2004. Proceedings of 2004 International Symposium on (pp. 270-273). doi:10.1109/ISIMP.2004.1434052

Sze, K.-W., Lam, K.-M., \& Qiu, G. (2005). A new key frame representation for video segment retrieval. Circuits and Systems for Video Technology, IEEE Transactions on, 15(9), 11481155. doi:10.1109/TCSVT.2005.852623

Tan, Y.-P., \& Lu, H. (2002). Model-based clustering and analysis of video scenes. In Image Processing. 2002. Proceedings. 2002 International Conference on (Vol. 1, pp. 617-620). doi:10.1109/ICIP.2002.1038099

Tapu, R., \& Zaharia, T. (2011a). A complete framework for temporal video segmentation. In Consumer Electronics - Berlin (ICCEBerlin), 2011 IEEE International Conference on (pp. 156-160). doi:10.1109/ICCE-Berlin.2011.6031875

Tapu, R., \& Zaharia, T. (2011b). High level video temporal segmentation. In Proceedings of the 7th international conference on Advances in visual computing - Volume Part I (pp. 224-235). Berlin, Heidelberg: Springer-Verlag. 
(Tavanapong \& Zhou, Tavanapong, W., \& Zhou, J. (2004). Shot clustering techniques for 2004) story browsing. Multimedia, IEEE Transactions on, 6(4), 517527. doi:10.1109/TMM.2004.830810

(Toffler, 1984)

Toffler, A. (1984). Future Shock(1st ed., 576 p.). Bantam.

(Torres \& Falcão, 2006)

Torres, R. da S., \& Falcão, A. X. (2006). Content-Based Image Retrieval: Theory and Applications. Revista de Informática Teórica e Aplicada, 13, 161-185.

(Torres et al., 2005)

Torres, R. da S., Falcão, A. X., Zhang, B., Fan, W., Fox, E. A., Gonçalves, M. A., \& Calado, P. (2005). A new framework to combine descriptors for content-based image retrieval. In Proceedings of the 14th ACM international conference on Information and knowledge management (pp. 335-336). New York, NY, USA: ACM. doi:10.1145/1099554.1099654

(Valle \& Cord, 2009) Valle, E., \& Cord, M. (2009). Advanced Techniques in CBIR: Local Descriptors, Visual Dictionaries and Bags of Features. In Computer Graphics and Image Processing (SIBGRAPI TUTORIALS), 2009 Tutorials of the XXII Brazilian Symposium on (pp. 72-78). doi:10.1109/SIBGRAPI-Tutorials.2009.14

(Wang et al., 2008) Wang, J., Tian, X., Yang, L., Zha, Z.-J., \& Hua, X.-S. (2008). Optimized video scene segmentation. In Multimedia and Expo, 2008 IEEE International Conference on (pp. 301-304). doi:10.1109/ICME.2008.4607431

(Xu et al., 2012)

Xu, S., Feng, B., Ding, P., \& Xu, B. (2012). Graph-based multimodal scene detection for movie and teleplay. In Acoustics, Speech and Signal Processing (ICASSP), 2012 IEEE International Conference on (pp. 1413-1416). doi:10.1109/ICASSP.2012.6288155

(Yamamoto \& Haseyama, 2009)

Yamamoto, M., \& Haseyama, M. (2009). Accurate graph-based scene segmentation using object matching and audio feature. In Consumer Electronics, 2009. ISCE '09. IEEE 13th International Symposium on (pp. 639-640). doi:10.1109/ISCE.2009.5156976

(Yeung \& Liu, 1995) Yeung, M. M., \& Liu, B. (1995). Efficient matching and clustering of video shots. In Image Processing, 1995. Proceedings., International Conference on (Vol. 1, pp. 338-341). doi:10.1109/ICIP.1995.529715

(Yeung et al., 1998) Yeung, M., Yeo, B.-L., \& Liu, B. (1998). Segmentation of Video by Clustering and Graph Analysis. Computer Vision and Image Understanding, 71(1), 94-109. doi:10.1006/cviu.1997.0628 
(Zhai \& Shah, 2005)

(Zhai \& Shah, 2006)

(Zhao et al., 2001a)

(Zhao et al., 2001b)

(Zhao et al., 2007)

(Zhou et al., 2010)

(Zhou \& Tavanapong, 2002)

(Zhou et al., 2009)

(Zhu \& Satoh, 2012)
Zhai, Y., \& Shah, M. (2005). A general framework for temporal video scene segmentation. In Computer Vision, 2005. ICCV 2005. Tenth IEEE International Conference on (Vol. 2, pp. 1111-1116). doi:10.1109/ICCV.2005.6

Zhai, Y., \& Shah, M. (2006). Video scene segmentation using Markov chain Monte Carlo. Multimedia, IEEE Transactions on, 8(4), 686-697. doi:10.1109/TMM.2006.876299

Zhao, L., Qi, W., Wang, Y.-J., Yang, S.-Q., \& Zhang, H.-J. (2001a). Video shot grouping using best first model merging. In Proceedings of Storage and Retrieval for Media Database (pp. 262-269).

Zhao, L., Yang, S.-Q., \& Feng, B. (2001b). Video scene detection using slide windows method based on temporal constrain shot similarity. In Multimedia and Expo, 2001. ICME 2001. IEEE International Conference on (pp. 1171-1174). doi:10.1109/ICME.2001.1237936

Zhao, W.-L., Ngo, C.-W., Tan, H.-K., \& Wu, X. (2007). NearDuplicate Keyframe Identification With Interest Point Matching and Pattern Learning. Multimedia, IEEE Transactions on, 9(5), 1037-1048. doi:10.1109/TMM.2007.898928

Zhou, H., Sadka, A. H., Swash, M. R., Azizi, J., \& Sadiq, U. A. (2010). Feature extraction and clustering for dynamic video summarisation. Neurocomput., 73(10-12), 1718-1729. doi:10.1016/j.neucom.2009.09.022

Zhou, J., \& Tavanapong, W. (2002). Shot Weave: A Shot Clustering Technique for Story Browsing for Large Video Databases. In A. Chaudhri, R. Unland, C. Djeraba, \& W. Lindner (Eds.), XMLBased Data Management and Multimedia Engineering - EDBT 2002 Workshops (Vol. 2490, pp. 529-533). Springer Berlin / Heidelberg.

Zhou, X., Zhou, X., Chen, L., Bouguettaya, A., Xiao, N., \& Taylor, J. A. (2009). An Efficient Near-Duplicate Video Shot Detection Method Using Shot-Based Interest Points. Multimedia, IEEE Transactions on, 11(5), 879-891. doi:10.1109/TMM.2009.2021794

Zhu, C.-Z., \& Satoh, S. (2012). Large Vocabulary Quantization for Searching Instances from Videos. In Proceedings of the $2 \mathrm{Nd}$ ACM International Conference on Multimedia Retrieval (pp. 52:1-52:8). New York, NY, USA: ACM. doi:10.1145/2324796.2324856 
(Zhu \& Liu, 2008a) Zhu, S., \& Liu, Y. (2008a). Scene Segmentation and Semantic Representation for High-Level Retrieval. Signal Processing Letters, IEEE, 15, 713-716. doi:10.1109/LSP.2008.2002718

(Zhu \& Liu, 2008b) Zhu, S., \& Liu, Y. (2008b). A novel scheme for video scenes segmentation and semantic representation. In Multimedia and Expo, 2008 IEEE International Conference on (pp. 1289-1292). doi:10.1109/ICME.2008.4607678 